\title{
REPORT
}

\section{Ithaka S+R US Faculty Survey 2018}

April 12, 2019

Melissa Blankstein

Christine Wolff-Eisenberg

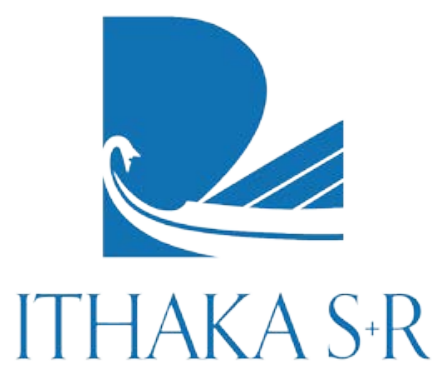




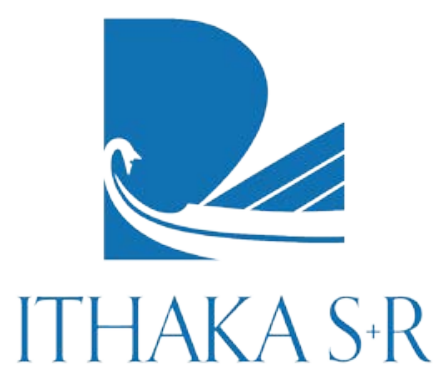

Ithaka $\mathrm{S}+\mathrm{R}$ provides research and strategic guidance to help the academic and cultural communities serve the public good and navigate economic, demographic, and technological change. Ithaka $S+R$ is part of ITHAKA, a not-for-profit organization that works to advance and preserve knowledge and to improve teaching and learning through the use of digital technologies. Artstor, J STOR, and Portico are also part of ITHAKA.
Copyright 2019 ITHAKA. This work is licensed under a Creative Commons Attribution-NonCommercial 4.0 International License. To view a copy of the license, please see http://creativecommons.org/licenses/by-nc/4.01.

ITHAKA is interested in disseminating this brief as widely as possible. Please contact us with any questions about using the report: research@ithaka.org. 
We thank the following organizations for supporting the US Faculty Survey 2018:
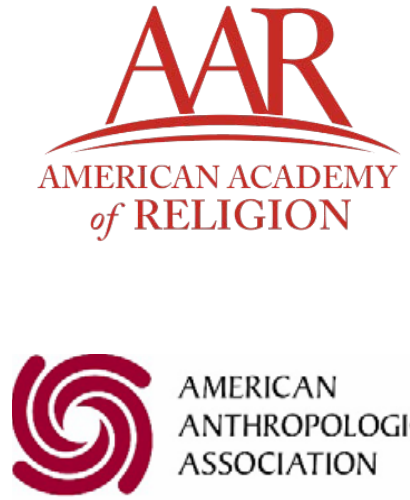

AMERICAN

ANTHROPOLOGICAL ASSOCIATION

Advancing Knowledge, Solving Human Problem

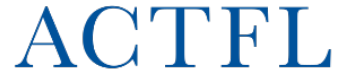

AMERICAN COUNCIL ON THE TEACHING OF FOREIGN LANGUAGES

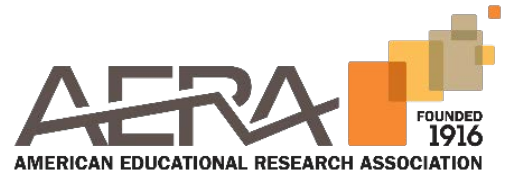

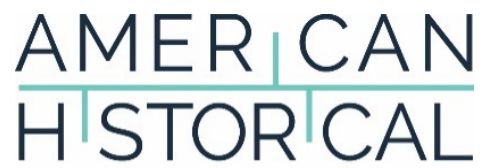
ASSOCIATION

\section{AMS}

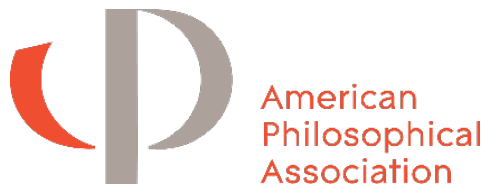

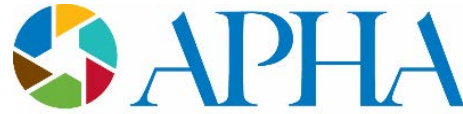

AMERICAN PUBLIC HEALTH ASSOCIATION For science. For action. For health.
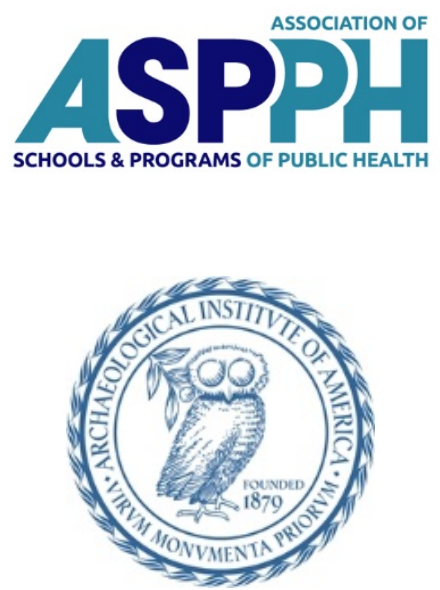

\section{Clarivate Analytics}

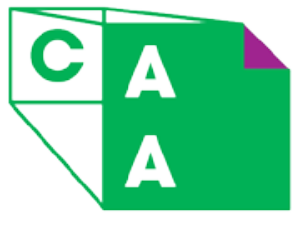

Advancing Art\&Design
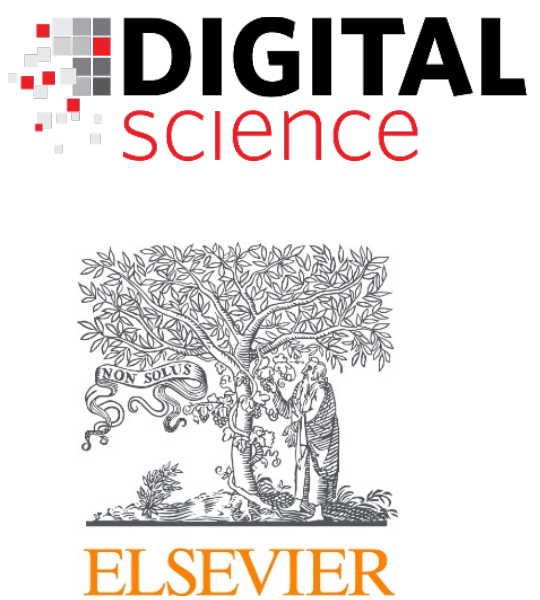
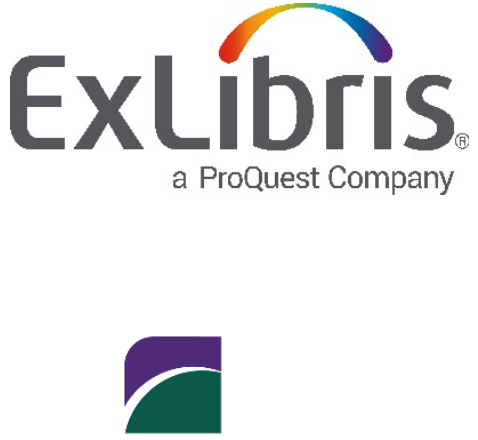

THE

GEOLOGICAL SOCIETY OF AMERICA ${ }^{\circledR}$

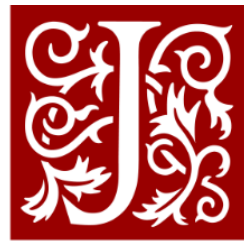

JSTOR
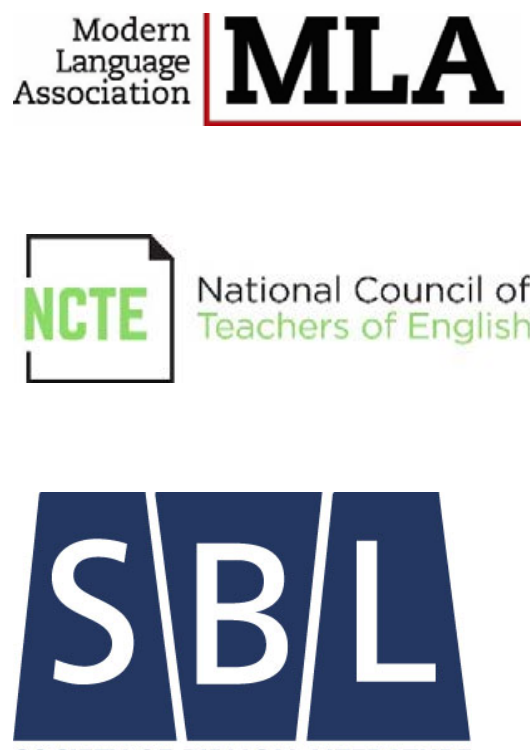

SOCIETY OF BIBLICAL LITERATURE 


\section{ITHAKA S·R}

\section{Table of contents}

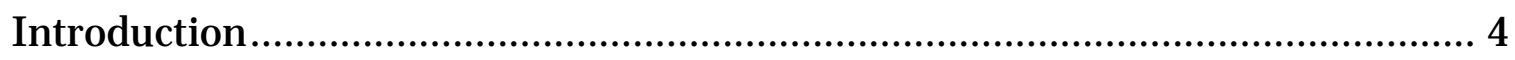

Discovery \&Access ............................................................................... 7

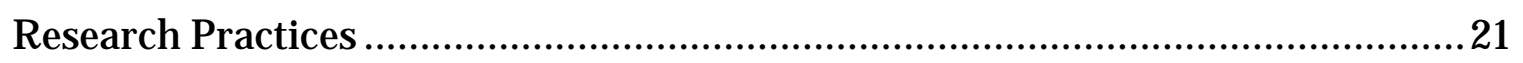

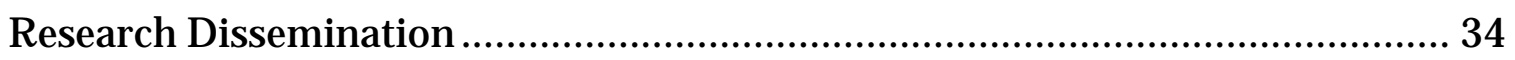

Teaching and Learning ............................................................................ 45

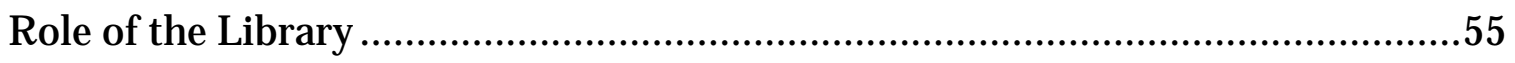

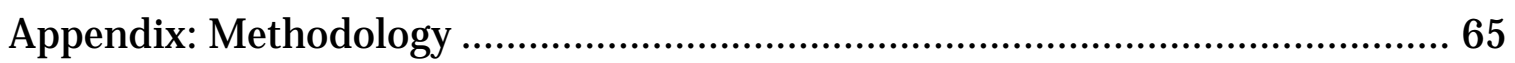




\section{Introduction}

The Ithaka S+R US Faculty Survey has tracked the changing research, teaching, and publishing practices of higher education faculty members on a triennial basis since 2000. Our aim in this project is to provide actionable findings and analysis to help colleges and universities as well as relevant support services, such as academic libraries, learned societies, and scholarly publishers, plan for the future.

In this seventh triennial cycle, we surveyed a random sample of faculty within the United States on topics from previous cycles, including information discovery and access, data management, research dissemination, perceptions of student research skills, and the value of the library. We also added new questions on emerging topics of interest, including open educational resources, learning analytics, and evolving scholarly communication models. Given the levels of response to the survey, findings can be analyzed by discipline, institution type, and other important demographic characteristics. The key findings below highlight many of the most notable results from the 2018 US Faculty Survey.

\section{Executive Summary of Key Findings}

- Discovery starting points are shifting towards Google Scholar and other general search engines. While specific scholarly databases remain the most frequent starting point for research, faculty are increasingly beginning their exploration of scholarly literature with Google Scholar and other general-purpose search engines.

- Faculty members increasingly prefer to manage and preserve their data using cloud-based storage services. Since the previous cycle of the survey, a greater share of faculty report use of cloud-based storage services, such as Google Drive, Dropbox, and Flickr, to organize, manage, and preserve their research data, media, or images. Faculty also report file hosting services, such as Box and Dropbox, as the most valuable source of support for managing and preserving these data compared to other sources.

- While faculty are increasingly interested in an open access publication model, traditional scholarly incentives continue to motivate their decision-making. Approximately two-thirds of respondents in this survey cycle indicated they would be happy to see the traditional subscription-based publication model replaced entirely by an open access system, which represents a greater share of respondents compared to the previous survey cycle. However, only four in ten 
faculty indicate open access characteristics of journals as highly influential in publication decisions.

- There is substantial interest in use of open educational resources for instructional practices, particularly from younger faculty members. About six in ten respondents are very interested in using open educational resources (OER), and roughly half strongly agreed that they would like to adopt new instructional approaches with OER.

- Faculty are skeptical about the value of using learning analytics tools. While faculty who have used learning analytics tools are more likely to agree that these tools could make a substantial impact on their teaching practices and outcomes, survey respondents across the board do not hold especially positive views of these tools.

- The role of the library in archiving materials is increasingly important. While faculty maintain that the library's most important function is as the buyer of resources they need, they are finding the library's ability to serve as a repository of resources increasingly important.

\section{Methodology}

The Ithaka S+R US Faculty Survey 2018 has been designed to track critical trends in higher education over time, while simultaneously including new questions to address newly emerging trends in the field. New questions were tested before the survey was fielded through a process of pre-tests and cognitive interviews.

The population for this survey is faculty members at four-year colleges and universities that offer a bachelor's degree or higher. This is the second cycle of the survey that includes faculty from medical institutions within its population and therefore our first opportunity to track changes within this subgroup of respondents. In the 2018 survey cycle, we also added faculty members from the fields of foreign languages and agriculture. While medical respondents have been included in our disciplinary analysis, these faculty, along with faculty within the foreign language and agriculture fields, are excluded from our aggregate analysis so that appropriate aggregate comparisons can be drawn against all previous survey cycles.

The survey was fielded in fall 2018 to a sample of 150,941 faculty members. We received a total of 10,919 complete responses, for an overall response rate of 7.2 percent. Invitations and reminder messages were deployed from a variety of sources, including Ithaka S+R, a number of partnered scholarly societies, and several colleges and 
universities. As the responses varied by discipline, we weighted the aggregated results proportionally to match population parameters.

Datasets from the 2006, 2009, 2012, and 2015 cycles of the US Faculty Survey have been deposited with ICPSR for long-term preservation and access. ${ }^{1}$ We intend to deposit the 2018 dataset in a similar fashion. Please contact research@ithaka.org if we can provide any assistance in access and working with the underlying data.

More detailed information on the survey methodology is available in the Appendix.

\section{Acknowledgements}

This project was guided by an advisory board that helped to establish its thematic priorities for the questionnaire revision and provided reactions to a draft of this report. We thank them for their tremendous contributions. The members of this board were:

- Dan Cohen, Northeastern University

- Elaine Westbrooks, UNC Chapel Hill

- Annette Thomas, Clarivate

- Annie Bélanger, Grand Valley State University

We are immensely grateful to our colleague Nicole Betancourt who led the administration of the faculty survey. This project would not be possible without her substantive contributions. We also thank our colleagues Roger Schonfeld and Kimberly Lutz for their input on this report.

The individuals named in this section provided a variety of important contributions to this project, and we thank them for their partnership. Final responsibility for the survey and its analysis rests with the authors.

${ }^{1}$ Datasets from Ithaka S+R's series of surveys may be found at http://www.icpsr.umich.edu/icpsrweb/ICPSR/series/226/studies. 


\section{Discovery \& Access}

Across the past six cycles of the US Faculty Survey, we have witnessed a general increase in preference for and use of electronic materials and tools within higher education and scholarly communication. As electronic materials and tools continue to evolve, faculty research and teaching practices, as well as faculty attitudes towards the use of these electronic formats, are also shifting. The following section discusses the findings and trends observed regarding the discovery and access of resources needed to begin research processes, as well as resources used in teaching practices, and the implications for the changing role of electronic materials in these contexts.

\section{Discovery of Scholarly Information}

Faculty members were asked where they begin their exploration of scholarly literature to find sources relevant to their field. Overall, respondents are most likely to search using a specific scholarly database, Google Scholar, their college or university library's website or online catalog, or a general purpose search engine (see Figure 1).

Figure 1: When you explore the scholarly literature to find new journal articles and monographs relevant to your research interests, how do you most often begin your process? Percent of respondents who indicated that each option is the starting point for their exploration. ${ }^{2}$

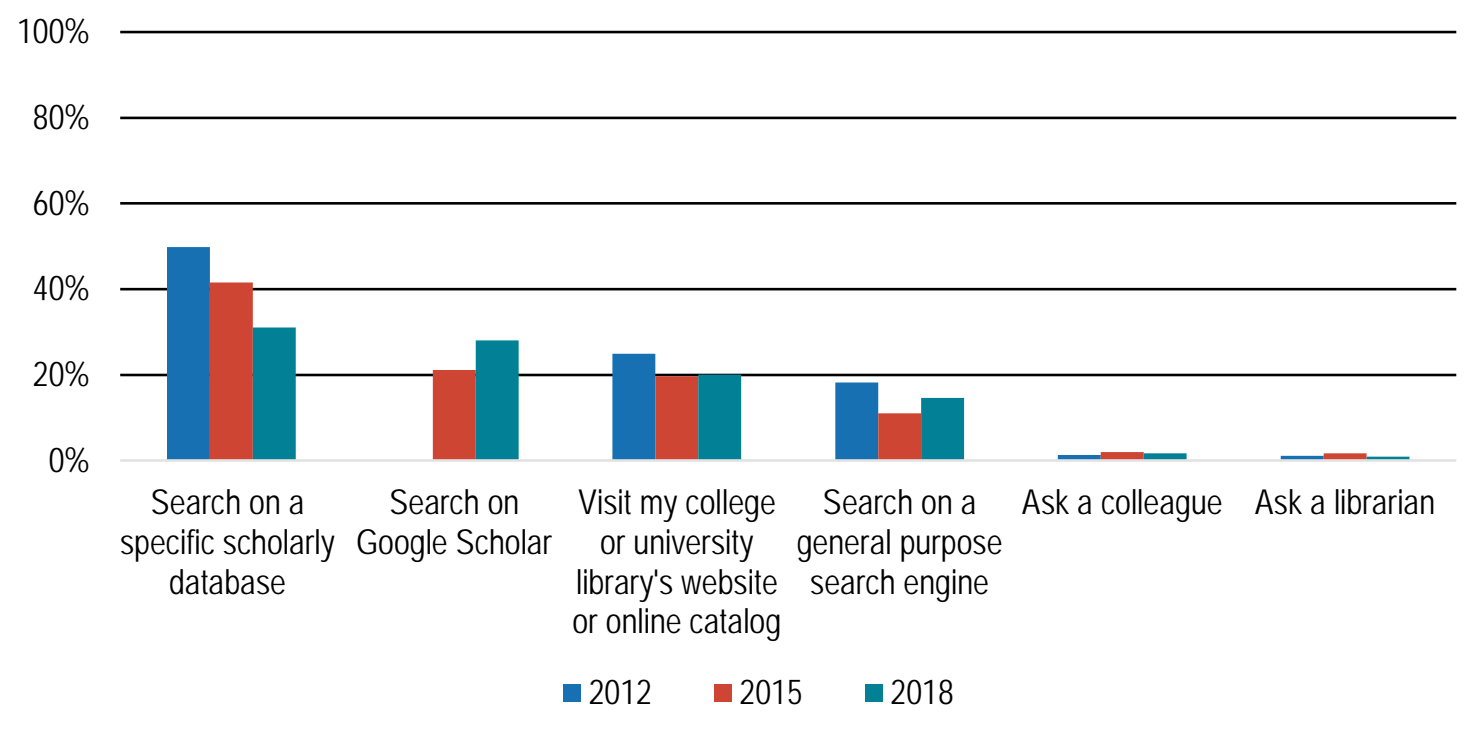

2 The item "Search on Google Scholar" was not included in the 2012 Faculty Survey. 
There are substantial differences by discipline in regards to where faculty members begin their discovery of new materials. Although the most frequently selected starting point for faculty members in the aggregate is a specific scholarly database, this starting point is more frequently utilized by humanists and medical faculty members than social scientists and scientists (see Figure 2). Conversely, social scientists and scientists are more likely than their peers in other disciplines to use Google Scholar for discovering relevant literature. Humanists and social scientists are also more likely to begin their research with their library's website or catalog than their colleagues in other disciplines.

Figure 2: When you explore the scholarly literature to find newjournal articles and monographs relevant to your research interests, how do you most often begin your process? Percent of respondents who indicated that each option is the starting point for their exploration.

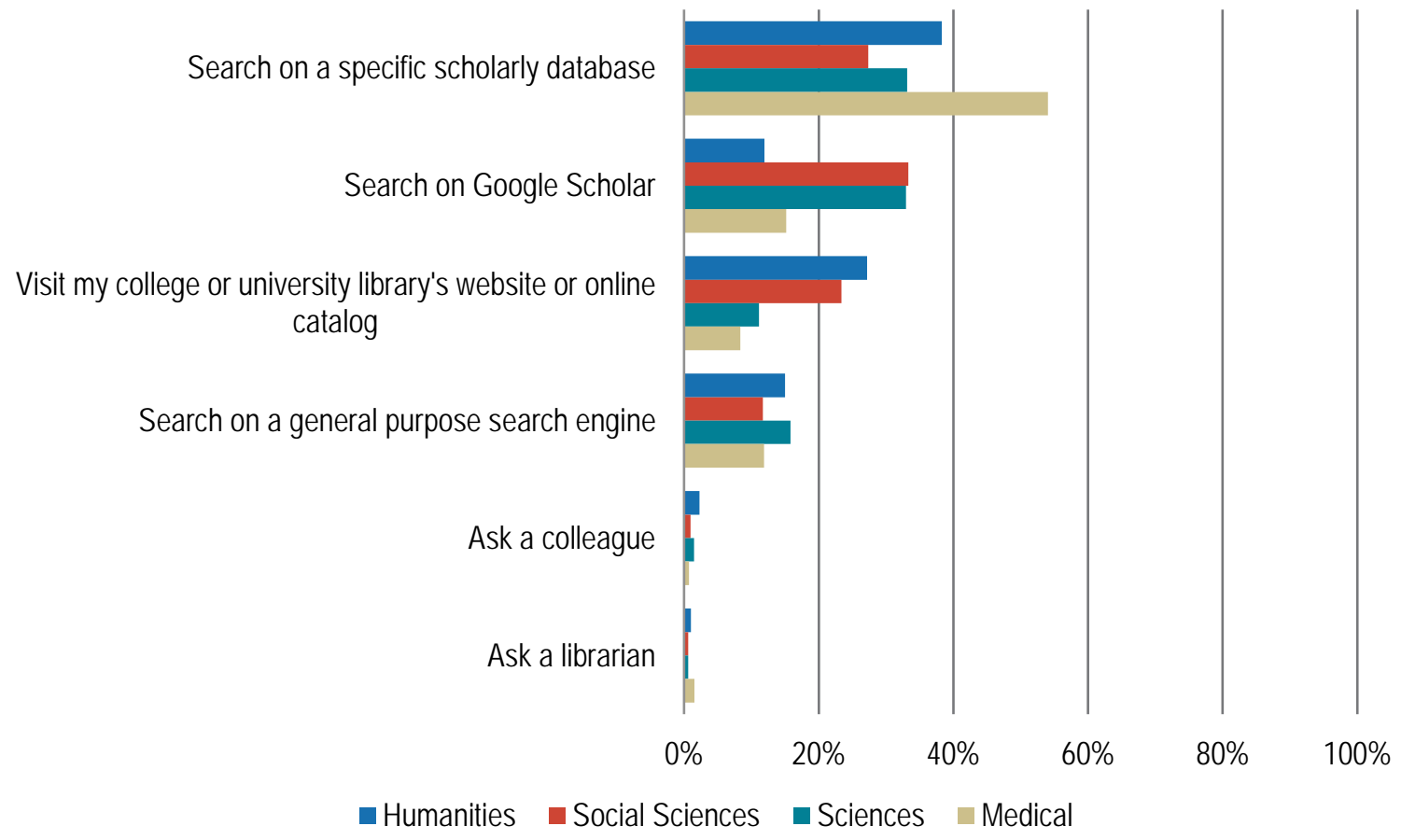

While these observed disciplinary differences are consistent with previous findings, when examined over time the use of specific scholarly databases is substantially declining (see Figure 1). Comparatively, there is an observed increase between 2015 and 2018 in the use of Google Scholar and general purpose search engines, with little to no difference in use of a respondent's library's website or online catalog or asking a colleague/librarian.

The shift towards Google Scholar from 2015 to 2018 has primarily been driven by scientists and social scientists (see Figure 3). In the 2018 survey, 33\% of scientists 
reported starting with Google Scholar compared to 23\% in 2015. Conversely, scientists have considerably decreased their use of specific scholarly databases, though this does remain as the most frequent starting point for discovery; approximately $47 \%$ of scientists indicated specific scholarly databases as their starting point in 2015 compared to $33 \%$ in the current survey cycle. Likewise, in 2015, $26 \%$ of social scientists reported using Google Scholar as their starting point compared to 33\% in 2018; 37\% reported starting with a specific scholarly database in 2015 compared to $27 \%$ in 2018 . Shifts in behavior of this magnitude were not observed for humanists and medical faculty.

Figure 3: When you explore the scholarly literature to find new journal articles and monographs relevant to your research interests, how do you most often begin your process? Percent of respondents who indicated that each option is the starting point for their exploration.

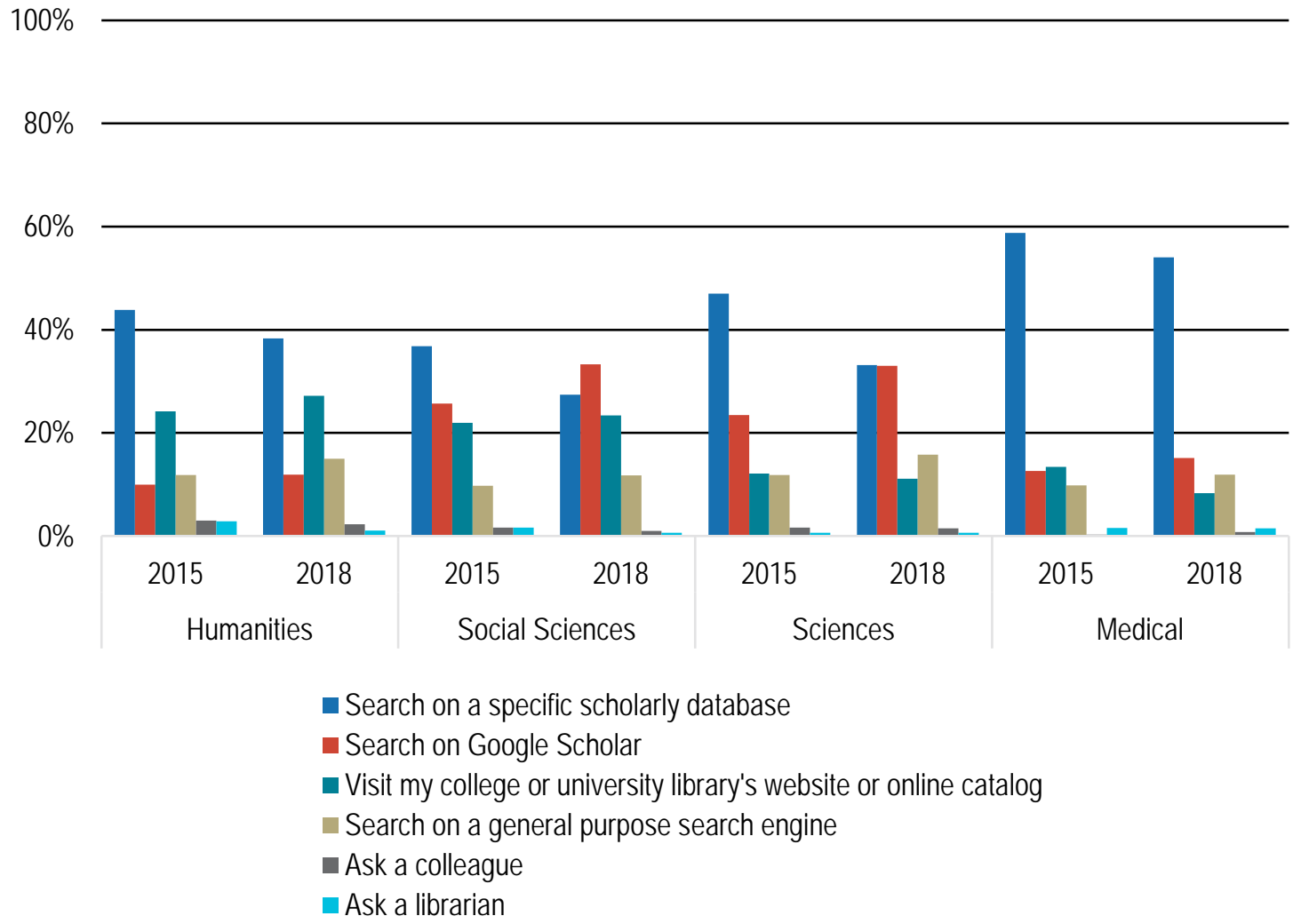

Faculty members were also asked to rate the importance of particular tactics they use to keep up with current scholarship within their respective fields. In accordance with previous findings, faculty members report attending conferences and workshops, reading materials suggested by other scholars, and regularly skimming new issues of key journals as the most important tactics (see Figure 4). 
Figure 4: You may employ a variety of different tactics to "keep up" with current scholarship in your field on a regular basis. Please use the scales below to rate from 10 to 1 how important each of the following methods is for staying current with new scholarship in your field. Percent of respondents who indicated that each of these methods is highly important.

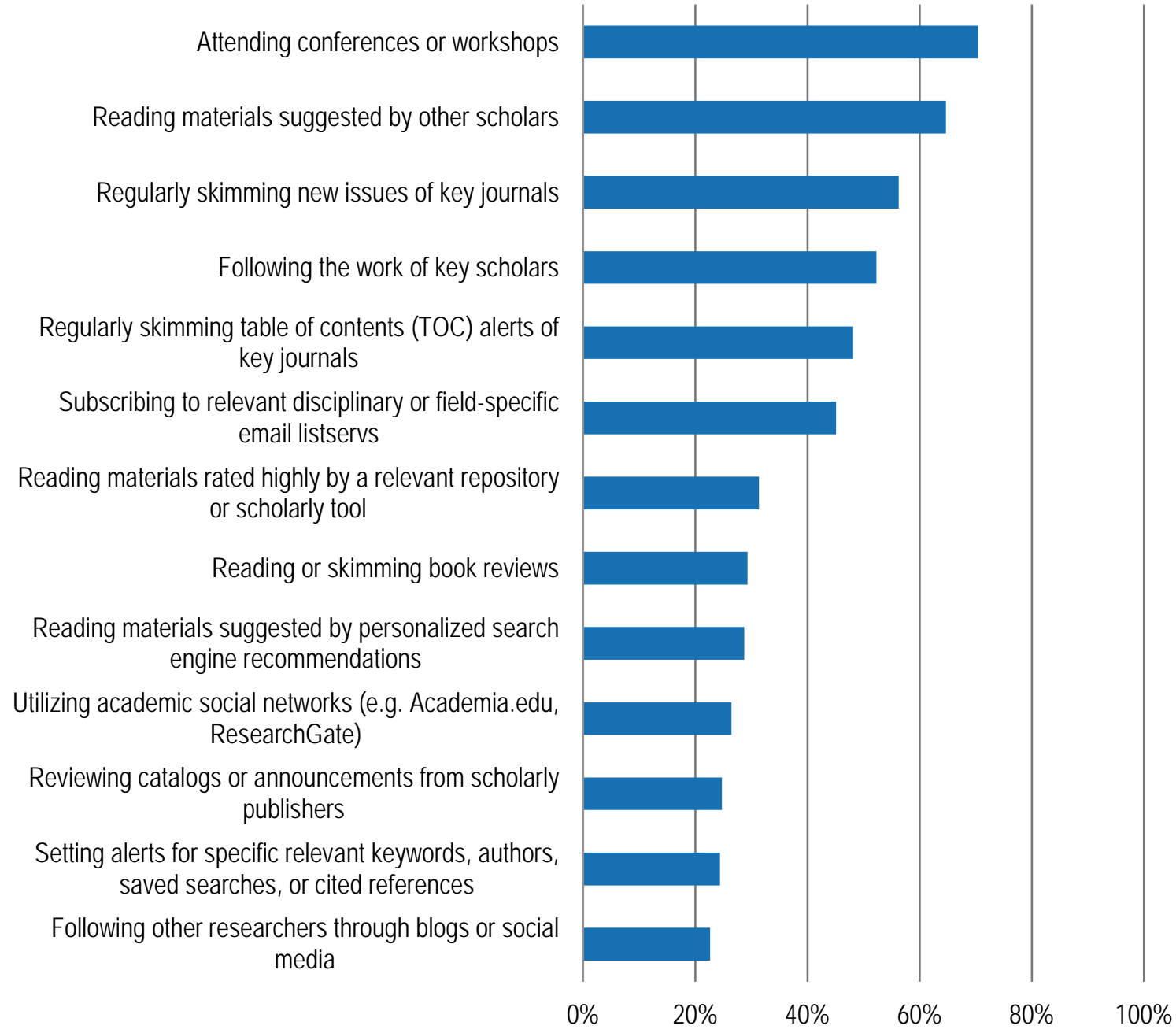

There are noteworthy differences in tactics used to keep up with current scholarship by discipline (see Figure 5). Humanists and social scientists indicate that reading materials suggested by other scholars, following the work of key scholars, reading or skimming book reviews, and reviewing catalogs or announcements from scholarly publishers as more important than their scientist or medical faculty colleagues. In contrast, social scientists and medical faculty are more likely to regularly skim new issues and the table of contents (TOC) alerts of key journals, as well as read materials suggested by personalized search engines. 
Figure 5: You may employ a variety of different tactics to "keep up" with current scholarship in your field on a regular basis. Please use the scales below to rate from 10 to 1 how important each of the following methods is for staying current with new scholarship in your field. Percent of respondents who indicated that each of these methods is highly important.

Attending conferences or workshops

Reading materials suggested by other scholars

Regularly skimming new issues of key journals

Following the work of key scholars

Regularly skimming table of contents (TOC) alerts of key journals

Subscribing to relevant disciplinary or field-specific email listservs

Reading materials rated highly by a relevant repository or scholarly tool

Reading or skimming book reviews

Reading materials suggested by personalized search engine recommendations

Utilizing academic social networks (e.g. Academia.edu, ResearchGate)

Reviewing catalogs or announcements from scholarly publishers

Setting alerts for specific relevant keywords, authors, saved searches, or cited references

Following other researchers through blogs or social media

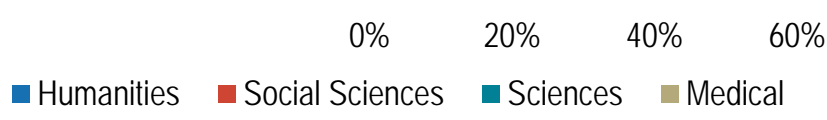

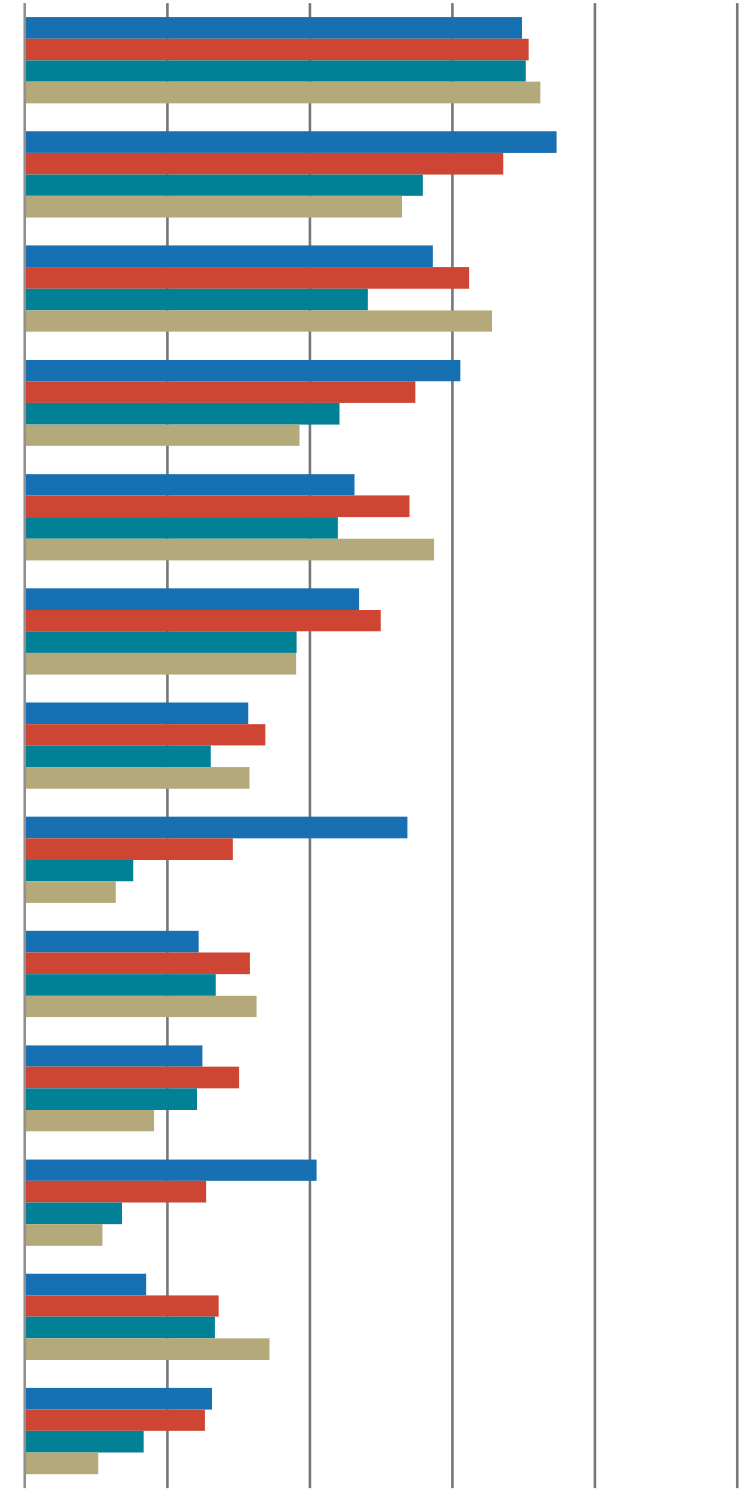

$80 \% \quad 100 \%$

In this survey cycle, faculty were also asked about how they use social networks including Academia.edu and ResearchGate - to keep up with relevant scholarship. Although this was not frequently rated as highly important, it was rated as more 


\section{ITHAKA S+R}

important than a number of other tactics, including reviewing catalogs or announcements from scholarly publishers, setting alerts for specific relevant keywords, authors, saved searches, or cited references, and following other researchers through blogs or social media.

Younger scholars ranked attending conferences and workshops, reading materials suggested by other scholars, and following the work of key scholars as more important than older cohorts. They also assigned more importance to academic social networks, subscribing to relevant disciplinary or field-specific email listservs, and following other researchers through blogs or social media (See Figure 6). 
Figure 6: You may employ a variety of different tactics to "keep up" with current scholarship in your field on a regular basis. Please use the scales below to rate from 10 to 1 how important each of the following methods is for staying current with new scholarship in your field. Percent of respondents who indicated that each of these methods is highly important.

\section{Attending conferences or workshops \\ Reading materials suggested by other scholars \\ Regularly skimming new issues of key journals \\ Following the work of key scholars \\ Regularly skimming table of contents (TOC) alerts of key journals \\ Subscribing to relevant disciplinary or field-specific email listservs}

Reading materials rated highly by a relevant repository or scholarly tool

Reading or skimming book reviews

Reading materials suggested by personalized search engine recommendations

Utilizing academic social networks (e.g. Academia.edu, ResearchGate)

Reviewing catalogs or announcements from scholarly publishers

Setting alerts for specific relevant keywords, authors, saved searches, or cited references

Following other researchers through blogs or social media

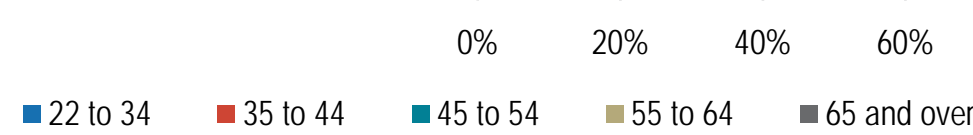

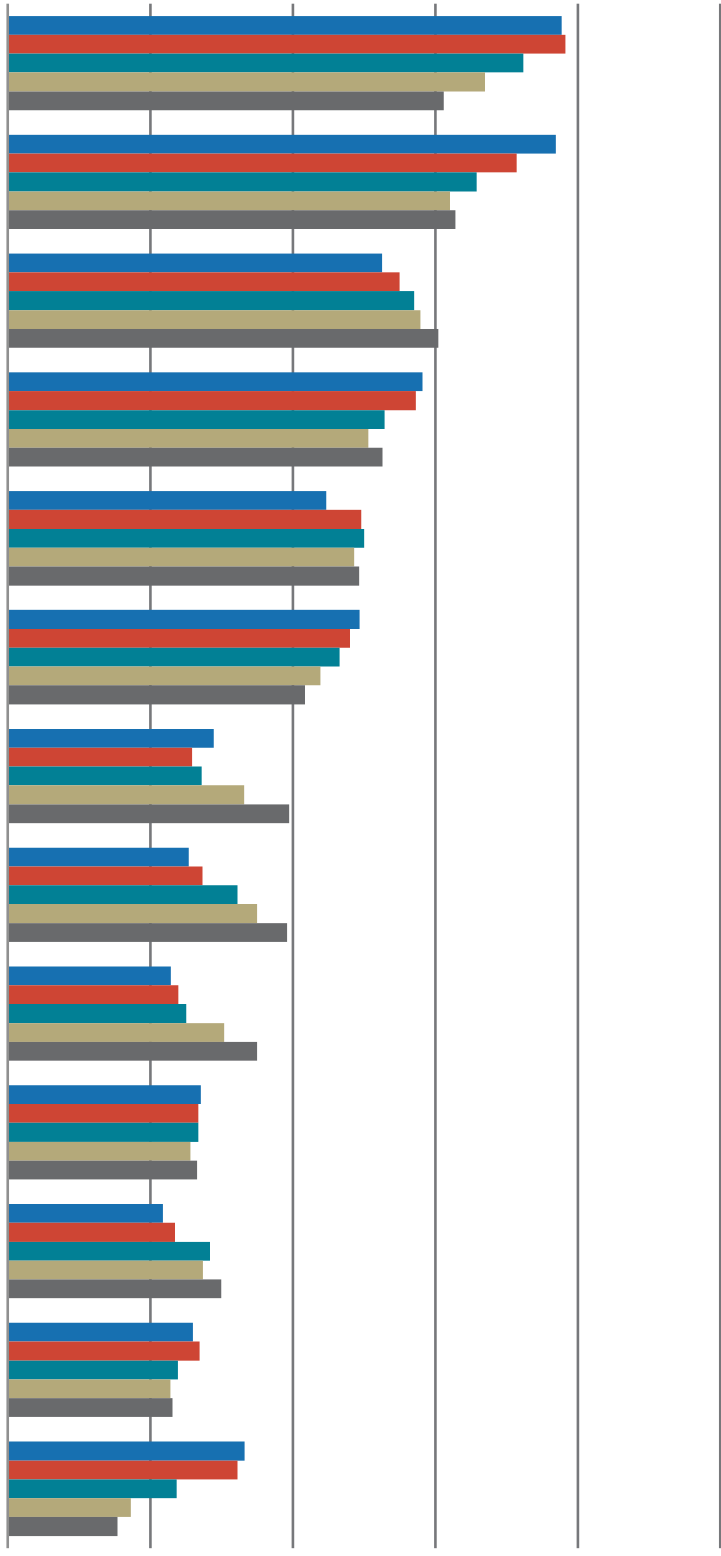

$80 \% \quad 100 \%$ 


\section{Monograph Format Transition}

Since 2015, a growing percentage of faculty report that both print and electronic versions of scholarly monographs are important for their research and teaching (see Figure 7). The importance of these materials predominately varies by discipline and age cohorts.

Figure 7: Please use the 10 to 1 scales to indicate how well each statement describes your point of view. Percent of respondents who strongly agreed with the following statements.

Within the next five years, the use of e-books will be so prevalent among faculty and students that it will not be necessary to maintain library collections of hard-copy books

Print versions of scholarly monographs play a very important role in my research and teaching

versions of scholarly monographs play a very important role in my research and teaching

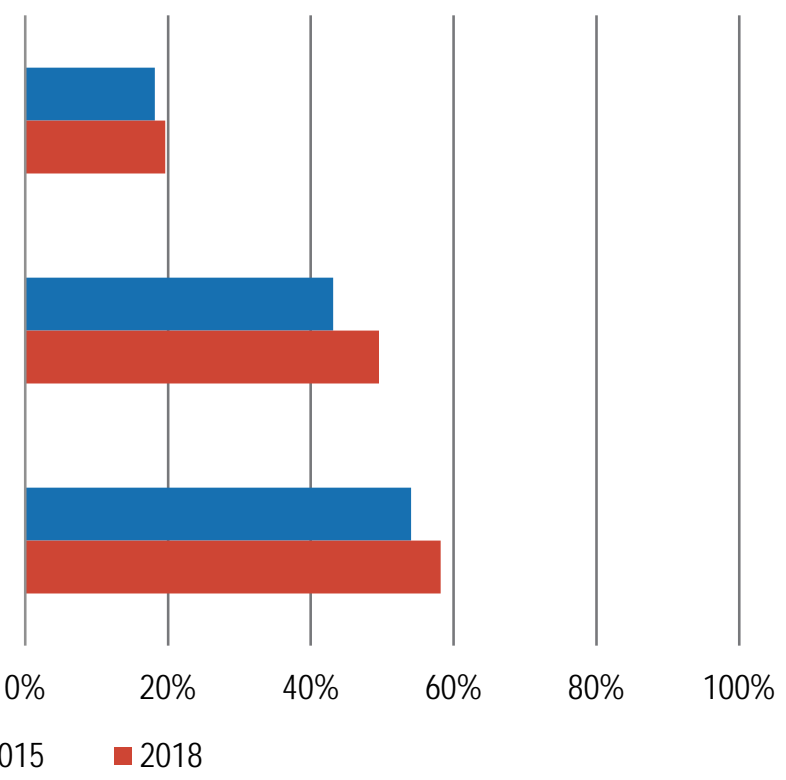

Greater shares of humanists have indicated that print versions of scholarly monographs play an important role for their teaching and research compared to their colleagues in other disciplines, and humanists also exhibited the largest increase in perceived importance of print versions since 2015 (see Figure 8). Scientists are similar to medical faculty in their responses, with roughly doubled shares of respondents indicating electronic versions of scholarly monographs as very important compared to those that regard print versions similarly. However, there is still an observed increase in reported importance for both print and electronic format types within these subgroups since 2015. 
Figure 8: Please use the 10 to 1 scales to indicate how well each statement describes your point of view. Percent of respondents who strongly agreed with the following statements.

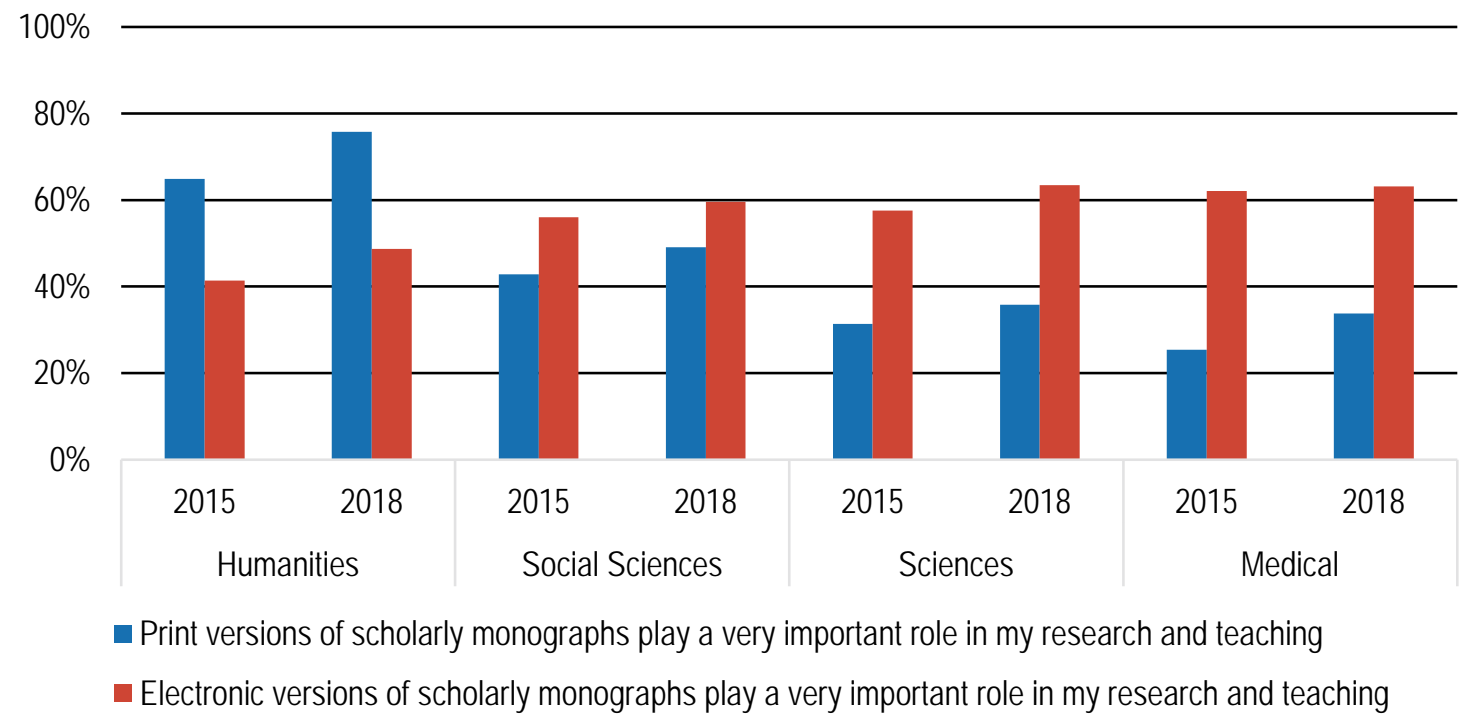

Respondents in younger cohorts are more likely to indicate that electronic versions of scholarly monographs, as compared to print versions, are important to their research and teaching practices. Faculty over 65 perceive print versions of monographs to be more important than electronic resources (see Figure 9).

However, faculty in younger cohorts are less likely to agree that libraries will not be needed in five years to maintain collections of hard-copy books (see Figure 9). Since greater shares of younger faculty have indicated they value electronic versions, they may also be more likely to recognize the limitations of the electronic format. 
Figure 9: Please use the 10 to 1 scales to indicate how well each statement describes your point of view. Percent of respondents who strongly agreed with the following statements.

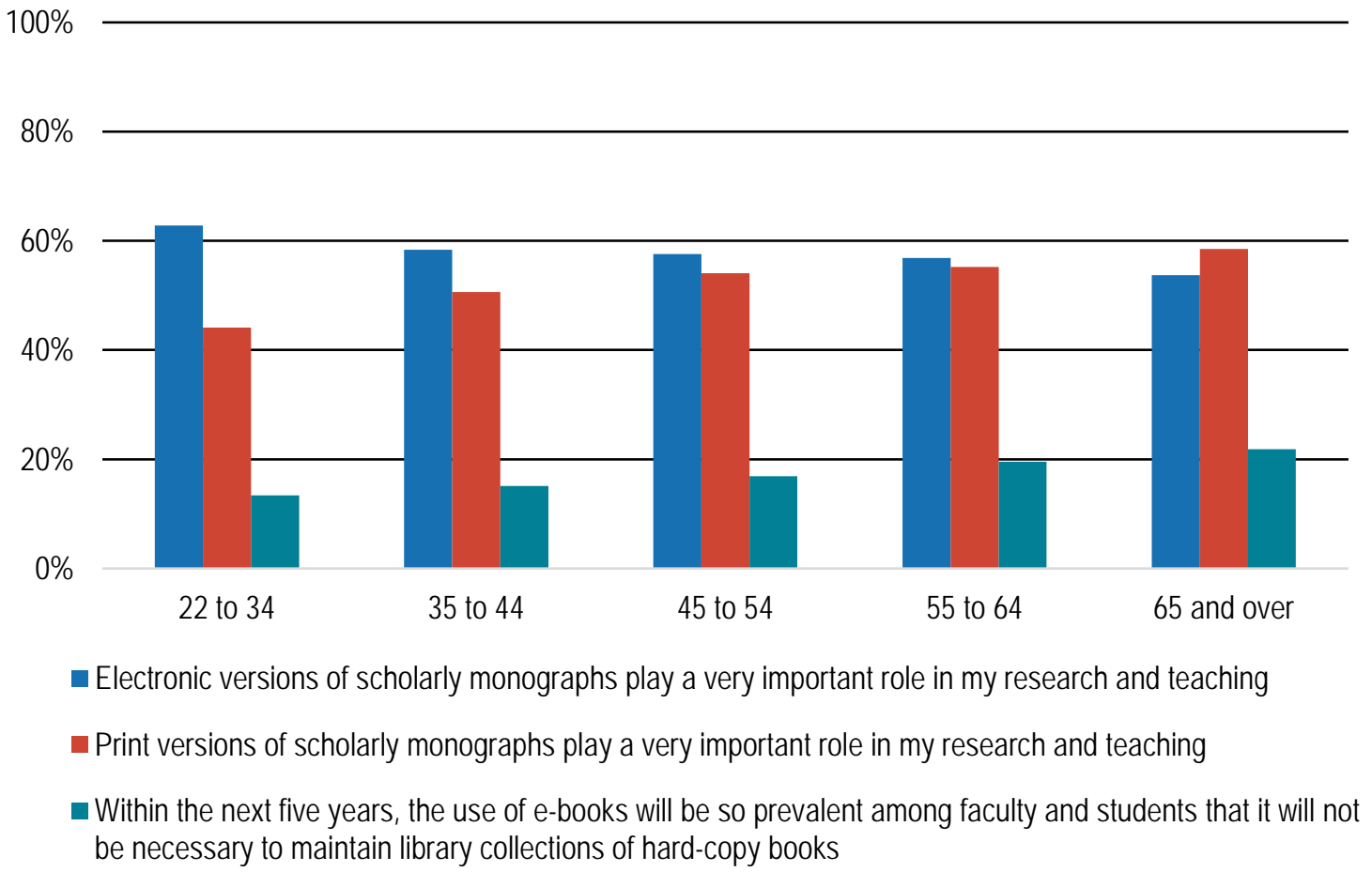

Respondents were also asked to rate whether a variety of activities were easier to perform using a print or digital version of a scholarly monograph. In accordance with the 2015 survey findings, long-form reading activities, such as reading cover to cover in depth and reading a section in depth, were rated as considerably easier to perform using a print format than digital. Conversely, exploring references and searching for a particular topic were rated considerably easier to perform using a digital format (see Figure 10). 
Figure 10: Below is a list of ways you may use a scholarly monograph. Please think about doing each of these things with a scholarly monograph in print format or in digital format, and use the scales below to indicate how much easier or harder is it to perform each activity in print or digital format. Please select one answer for each item.

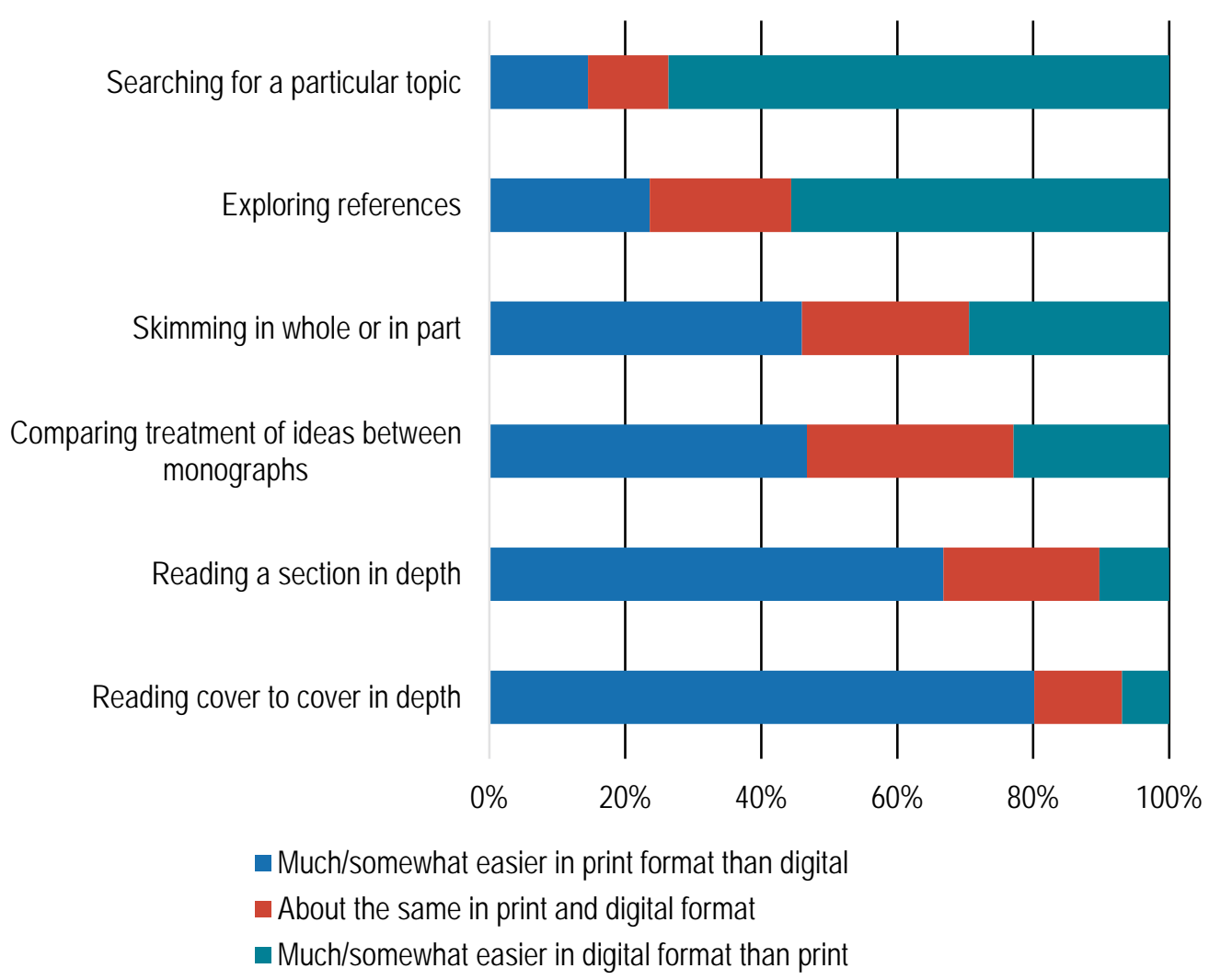

While there was a notable increase in the share of respondents who indicated that these activities were easier to perform in print between 2012 and 2015, perceptions regarding the ease of using print versions have generally stayed the same or slightly reversed in this most recent cycle (see Figure 11). Consistent with previous cycles, humanists expressed an inclination towards print versions, as a greater share rated each activity as substantially easier to perform using print versions compared to their peers in other disciplines. Additionally, greater shares of respondents in younger cohorts indicated that many of these activities were easier to perform using digital versions over print versions. 
Figure 11: Below is a list of ways you may use a scholarly monograph. Please think about doing each of these things with a scholarly monograph in print format or in digital format, and use the scales below to indicate how much easier or harder is it to perform each activity in print or digital format. Percent of respondents who indicated that each of these activities is much or somewhat easier in print than digital format.

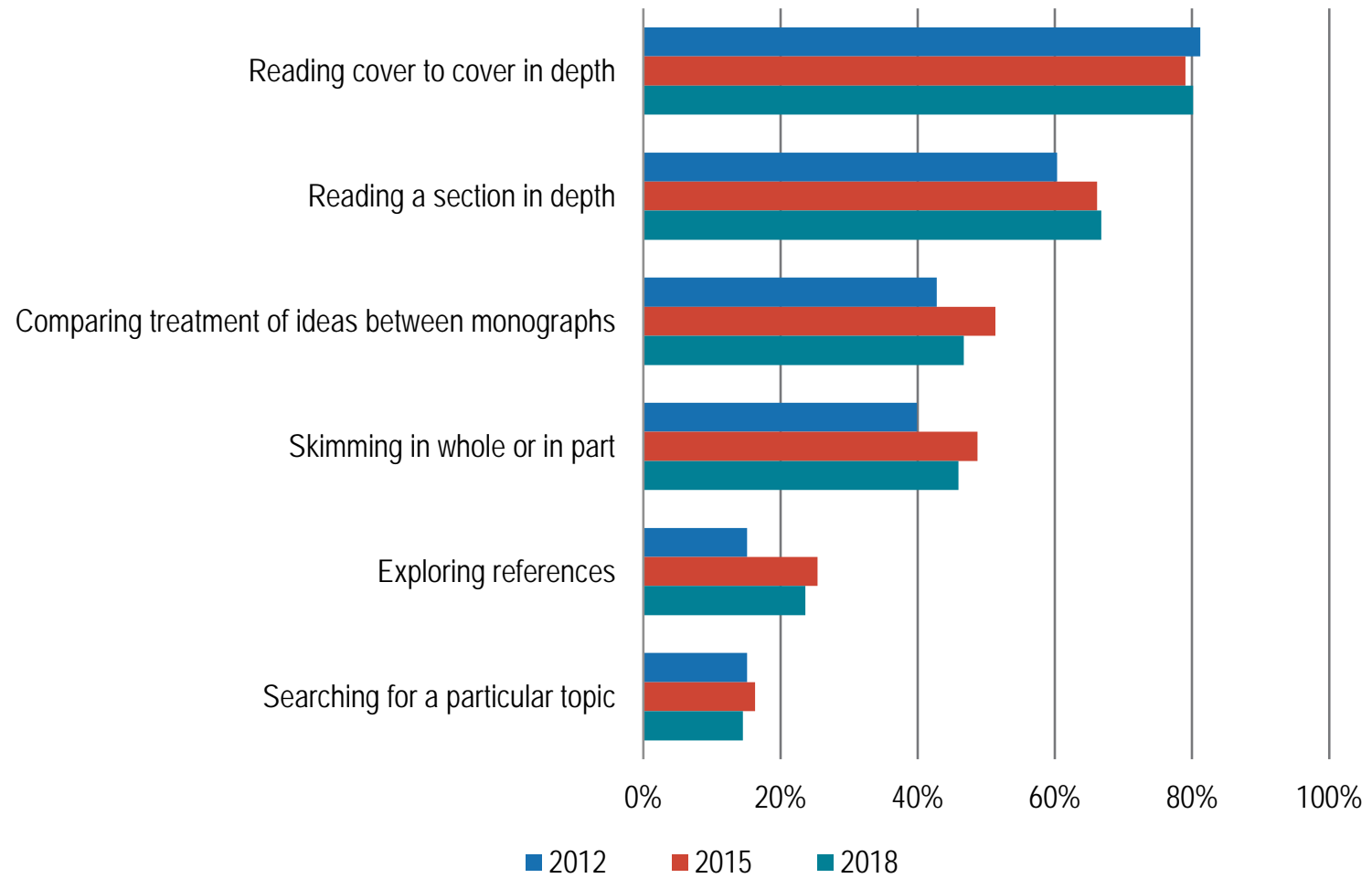

\section{Gaining Access to Materials for Research and Teaching}

Although faculty members are increasingly using freely available search engines, such as Google Scholar and other general purpose search engines (see Figure 1), to discover and explore scholarly literature relevant to their field, there are often challenges in accessing desired materials. When asked to rate the importance of specific sources used to access journal articles and scholarly monographs, respondents indicated that they are most likely to use their college or university library's collections or subscriptions, materials that are freely available online, and their own personal collections or subscriptions.

Faculty continue to seek journal articles and monographs in similar ways as noted in previous cycles. The importance of one's own library collection or subscriptions, freely available materials online, and one's own personal collection or subscriptions have all remained relatively stable since 2015 (see Figure 12). 
Figure 12: When you think about the journal articles and scholarly monographs that you routinely use - for research as well as teaching - how important are each of the following sources? Percent of respondents who indicated that each of these methods is highly important.

My college or university library's collections or subscriptions

Materials that are freely available online

My own personal collection or subscriptions

Collections or subscriptions of other institutions

My academic department's collections or subscriptions

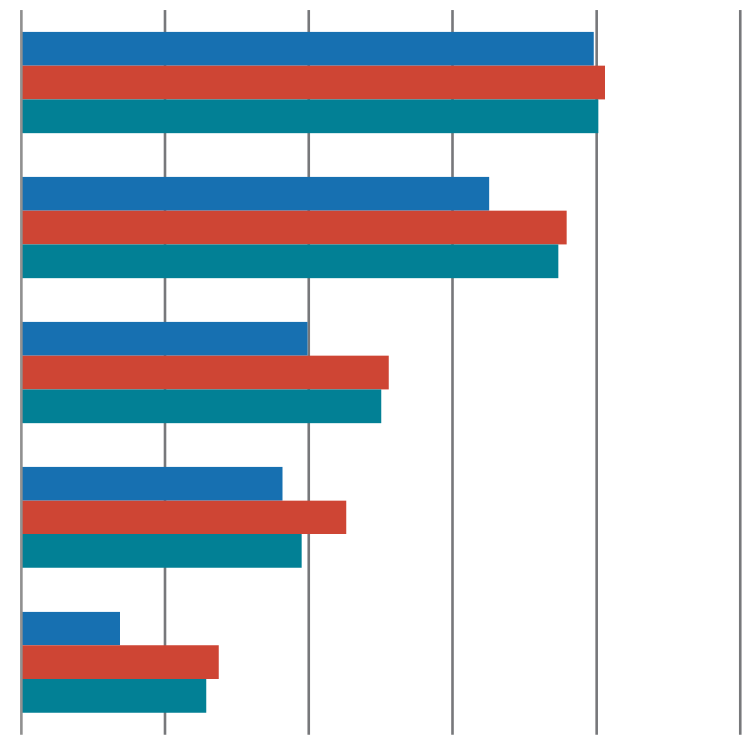

$$
\text { - } 2012-2015 \quad-2018
$$

While the importance of these sources has not substantially changed since 2015, there is an observed decrease in the use of other institutions' collections or subscriptions. This decrease was particularly driven by social scientists, scientists, and medical faculty; $38 \%$ of social scientists, $34 \%$ of scientists, and $22 \%$ of medical faculty indicated that the collections or subscriptions of other institutions are highly important in 2018, compared to $45 \%$ of social scientists, $41 \%$ of scientists, and $32 \%$ of medical faculty in 2015 . Humanists' ratings of these collections and subscriptions did not change over this time period, with 51\% indicating this source as highly important.

Consistent with the 2015 survey cycle, when faculty members are unable to immediately access a scholarly monograph or journal article, they are most likely to search for a freely available version online, use ILL/ document delivery services provided by their library, or give up and look for a different resource (see Figure 13). 


\section{ITHAKA S+R}

Figure 13: When you want a scholarly monograph or journal article that you do not have immediate access to through your college or university library's physical or digital collections, how often do you use each of the following methods to seek access to that material? Percent of respondents who indicated that each of these methods is used often or occasionally.

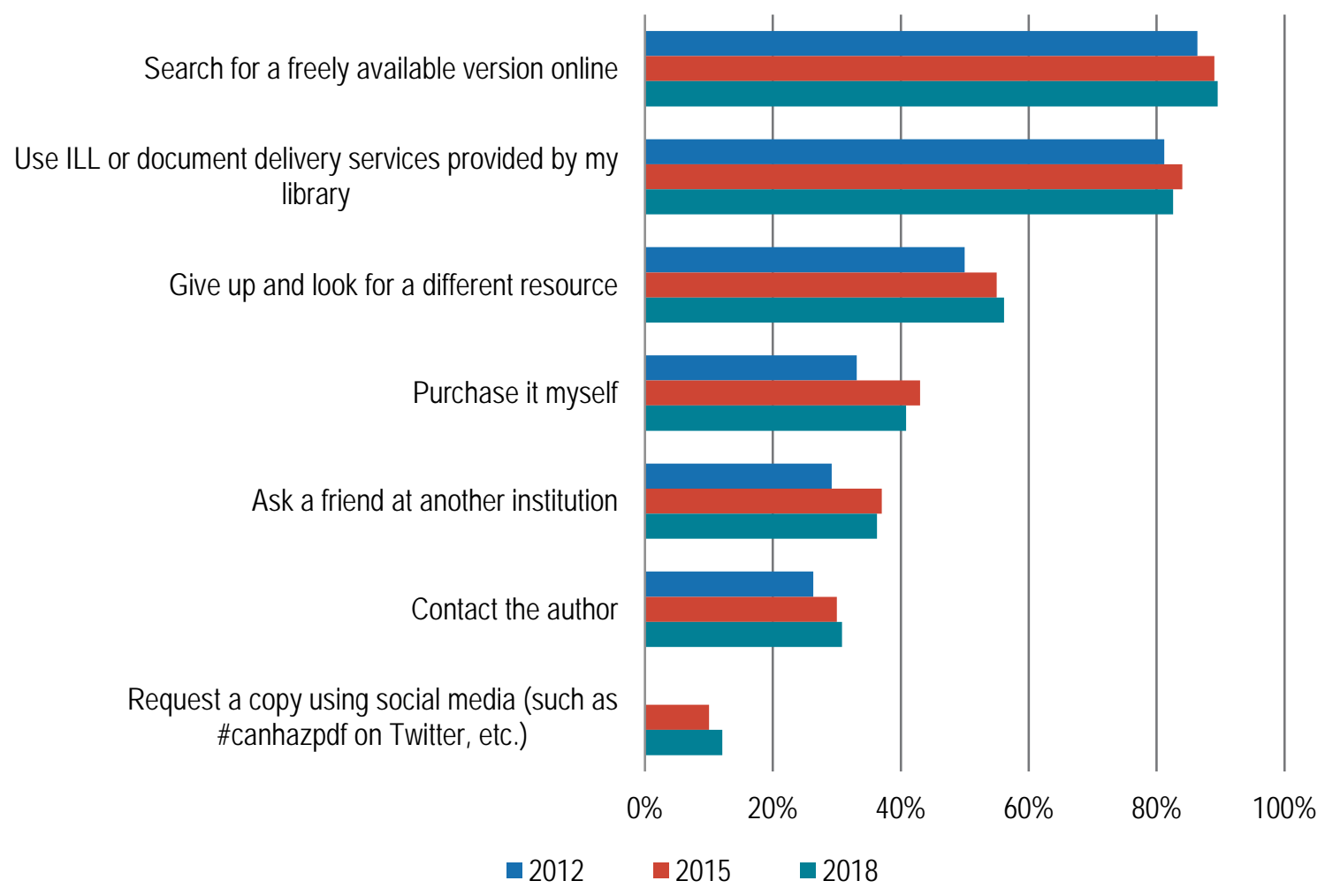




\section{Research Practices}

In this section, we focus on the data collection, analysis, management, and preservation practices of faculty and how these practices have evolved over time. Questions on research practices were only displayed to individuals who indicated that conducting academic research is among their professional responsibilities. Overall, $84 \%$ of respondents received these questions. This share of faculty varied slightly by institution type, with $85 \%$ of faculty from Baccalaureate colleges, $80 \%$ from Master's colleges and universities, and $88 \%$ from Doctoral universities. Tenure-line faculty are more likely to conduct research than contingent faculty; approximately nine in ten tenure-line faculty conduct research compared to roughly half of contingent faculty. ${ }^{3}$

\section{Data Analysis}

Faculty members who conduct research were asked to rate the importance of a variety of activities and methodologies to their research practices. The most important activities and methodologies were analysis of quantitative and qualitative data generated in the course of research, with $60 \%$ and $52 \%$ of respondents indicating these activities as highly important respectively; these most highly ranked methodologies are consistent with the previous survey cycle results. Analysis of pre-existing quantitative data (39\%), using models or simulations (34\%), and analysis of pre-existing qualitative data (33\%) followed those activities in importance.

Across disciplines, scientists, medical faculty, and social scientists rate the analysis of quantitative data generated in the course of research as the most important activity to their practice (see Figure 14). Humanists designate much more importance to qualitative data than quantitative data. These findings have remained consistent with the 2015 survey cycle.

\footnotetext{
${ }^{3}$ Tenure-line faculty include respondents who are professors, associate professors, and assistant professors. Contingent faculty include respondents who are adjunct professors, lecturers, and instructors.
} 
Figure 14: How important to your research is each of the following digital research activities and methodologies today? Percent of respondents who indicated that each of these activities and methodologies is highly important.

Analysis of quantitative data that you generate in the course of your research

Analysis of qualitative data that you generate in the course of your research

Analysis of pre-existing quantitative data that you do not generate in the course of your research

Using models or simulations

Analysis of pre-existing qualitative data that you do not generate in the course of your research

Writing software or code

Computational analysis of text (text mining)

GIS/mapping of data

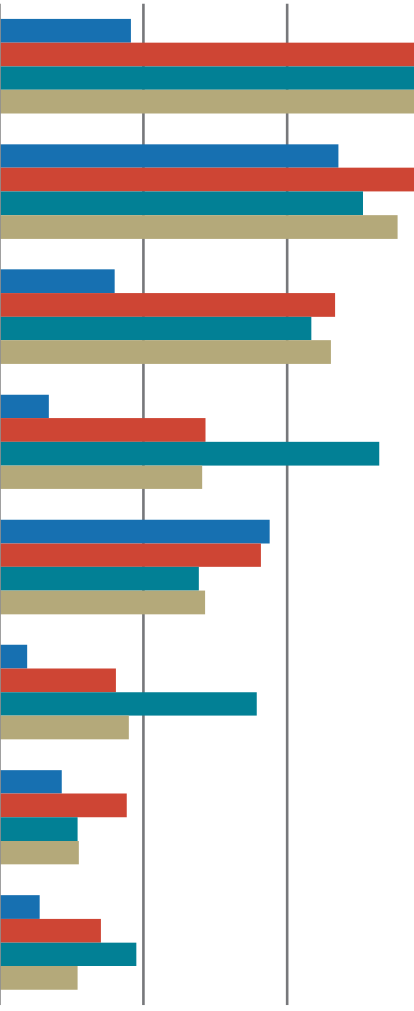

$40 \%$

$60 \%$

Faculty who indicated that they received external funding from a public or government grant-making organization (i.e. NSF, NIH, NEH, etc.) within the past five years assigned considerably more importance to the analysis of quantitative data over qualitative data generated in the course of research (see Figure 15). Faculty who received external funding also rate the analysis of pre-existing quantitative data not generated in the course of research, the use of models or simulations, the writing of software or code, and the GIS/ mapping of data as much higher than their non-externally funded colleagues. ${ }^{4}$

\footnotetext{
${ }^{4}$ These findings emulate disciplinary differences (see Figure 14). Approximately $63 \%$ of scientists and $70 \%$ of medical faculty have received or are currently receiving external funding, compared to $16 \%$ of humanists and $26 \%$ of social scientists.
} 
Figure 15: How important to your research is each of the following digital research activities and methodologies today? Percent of respondents who indicated that each of these activities and methodologies is highly important.

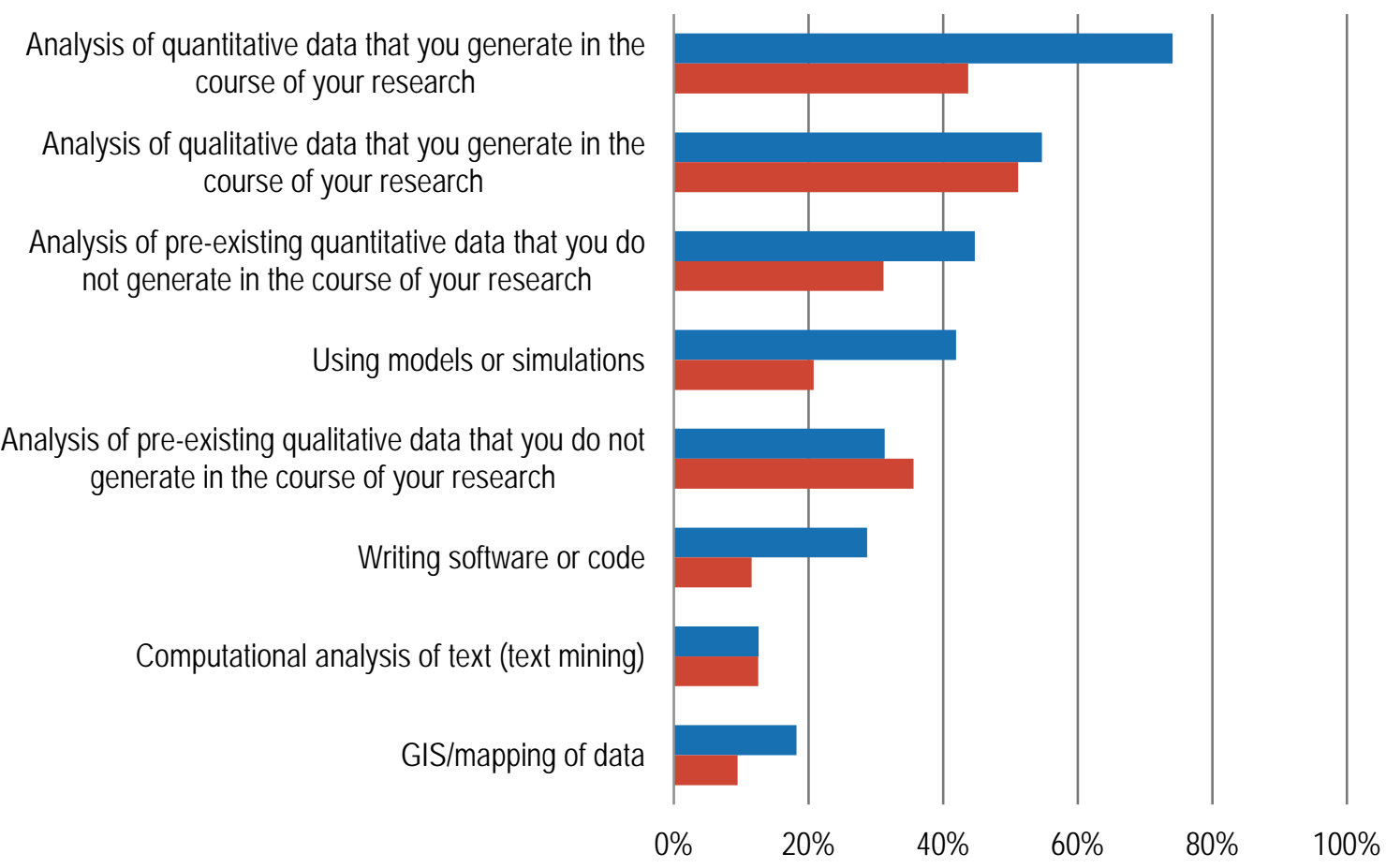

- Has received external funding within the last five years

- Has not received external funding within the last five years

Faculty were also asked to identify the types of research data they are building or collecting for their own research. Overall, 68\% responded that they are collecting quantitative data, $66 \%$ are collecting qualitative data, and $26 \%$ are collecting scientific data Humanists and social scientists are more likely to collect or create qualitative data than their peers, whereas scientists and medical faculty are more likely to generate scientific and quantitative data (see Figure 16). 
Figure 16: Which of the following types of research data do you build up or collect for your own research? Percent of respondents who indicated they build up or collect each type of data.

Quantitative (such as numeric files, survey responses, geospatial data files, etc.)

Qualitative (such as interview or focus group transcripts, field notes, text, documents, images, video, audio, open-ended survey responses, etc.)

Scientific (such as slides, biological specimens, samples, etc.)

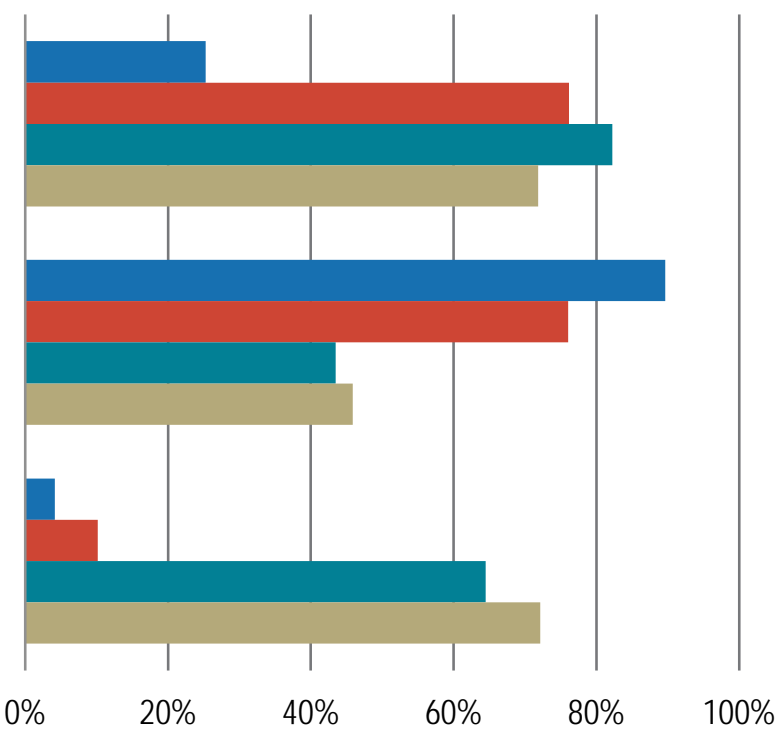

Humanities $\square$ Social Sciences $\square$ Sciences Medical

\section{Data Management \& Preservation}

In managing, storing, and preserving data collected in the course of research, faculty have a preference for independently maintaining data on their own computers and storing the data using commercially or freely available software.

When asked what methods are used to organize or manage research data during the research process, the vast majority of faculty replied that they use their own computer(s) with roughly half using a cloud storage service (such as Google Drive, Dropbox, Flickr, etc.). Very few faculty members are using their institution's library to preserve these materials on their behalf.

Although the majority of respondents are organizing or managing research data on their own computer(s), the use of this method has slightly decreased among faculty since 2015 (see Figure 17). Correspondingly, use of cloud storage services - which may include both personal and institutionally-provided accounts - has notably increased, indicating a shift towards the use of online, cloud-based storage services for the organization, management, and preservation of faculty research data. 


\section{ITHAKA S R}

Figure 17: Please use the 10 to 1 scales below to indicate how well each statement below describes your point of view. Percent of respondents who strongly agreed with each of these statements.

When I am in the process of collecting data, media, or images for my research, I often organize or manage these data on my own computer or computers

When I am in the process of collecting data, media, or images for my research, I often organize or manage these data on a cloud storage service (such as Google Drive, Dropbox, Flickr, etc.)

My college or university library manages or organizes my data, media, or images on my behalf

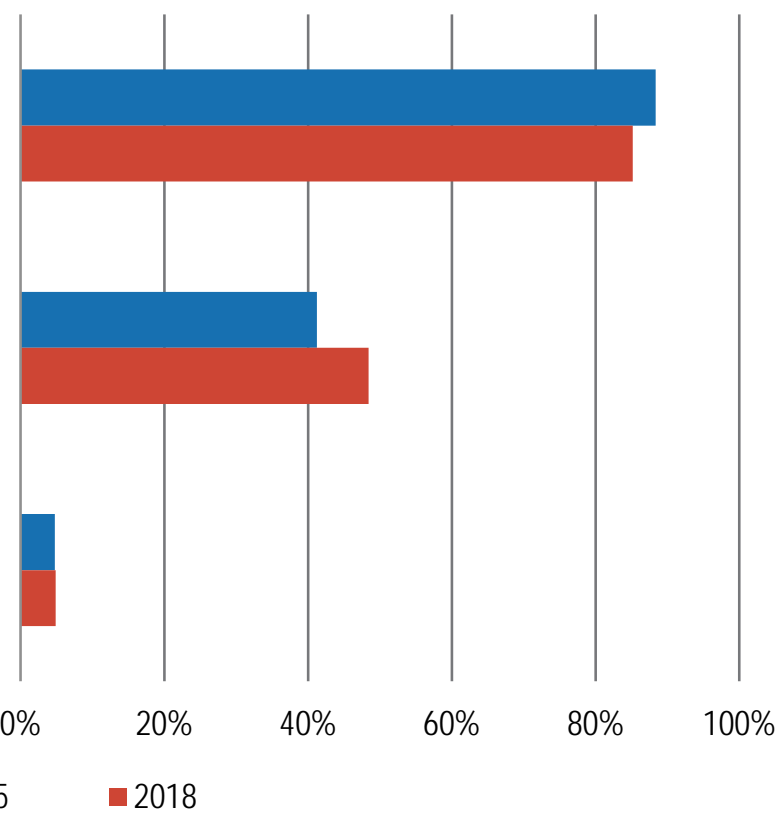

The utilization of cloud-based storage services varies by discipline, with $50 \%$ of humanists and $51 \%$ of social scientists reporting frequent use of this method of storage compared to $44 \%$ of scientists and $37 \%$ of medical faculty. Younger faculty are substantially more likely to use cloud storage services; approximately six in ten faculty aged 22 to 44 often engage in this practice compared to less than four in ten aged 55 and older (see Figure 18). 
Figure 18: Please use the 10 to 1 scales below to indicate how well each statement below describes your point of view. Percent of respondents who strongly agreed with each of these statements.

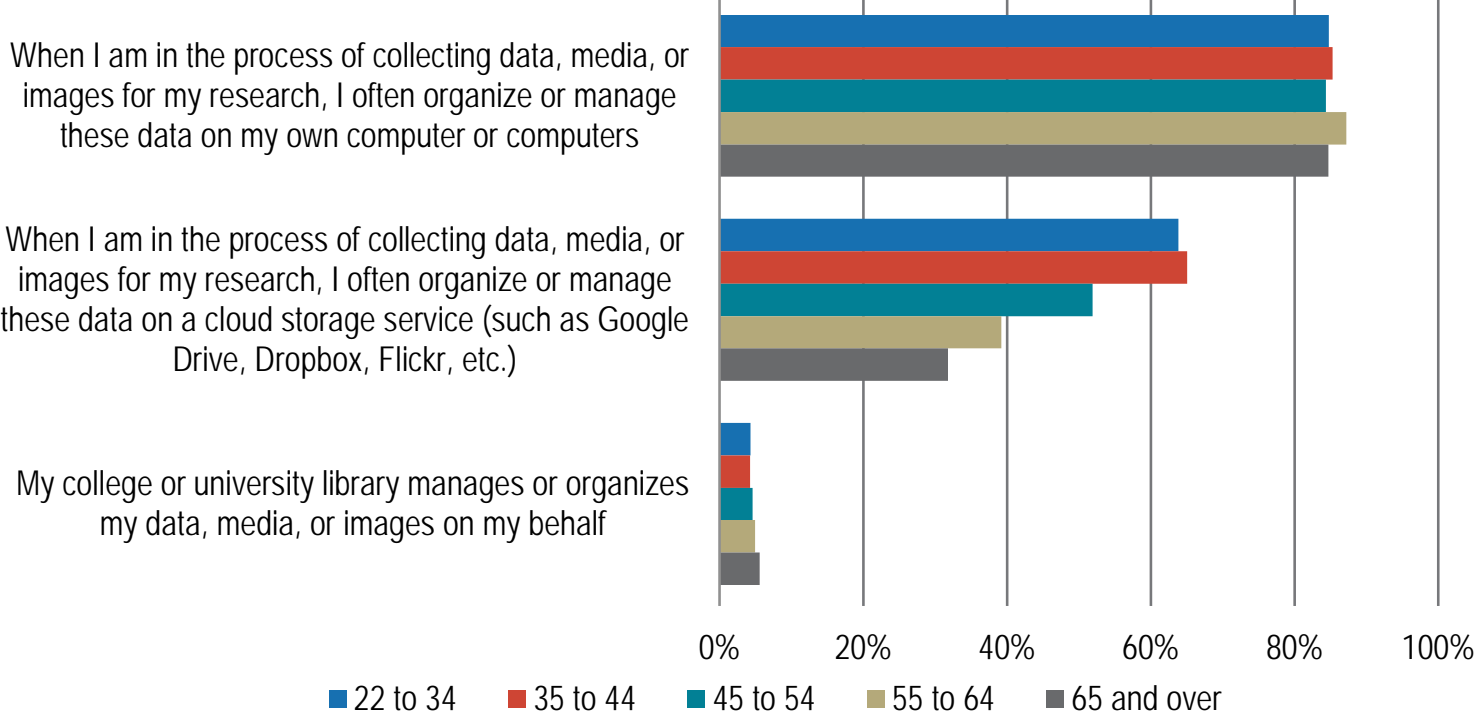

When faculty were asked about the sources of support they find most valuable for managing or preserving research data, media, or images, the majority of respondents generally indicated that online services and software were the most valuable for their needs. The source of support that the largest share of faculty found useful was file hosting services (e.g. Box, Dropbox), followed by freely available software and their institution's library (see Figure 19). Support provided by AV/media support departments, third-party data repositories, and disciplinary repositories at other institutions were viewed as relatively less useful. These findings further reinforce the value that faculty place on tools that allow them to independently maintain their own data.

There is fairly broad consensus across disciplines in the importance and value of file hosting services and freely available software to support the management and preservation of data. Humanists and social scientists value support from their college or university's library relatively more so than their colleagues, while greater shares of social scientists, scientists, and medical faculty value other services from their institution, such as IT departments, disciplinary or departmental repositories, and third-party data repositories (see Figure 19). Preferences for data management and preservation support vary greatly across faculty of different age cohorts. Younger faculty broadly value webbased services and freely available software considerably more than their older colleagues (see Figure 20). 


\section{ITHAKA S R}

Figure 19: Please use the scale below to rate from 10 to 1 how valuable you would or do find each of the following possible sources of support for managing or preserving research data, media, or images. Percent of respondents who indicated each of these sources is highly valuable.

File hosting service (e.g. Box, Dropbox)

Freely available software

My college or university library

My college or university IT department

A disciplinary or departmental repository at my institution

A scholarly society

A publisher or a university press

An AV or media support department at my institution

A third-party data repository (e.g. ICPSR, Mendeley Data, Figshare)

A disciplinary repository at another institution

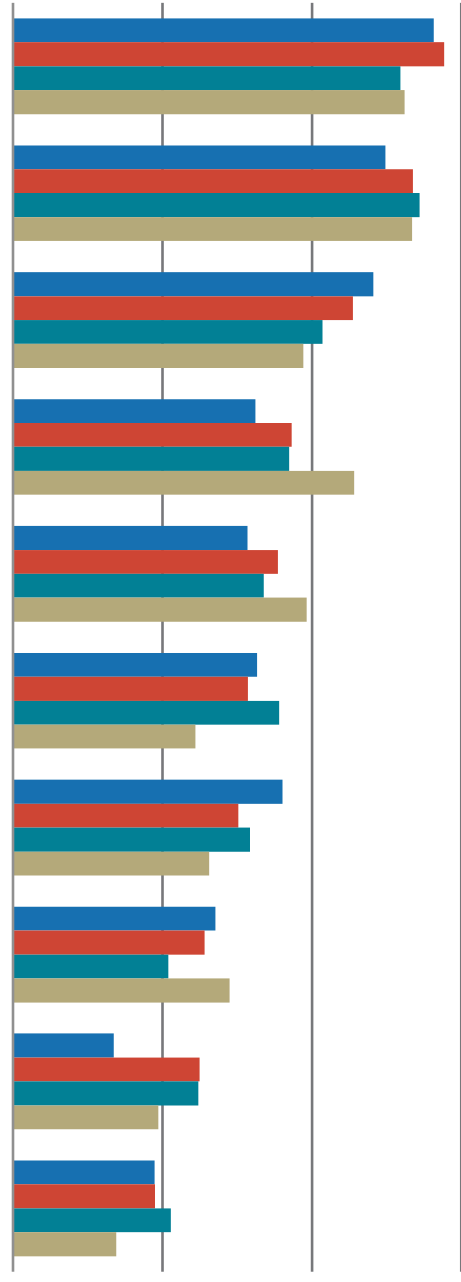

$0 \%$

$20 \%$

$40 \%$

$60 \%$

$80 \%$

$100 \%$ 
Figure 20: Please use the scale below to rate from 10 to 1 how valuable you would or do find each of the following possible sources of support for managing or preserving research data, media, or images. Percent of respondents who indicated each of these sources is highly valuable.

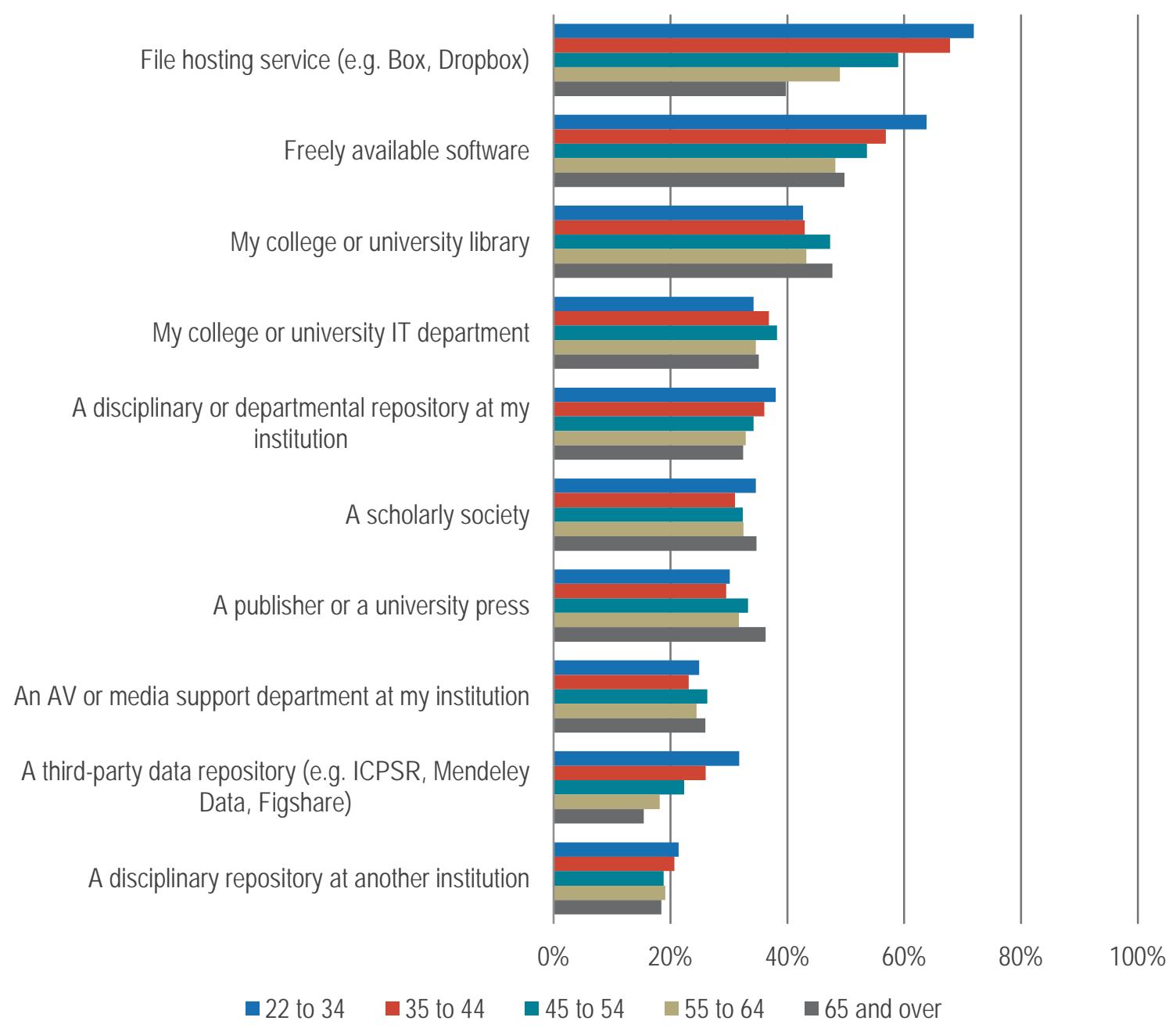

Faculty also have a preference for independently storing research data following the conclusion of a project. When queried on where they preserve these data, approximately three-quarters of faculty replied that they use commercially or freely available software/ services compared to roughly one-third who use a repository available through their institution or elsewhere. These preservation practices and preferences have not shifted substantially since 2015 when we first measured these behaviors.

Long-term data storage practices vary by age. Of respondents in the 22 to 34 years old age range, $80 \%$ indicated they preserve their data using freely available software or 
services, followed closely by $76 \%$ of respondents aged 35 to 44 , while $69 \%$ of faculty ages 55-64 and 67\% of faculty ages 65 and older use this method of preservation.

Additionally, preserving data via institutional or other online repositories notably varies by institution type and discipline. Respondents at Doctoral universities are more likely to preserve materials using a repository than their colleagues, with $32 \%$ of Doctoral faculty using repositories, compared to only $25 \%$ of Baccalaureate faculty, and $22 \%$ of Master's faculty. By discipline, scientists and medical faculty are more likely to preserve their data using a repository than humanists or social scientists (see Figure 21). Scientists are also more likely than their colleagues to have a publisher preserve their data on their behalf.

Figure 21: If your collections or sets of research data are preserved following the conclusion of your projects, what methods are used to preserve them? Please select each method by which they are preserved or indicate they are not preserved. Percent of respondents who indicated that each method is used.

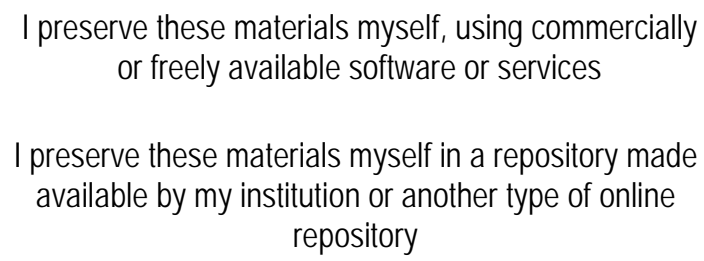

I preserve these materials myself in a repository made available by my institution or another type of online repository

My campus or university library preserves these materials on my behalf

A publisher preserves these materials on my behalf alongside the final research output

These materials are generally not preserved following the conclusion of a project

$$
\begin{aligned}
& 0 \% \quad 20 \% \quad 40 \% \quad 60 \% \\
& \text { - Humanities } \square \text { Social Sciences } \square \text { Sciences Medical }
\end{aligned}
$$

\section{Perspectives on Research Fraud}

Questions surrounding the attitudes, potential concerns, and possible solutions to data falsification, fabrication, and fraud were newly added to this cycle of the US Faculty Survey. 
Respondents appear to hold some concern regarding data fabrication, falsification, and other types of research fraud, but do not necessarily agree that this is becoming increasingly prevalent. Approximately half of respondents disagreed or strongly disagreed that they are not concerned about these issues while two in ten agreed or strongly agreed that these issues are becoming increasingly prevalent (see Figure 22). Faculty are fairly divided on whether there are sufficient processes and protocols currently in place to minimize research fraud; roughly two thirds of respondents agreed and disagreed that current processes and protocols are sufficient. Faculty overwhelmingly agree that defining research questions and an analysis plan prior to conducting research improves the credibility of research findings.

Figure 22: Please read the following statements and indicate the degree to which you agree or disagree with each. Percent of respondents who strongly agreed/ agreed somewhat agreed/ neither agreed nor disagreed/ somewhat disagreed or strongly disagreed/ disagreed with each statement.

Defining research questions and an analysis plan prior to conducting research improves the credibility of scholarly research findings

Data fabrication, falsification, and other types of scholarly research fraud are becoming increasingly prevalent

There are sufficient processes and protocols currently in place to minimize data fabrication, falsification, and other types of scholarly research fraud

I am not concerned about data fabrication, falsification, and other types of scholarly research fraud

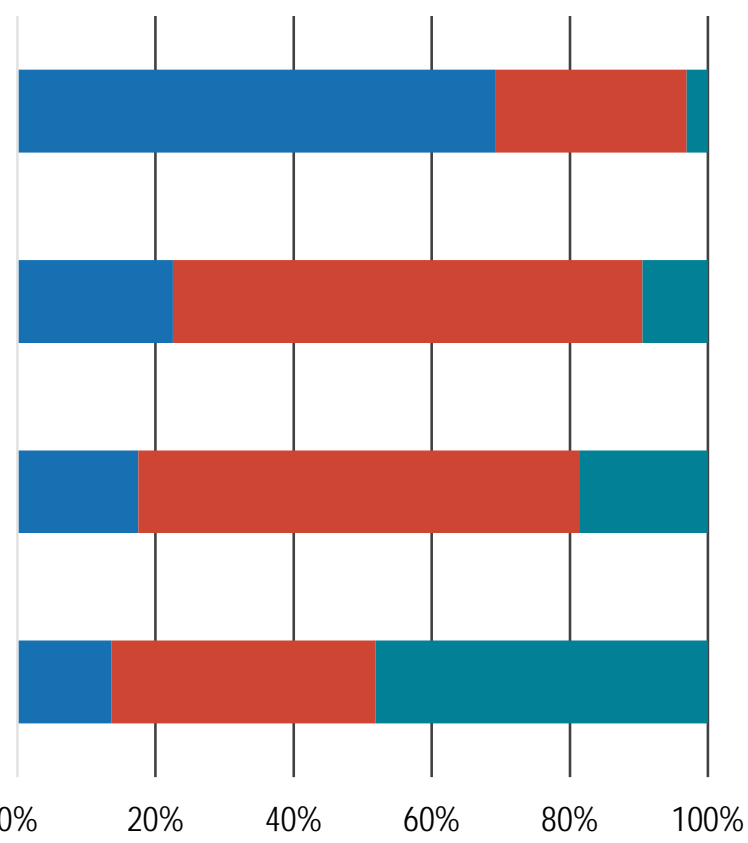

घtrongly agree/agree $\quad$ Somewhat agree/neither agree nor disagree/somewhat disagree $\square$ Stongly disagree/disagree

Social scientists and humanists are relatively less concerned about data or research fraud than their scientist and medical faculty colleagues, while medical faculty are substantially more concerned that research fraud is becoming increasingly prevalent (see Figure 23). Younger faculty are relatively less concerned about potential research fraud and are less likely to see these issues as becoming more prevalent compared to older faculty (see Figure 24). 


\section{ITHAKA S+R}

Figure 23: Please read the following statements and indicate the degree to which you agree or disagree with each. Percent of respondents who strongly agreed/ agreed with each statement.

\section{Defining research questions and an analysis plan prior to conducting research improves the credibility of scholarly research findings}

Data fabrication, falsification, and other types of scholarly research fraud are becoming increasingly prevalent

There are sufficient processes and protocols currently in place to minimize data fabrication, falsification, and other types of scholarly research fraud

I am not concerned about data fabrication, falsification, and other types of scholarly research fraud

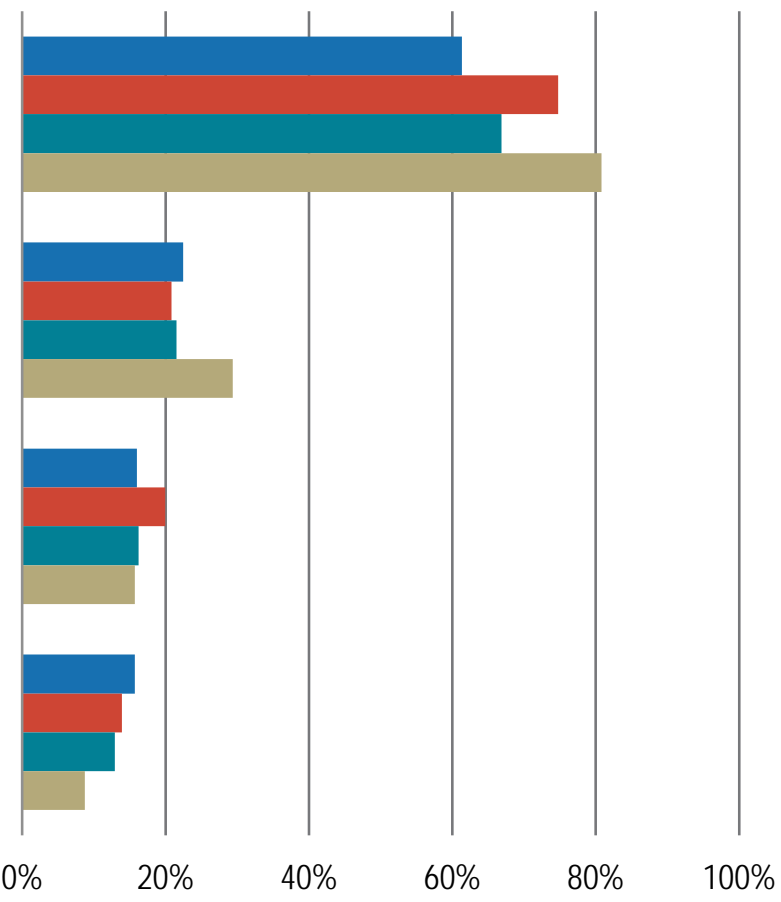

Humanities Social Sciences $\square$ Sciences Medical 


\section{ITHAKASR}

Figure 24: Please read the following statements and indicate the degree to which you agree or disagree with each. Percent of respondents who strongly agreed/ agreed with each statement.

Defining research questions and an analysis plan prior to conducting research improves the credibility of scholarly research findings

Data fabrication, falsification, and other types of scholarly research fraud are becoming increasingly prevalent

There are sufficient processes and protocols currently in place to minimize data fabrication, falsification, and other types of scholarly research fraud

I am not concerned about data fabrication, falsification, and other types of scholarly research fraud

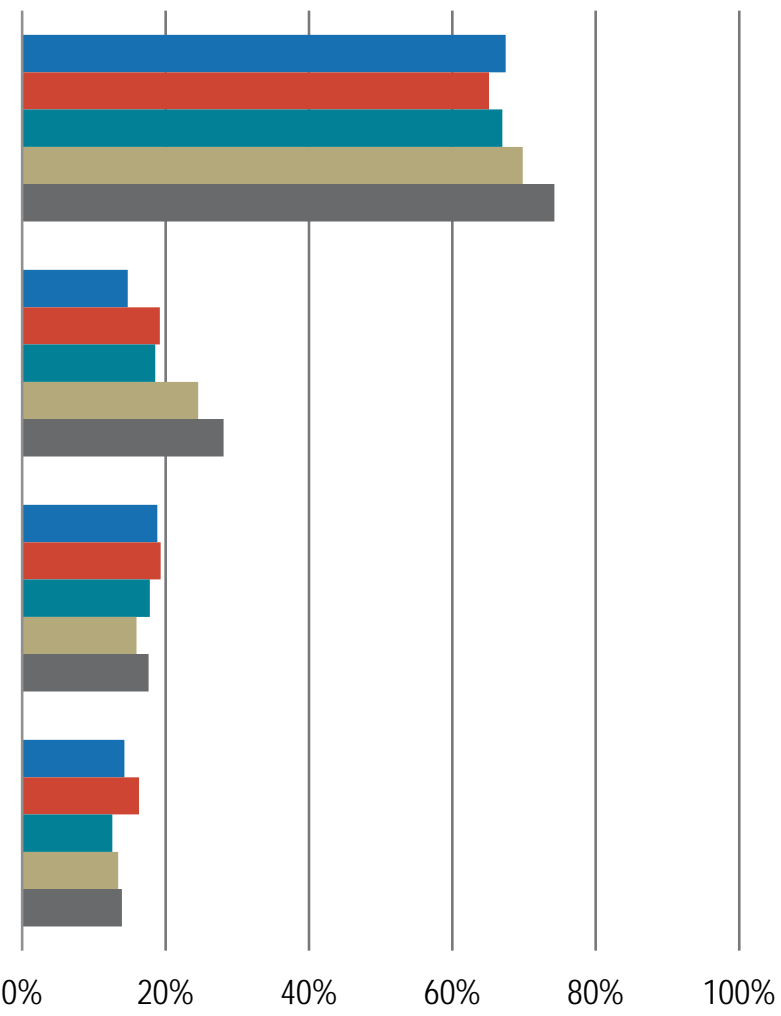

$\square 22$ to $34 \quad-35$ to $44 \quad \square 5$ to $54 \quad \square 5$ to $64 \quad \square 5$ and over

In addition to valuing the definition of research questions and analysis plans prior to conducting research, faculty view the organization and deposit of research datasets as broadly important, though roughly one in three do not think that the time it would take for them to deposit data is worth it. Scientists were most likely to strongly agree that this is an important practice for others and that it is worth their time to do this (see Figure 25). 


\section{ITHAKA S R}

Figure 25: Please use the 10 to 1 scales below to indicate how well each statement below describes your point of view. Percent of respondents who strongly agreed with each statement.

The time that it does or would take me to organize and develop documentation to make a dataset available for reuse by others is not worth it

It is important for researchers to organize and deposit their datasets so others can attempt to reproduce their findings

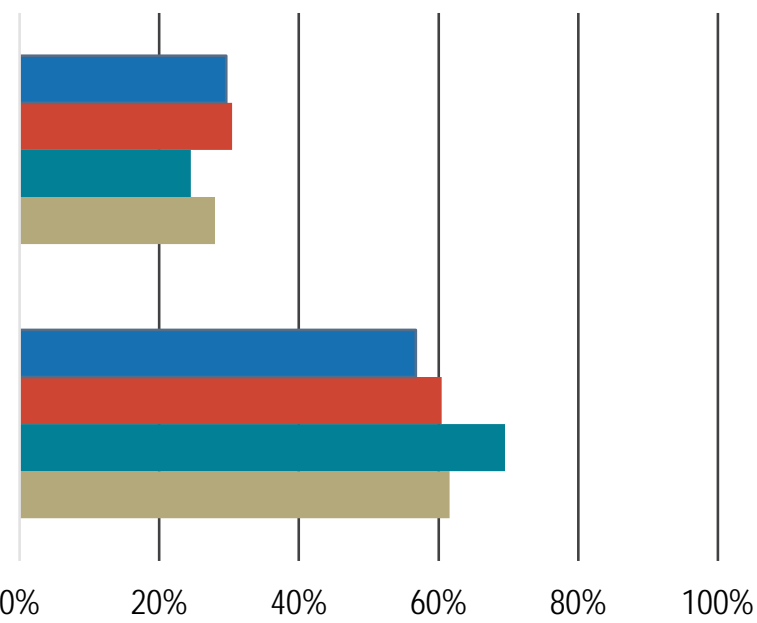

Humanities $\square$ Social Sciences $\square$ Sciences Medical 


\section{Research Dissemination}

This section explores the types of publications faculty are producing, characteristics of those research products, and audiences they are trying to reach, as well as viewpoints on open access publishing and incentives for advancement. Questions regarding these scholarly communication topics were only displayed to respondents who conduct academic research.

\section{Publication Formats and Characteristics}

Approximately $90 \%$ of respondents have often or occasionally shared their findings in peer-reviewed journals within the past five years; faculty members also frequently publish conference proceedings, scholarly monographs or edited volumes published by an academic publisher, and working papers or pre-prints (see Figure 26). These findings are broadly consistent with those from the 2015 survey cycle, though there has been a slight increase of faculty sharing findings in blogs or via social media (see Figure 26).

Figure 26: You may have the opportunity to share the findings of your scholarly research in a variety of different formats. Please use the scales below to indicate how often you have shared the findings of your scholarly research in each of the following ways in the past five years. Percent of respondents who indicated they share their findings often or occasionally in this format.

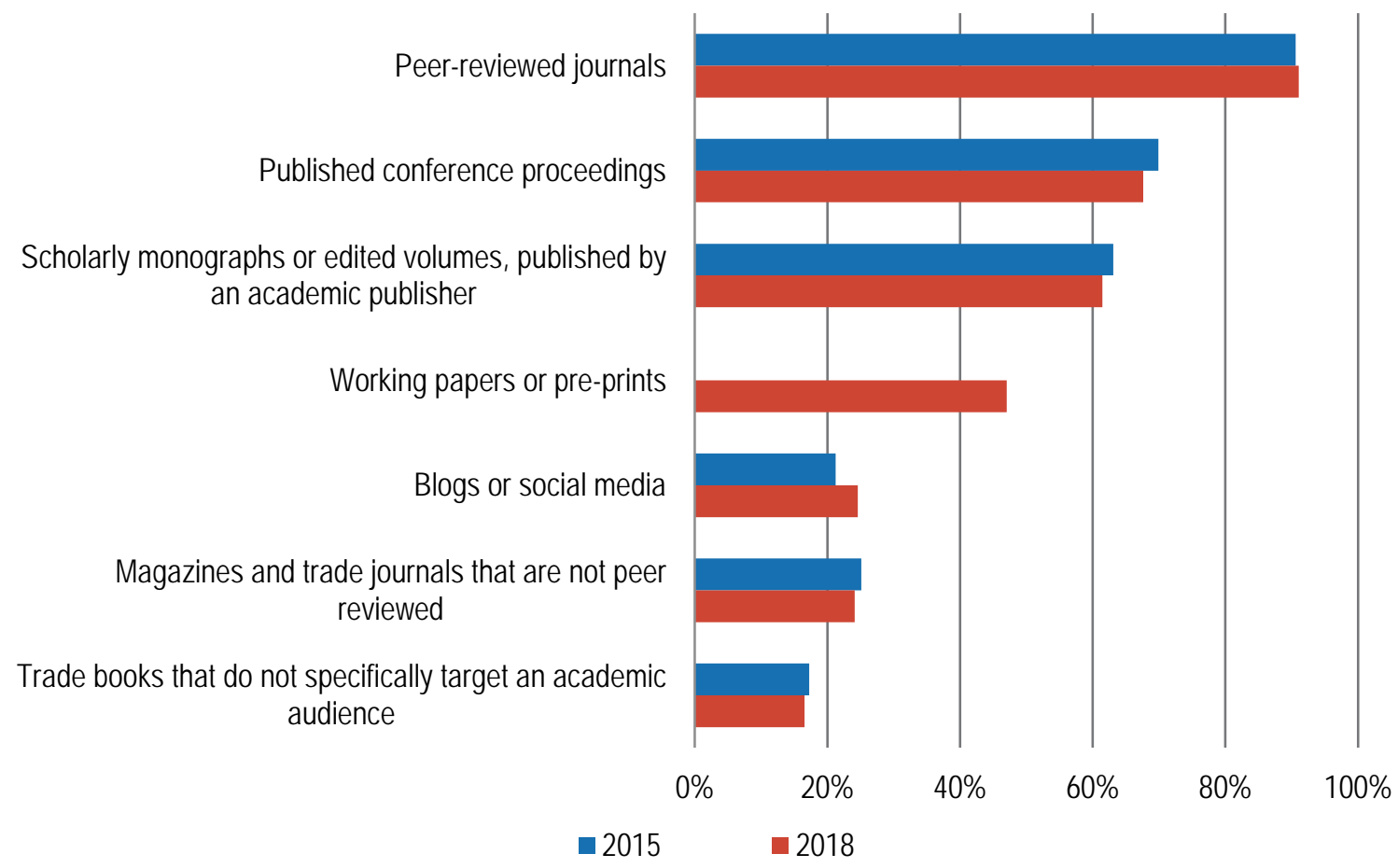


By discipline, the outlets in which faculty are sharing their scholarly findings are also consistent with the 2015 survey cycle. Humanists most frequently share their research in peer-reviewed journals and scholarly monographs or edited volumes, whereas scientists are relatively less likely to publish scholarly monographs (see Figure 27). Scientists also most frequently share their research in peer-reviewed journals and published conference proceedings. Faculty in contingent positions, compared to those in tenure-line positions, more frequently share their research findings in non-traditional scholarly formats, such as in blogs or social media, non-peer reviewed magazines and trade journals, and trade books (see Figure 28). Those in tenure-line positions more frequently share their findings in peer-reviewed journals and scholarly monographs.

Figure 27: You may have the opportunity to share the findings of your scholarly research in a variety of different formats. Please use the scales below to indicate how often you have shared the findings of your scholarly research in each of the following ways in the past five years. Percent of respondents who indicated they share their findings often or occasionally in this format.

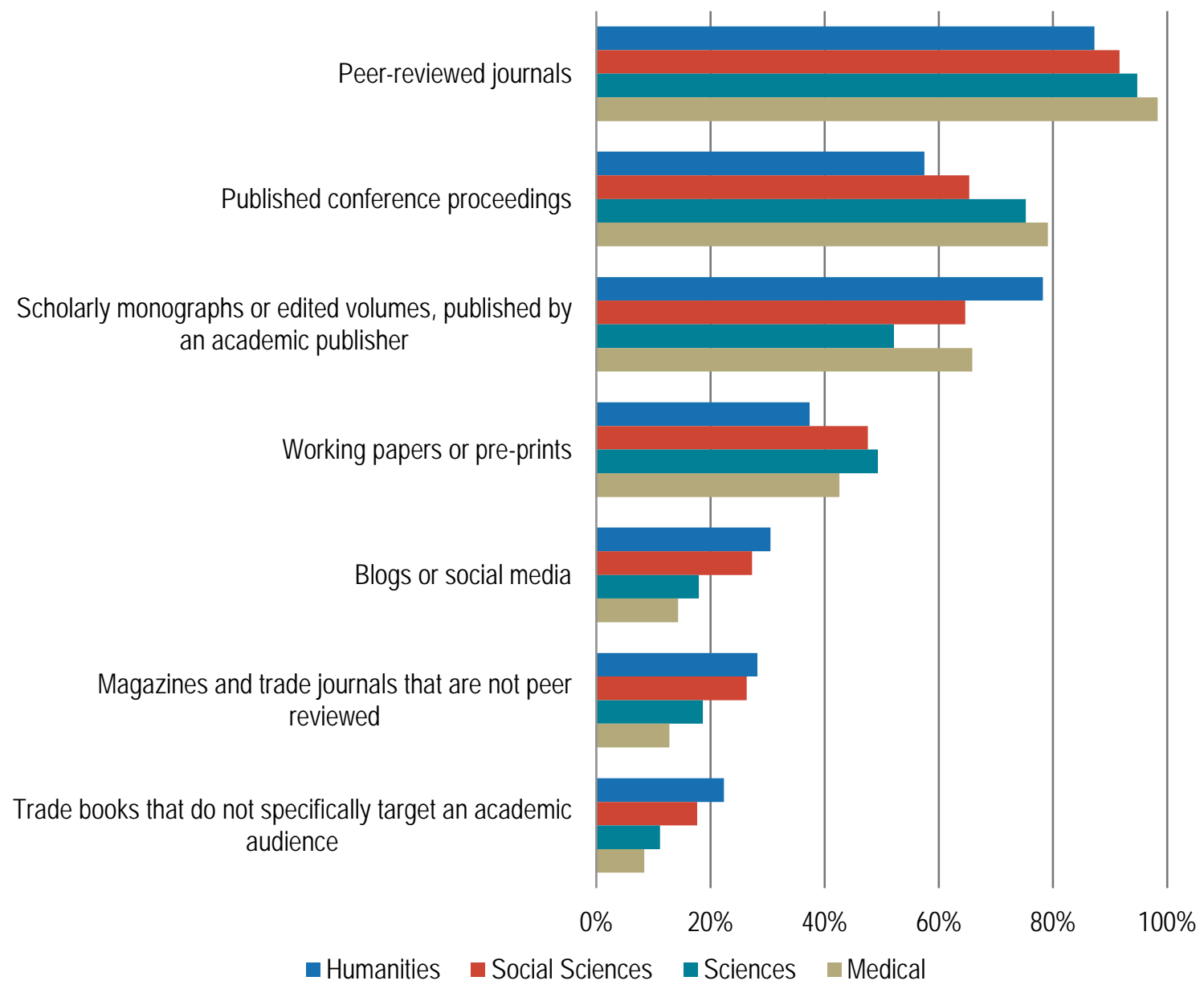


Figure 28: You may have the opportunity to share the findings of your scholarly research in a variety of different formats. Please use the scales below to indicate how often you have shared the findings of your scholarly research in each of the following ways in the past five years. Percent of respondents who indicated they share their findings often or occasionally in this format.

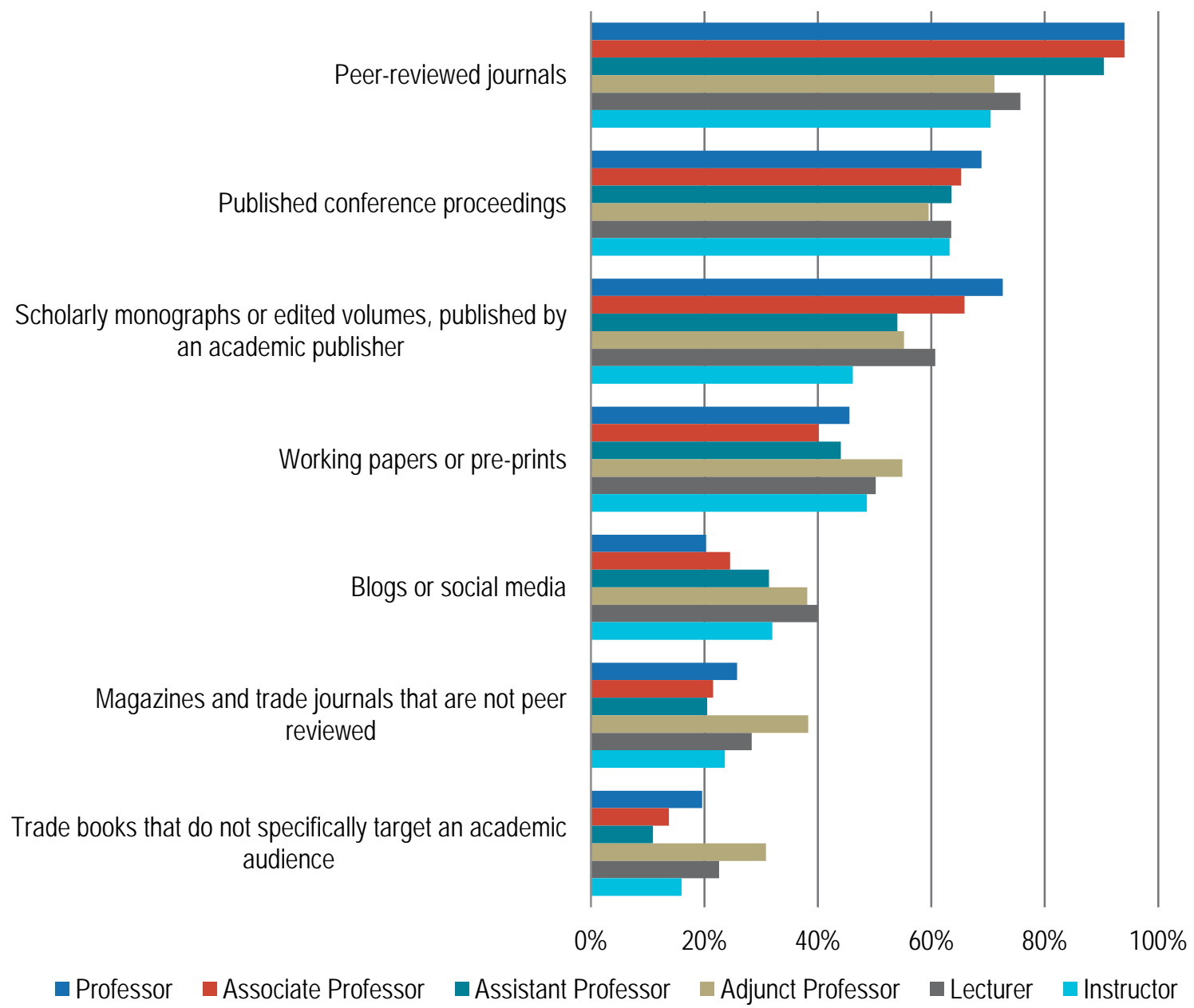

Faculty who indicated in an earlier question that they produce each of the following types of publications and/ or products were then asked if and where they have hosted them online or made them freely available. The majority of faculty who freely share each type of publication or product are doing so in various places online (such as on a personal webpage), compared to their institution's repository, or a specific disciplinary repository (such as arXiv, SSRN, etc.), with the exception of books or scholarly monographs. Faculty are just as likely to make their books or scholarly monographs available within their own institution's repository compared to elsewhere online (see Figure 29). 
Figure 29: Are your research publications and/ or products freely available online through your institution's repository, a disciplinary repository (such as arXiv, SSRN, etc.), or available elsewhere online (such as your personal webpage)? For each type(s) of scholarly work(s) listed below, please select all hosting sources that apply. Of the respondents that make each of the following types of publications and/ or products freely available online, the percent who indicated their research is hosted in each of the following.

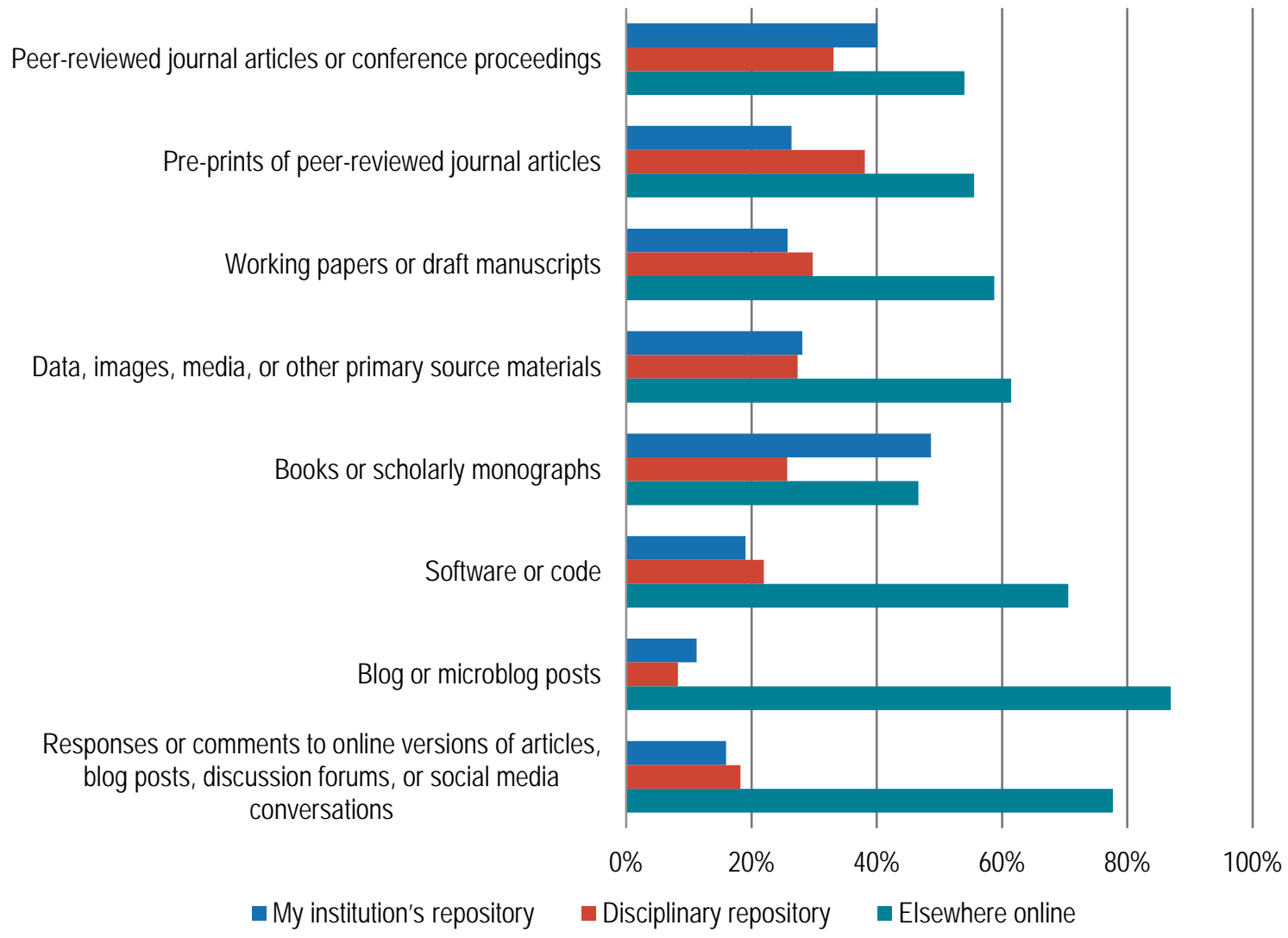

Considering where faculty are predominantly continuing to disseminate their research findings, it is perhaps unsurprising that the characteristics of scholarly journals that have historically been mostly highly valued continued to be viewed as such and continue to motivate publishing behavior accordingly (see Figure 30). These most highly valued characteristics include the journal's area of coverage aligning closely to one's immediate area of research, the current issues of the journal being circulated widely and being well read by scholars in one's field, and the journal having a high impact factor or excellent academic reputation.

The least-valued characteristic by faculty is the ability to link the dataset(s) or digital primary source(s) associated with an article. While a majority of faculty note that it is 
important for researchers to deposit datasets for future replication studies, this is a relatively unimportant consideration in determining a journal for publication.

Figure 30: When it comes to influencing your decisions about journals in which to publish an article of yours, how important to you is each of the following characteristics of an academic journal? Percent of respondents who indicated that each of these characteristics is highly important.

The journal's area of coverage is very close to my immediate area of research

The current issues of the journal are circulated widely, and are well read by scholars in your field

The journal has a high impact factor or an excellent academic reputation

The journal permits scholars to publish articles for free, without paying page or article charges

If accepted, the journal will publish my article quickly, with relatively little delay

The journal is highly selective; only a small percentage of submitted articles are published

Measures have been taken to ensure the protection and safeguarding of the journal's content for the long term

The journal is accessible to readers not only in developed nations, but also in developing nations

The journal makes its articles freely available on the internet, so there is no cost to purchase or read

The journal allows me to link to the dataset(s) or digital primary source(s) associated with my article

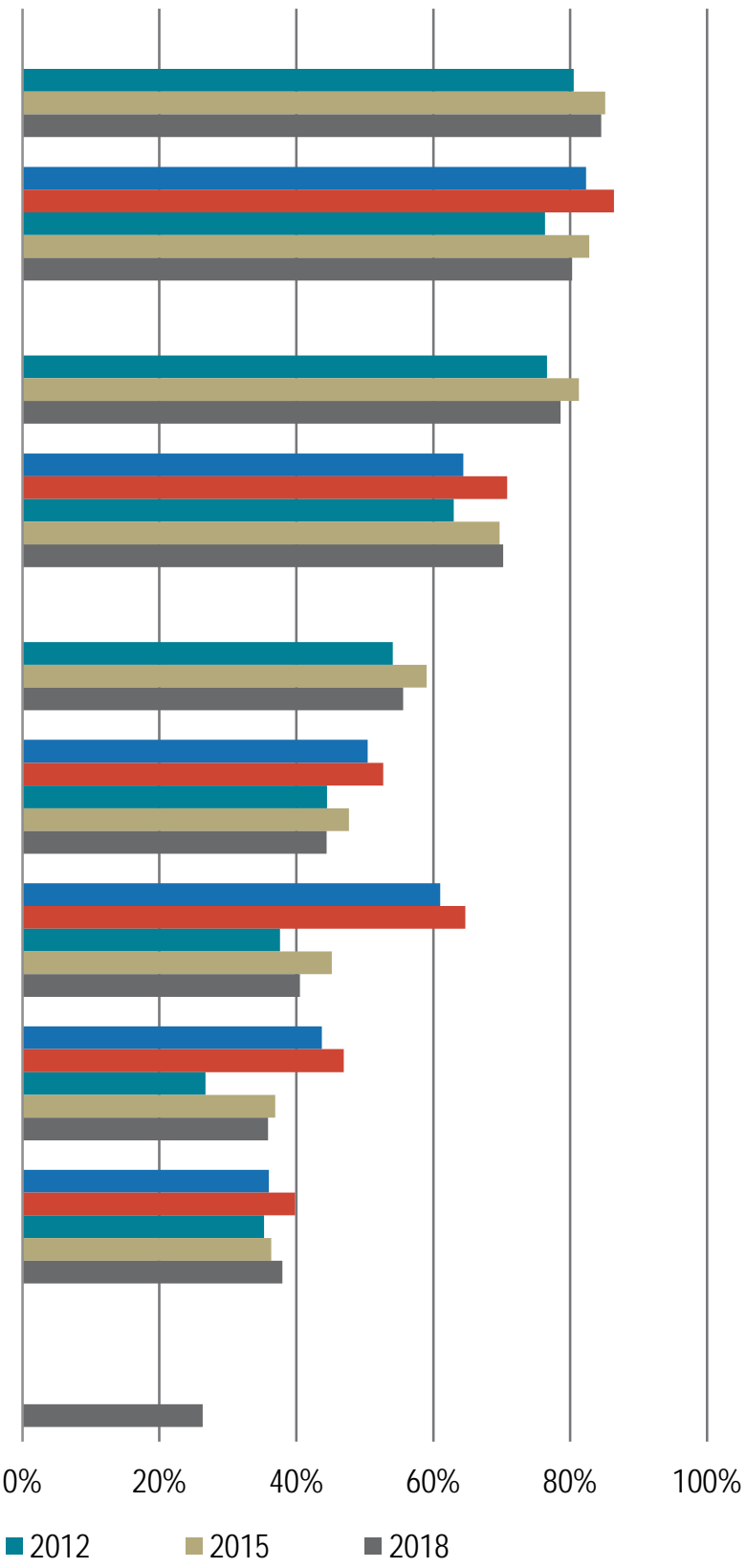

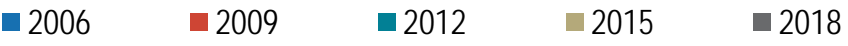


Additionally, older faculty are more concerned with many other characteristics of journals than their younger colleagues, including an expeditious publishing timeline, high selectivity, protection and safeguarding of content for the long term, and accessibility to readers in developing nations (see Figure 31). Older faculty are also more concerned with characteristics relating to open access, as they find notably more value than younger faculty in ajournal making its articles freely available on the internet with no cost to the reader.

Figure 31: When it comes to influencing your decisions about journals in which to publish an article of yours, how important to you is each of the following characteristics of an academic journal? Percent of respondents who indicated that each of these characteristics is highly important.

The journal's area of coverage is very close to my immediate area of research

The current issues of the journal are circulated widely, and are well read by scholars in your field

The journal has a high impact factor or an excellent academic reputation

The journal permits scholars to publish articles for free, without paying page or article charges

If accepted, the journal will publish my article quickly, with relatively little delay

The journal is highly selective; only a small percentage of submitted articles are published

Measures have been taken to ensure the protection and safeguarding of the journal's content for the long term

The journal makes its articles freely available on the internet, so there is no cost to purchase or read

The journal is accessible to readers not only in developed nations, but also in developing nations

The journal allows me to link to the dataset(s) or digital primary source(s) associated with my article

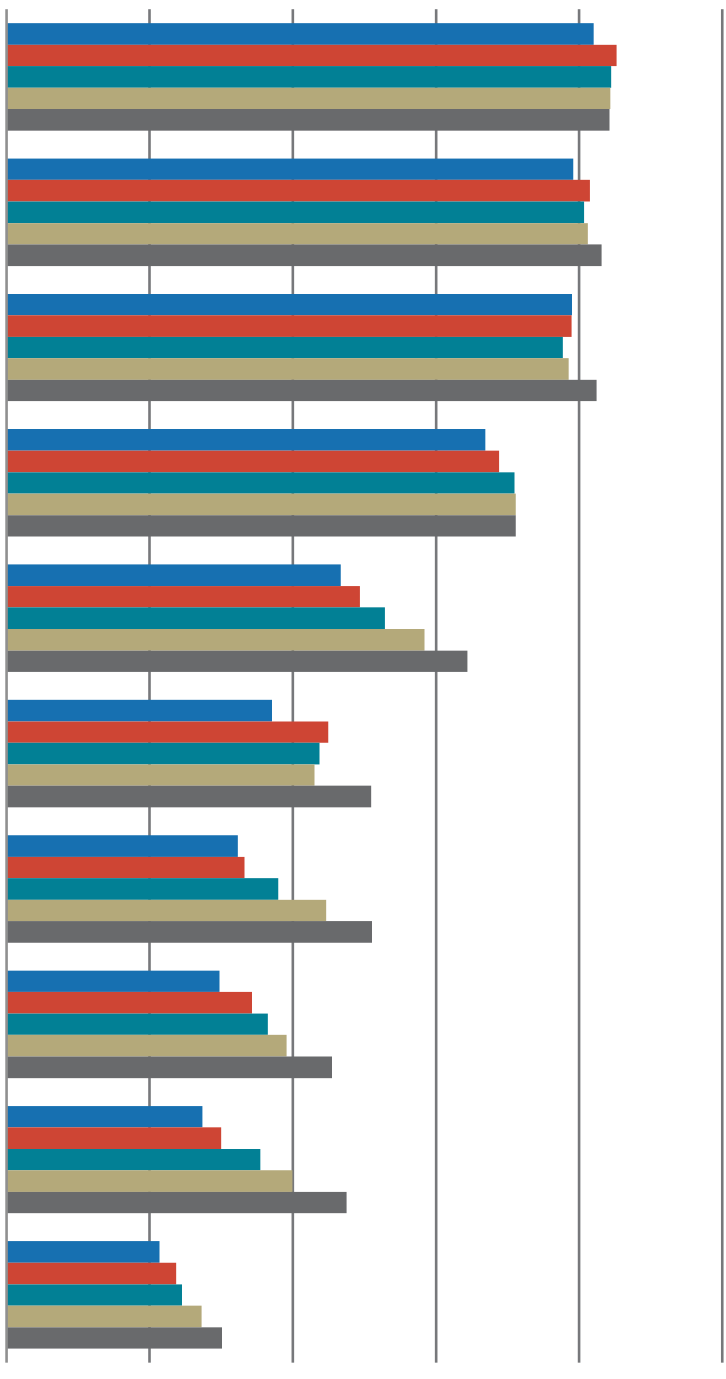

$0 \% \quad 20 \% \quad 40 \% \quad 60 \% \quad 80 \% \quad 100 \%$

$\square 22$ to $34 \quad 35$ to $44 \quad \square 5$ to $54 \quad \square 5$ to $64 \quad \square 65$ and over 


\section{ITHAKA S+R}

\section{Scholarly Incentives \& Influences}

Faculty have displayed a notable increase in interest for an open access publication system since the last survey cycle. Approximately 64\% of respondents in 2018 indicated they would be happy to see the traditional subscription-based publication model replaced entirely by an open access system compared to 57\% in 2015.

Younger faculty are more interested than their older colleagues in replacing the traditional subscription-based system with an open access one (See Figure 32). This is perhaps surprising given that older faculty place more importance on the characteristics of open access when deciding in which journals to publish (see Figure 31). Older faculty are also more likely to understand the criteria used in tenure and promotion evaluations, and are less likely than younger faculty to shape their research outputs and publication choices to match the criteria for success in tenure and promotion (see Figure 32). This suggests that older faculty, who are often more established, published, and/ or tenured, may make their publications and findings open because the traditional scholarly incentives are not as relevant for them. 
Figure 32: Please use the 10 to 1 scales below to indicate how well each statement below describes your point of view. Percent of respondents who strongly agreed with each of these statements.

\begin{abstract}
I clearly understand the criteria that are used to evaluate me in tenure and promotion decision-making

If the traditional subscription-based publication model is replaced entirely by an open access model, I would be happy to see the same publishers stay involved in the open access model
\end{abstract}

Enabling the broadest possible readership of my research outputs is an important way for me to maximize the impact of my research findings

I would be happy to see the traditional subscriptionbased publication model replaced entirely by an open access publication system in which all scholarly research outputs would be freely available to the public

I shape my research outputs and publication choices to match the criteria I perceive for success in tenure and promotion processes

Circulating pre-print versions of my research outputs is an important way for me to communicate my research findings with my peers

Scholarly publishers have been rendered less important to my process of communicating scholarly knowledge by my increasing ability to share my work directly with peers online

$$
\square 22 \text { to } 34 \quad 35 \text { to } 44 \quad \square 5 \text { to } 54 \quad 55 \text { to } 64 \quad \square 5 \text { and over }
$$

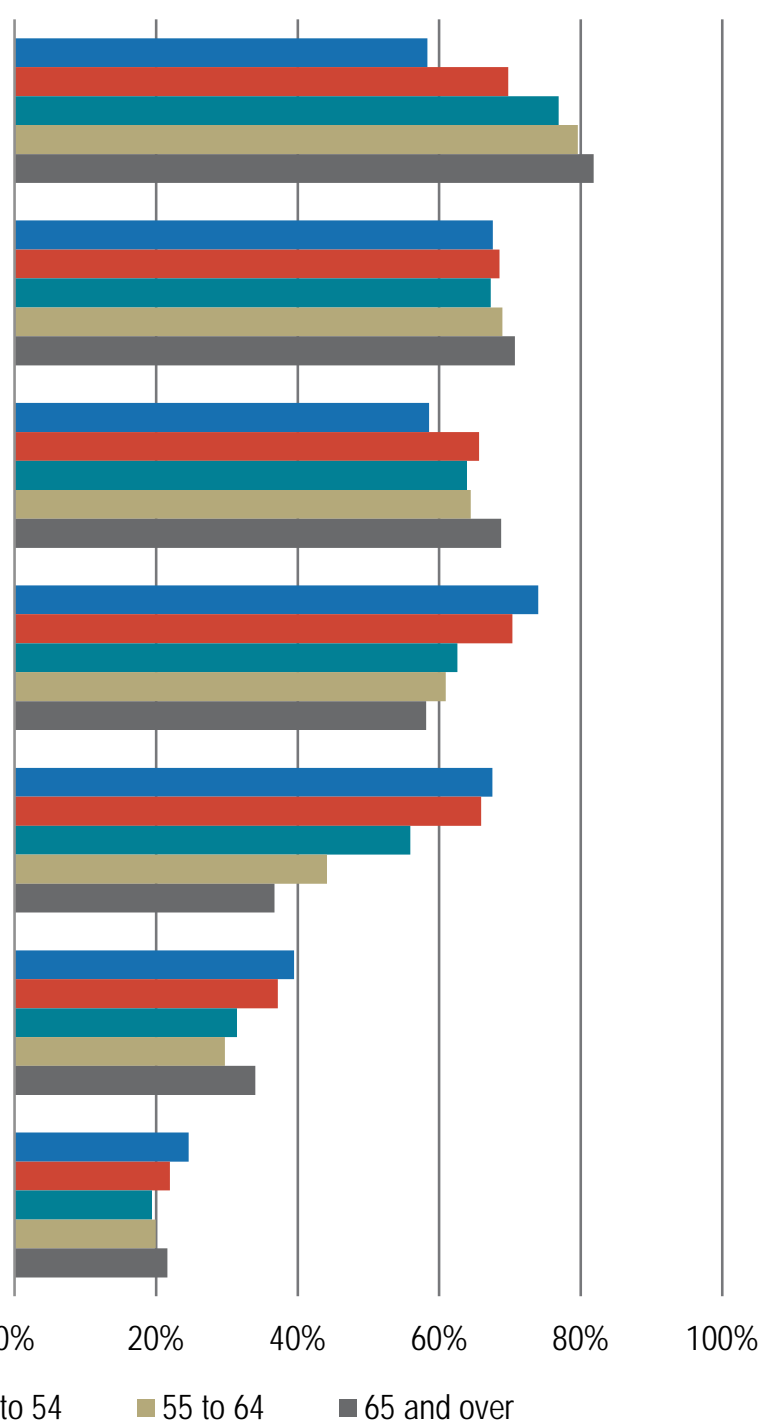

Faculty members generally believe that less recognition should be awarded for research products other than traditional scholarly publications, such as blog or microblog posts; responses or comments to online versions of articles, blog posts, and discussion posts; software or code; and data, images, media or other primary source materials. However, about a third of faculty responded that pre-prints or e-prints should be recognized with as much importance as more traditional research publications. This is broadly consistent with the 2015 survey findings. In general, faculty believe that traditional scholarly publications should hold more value in assessments for tenure, promotion, research funding, and continuing appointment or contract renewal. 
Faculty are also continuing to rely on scholarly publishers for dissemination of their research products. Consistent with the 2015 survey cycle, roughly $40 \%$ of faculty strongly disagree that scholarly publishers have been rendered less important to their process of communication of scholarly knowledge because of the increasing ability to share work directly online (see Figure 32). Additionally, approximately $70 \%$ of respondents strongly agreed that if the traditional subscription-based publication model is replaced entirely by an open access model, they would be happy to see the same publishers stay involved; this was a newly added item to the 2018 survey cycle. While faculty increasingly report that they would be happy to have an open access publication system replace the current subscription-based one, traditional scholarly incentives are still a major driving force behind their publishing behavior, and they continue to value publishers involved in the current subscription-based system.

\section{Publication Audiences}

Another key factor driving decision making on where to publish findings is readership. Overall, approximately six in ten faculty responded that enabling the broadest possible readership is an important way to maximize the impact of their research. Specifically, faculty hope their work reaches scholars within their subdiscipline or field of research, graduate students, and scholars within their discipline but outside of their specific subdiscipline (see Figure 33).

A majority of respondents stated that professionals outside of academia and policy makers in areas related to their field of research are an important audience to reach, with social scientists seeing these audiences as more important than do their peers.

Humanists and social scientists particularly indicated that the general public outside of the scholarly and associated professional community is an important audience to reach.

While the impact of research outside of scholarly and professional communities is relatively less important than those within these communities, policy makers, the general public, and scholars in different fields are still important audiences for a relatively substantial portion of faculty. 
Figure 33: How important is it to you that your research reaches each of the possible audiences? Percent of respondents who indicated each of these items as highly important.

Scholars in my specific subdiscipline or field of research

Graduate students

Scholars in my discipline but outside of my specific subdiscipline or field of research

Professionals outside of academia in areas related to my research interests

Policy makers in areas related to my field of research

Scholars outside my discipline

The general public beyond the scholarly and associated professional community

Undergraduate students

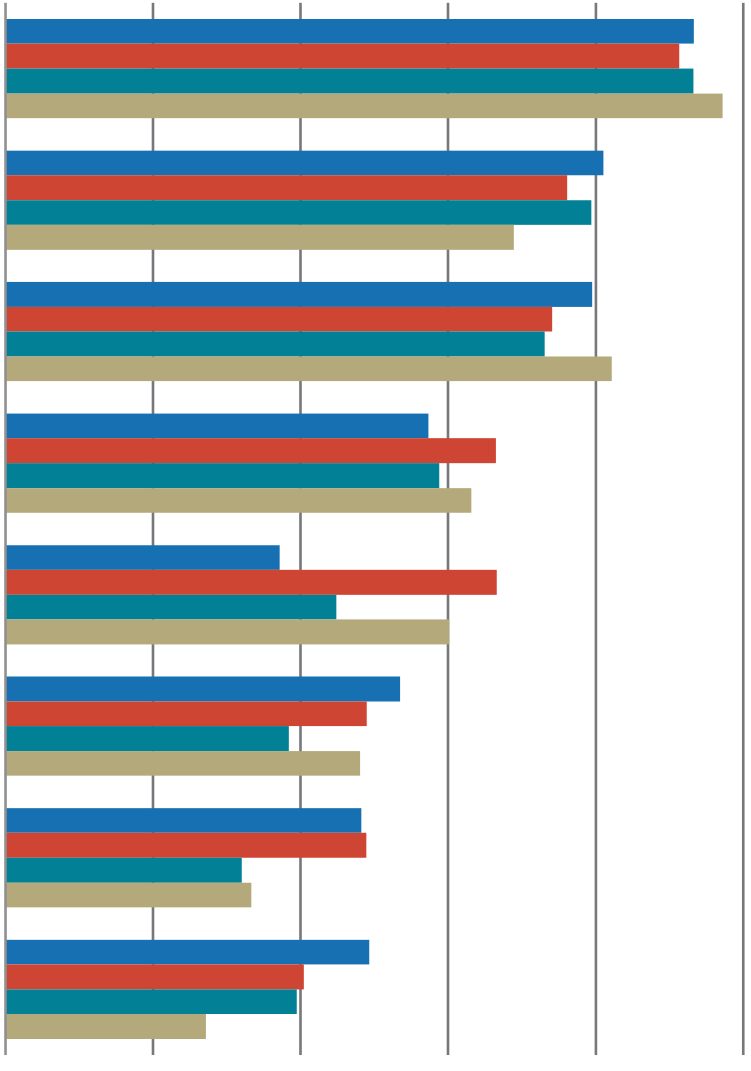

$0 \% \quad 20 \% \quad 40 \% \quad 60 \% \quad 80 \% \quad 100 \%$

-Humanities $\square$ Social Sciences $\square$ Sciences Medical

Additionally, roughly a third of respondents agreed or strongly agreed that societal impact, or the benefit of scholarly work and research products to society, should be a key measure of research performance for tenure, promotion, or funding proposals, with social scientists indicating the most agreement with this sentiment, followed closely by medical faculty (see Figure 34). This has remained fairly stable over time, with 31\% agreement in 2018 compared to $28 \%$ in 2015. 
Figure 34: Please read the following statement and tell us whether you strongly agree with the statement, agree, somewhat agree, neither agree nor disagree, somewhat disagree, disagree, or strongly disagree. Societal impact, or the benefit of scholarly work and research products to society, should be a key measure of research performance for tenure, promotion, or funding proposals.

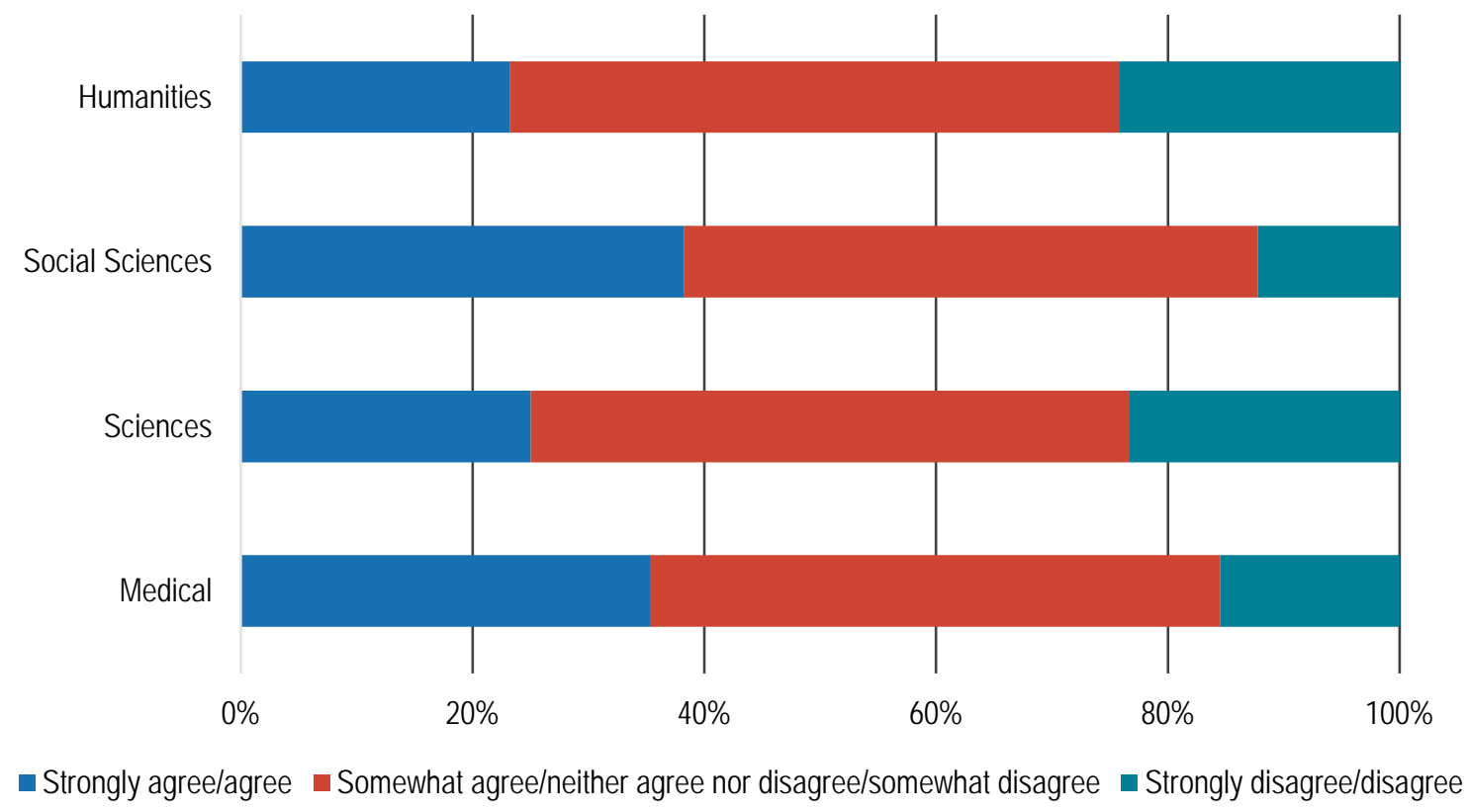




\section{Teaching \& Learning}

Faculty were queried regarding their instructional practices and attitudes in addition to their research tendencies. In this survey cycle, due to emerging interest within the higher education community, we added a number of questions examining the development, use, and attitudes surrounding open educational resources (OER) and learning analytics tools. Questions on these topics were only displayed to faculty who responded that they teach undergraduate or graduate students; nearly all respondents (99\%) described teaching as part of their professional responsibilities.

\section{Perceptions of Research Skills}

Consistent with the last survey cycle, approximately half of respondents perceive that their undergraduate students have poor skills related to locating and evaluating information. About two thirds of respondents agreed that improving undergraduate students' research skills is an important goal for the courses they teach, with faculty from Baccalaureate colleges relatively more likely than those at other institution types to see this as an important goal (see Figure 35). Humanists and social scientists are more likely than their scientist or medical faculty colleagues to agree that their undergraduate students lack these skills, and also are more likely to see their role in improving these skills as an important goal (see Figure 36).

Figure 35: Please use the 10 to 1 scales below to indicate how well each statement below describes your point of view. Percent of respondents who strongly agreed with each statement.

My undergraduate students have poor skills related to locating and evaluating scholarly information

Improving my undergraduate students' research skills related to locating and evaluating scholarly information is an important educational goal for the courses I teach

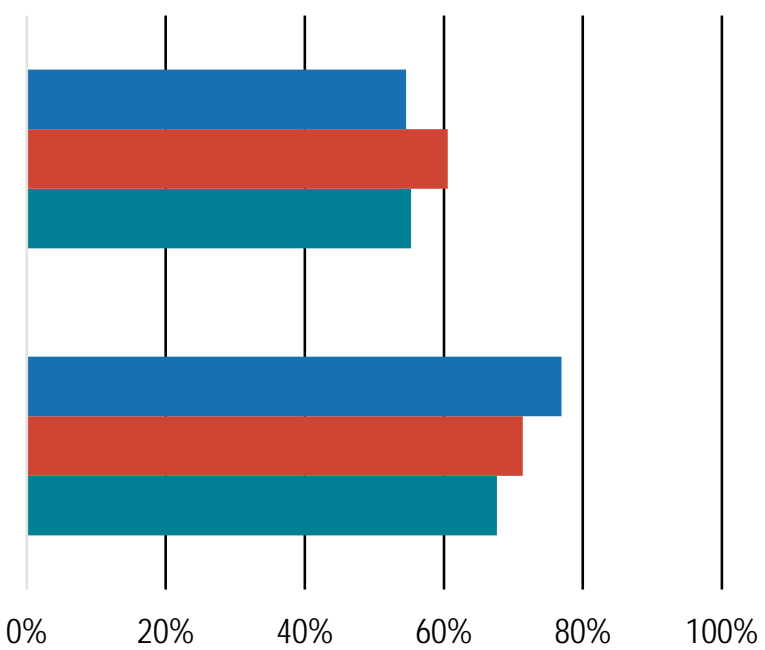

Baccalaureate $\quad$ Masters Doctoral 
Figure 36: Please use the 10 to 1 scales below to indicate how well each statement below describes your point of view. Percent of respondents who strongly agreed with each statement.

My undergraduate students have poor skills related to locating and evaluating scholarly information

Improving my undergraduate students' research skills related to locating and evaluating scholarly information is an important educational goal for the courses I teach

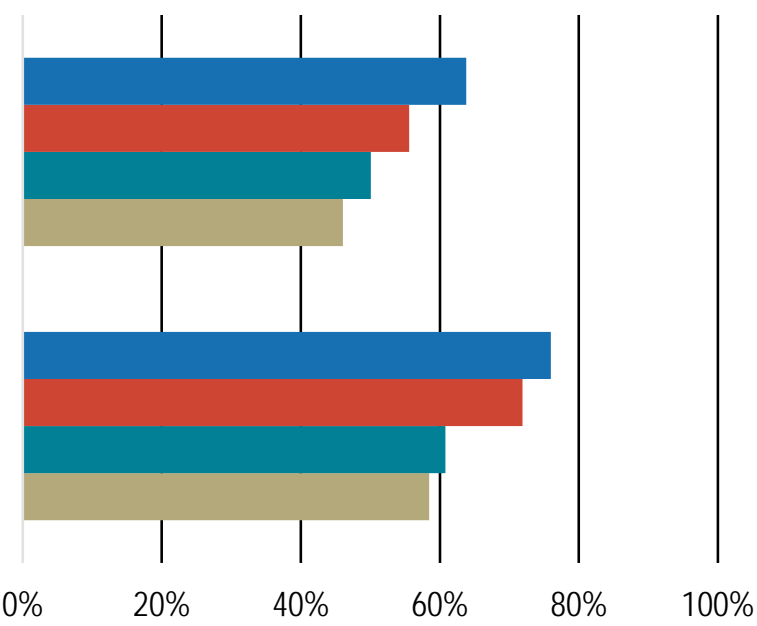

$\square$ Humanities $\square$ Social Sciences $\square$ Sciences $\square$ Medical

\section{Open Educational Resources}

This survey cycle was the first one in which questions were included regarding the development of, practices with, and attitudes surrounding OER. Open educational resources were defined as teaching, learning, and research materials used for educational purposes that reside in the public domain or have been released under an open license, such as Creative Commons, that permits no-cost access, use, adaptation, and redistribution by others with no or limited restrictions. Through these questions, we aim to establish baseline data to inform current use and creation of OER as well as how use and creation can be better supported in the future.

To understand the relative affordances provided to faculty members in selecting their course materials, we first asked about their role in making these decisions. Approximately eight in ten respondents indicated they are the primary decision maker. Humanists and social scientists have more decision-making power than their scientist or medical faculty peers, with medical faculty much less likely than those in other disciplines to be the primary decision maker (see Figure 37). 
Figure 37: Which of the following statements best describes your role in deciding what textbooks and other course materials will be used in the courses you teach? Percent of respondents who selected each item.

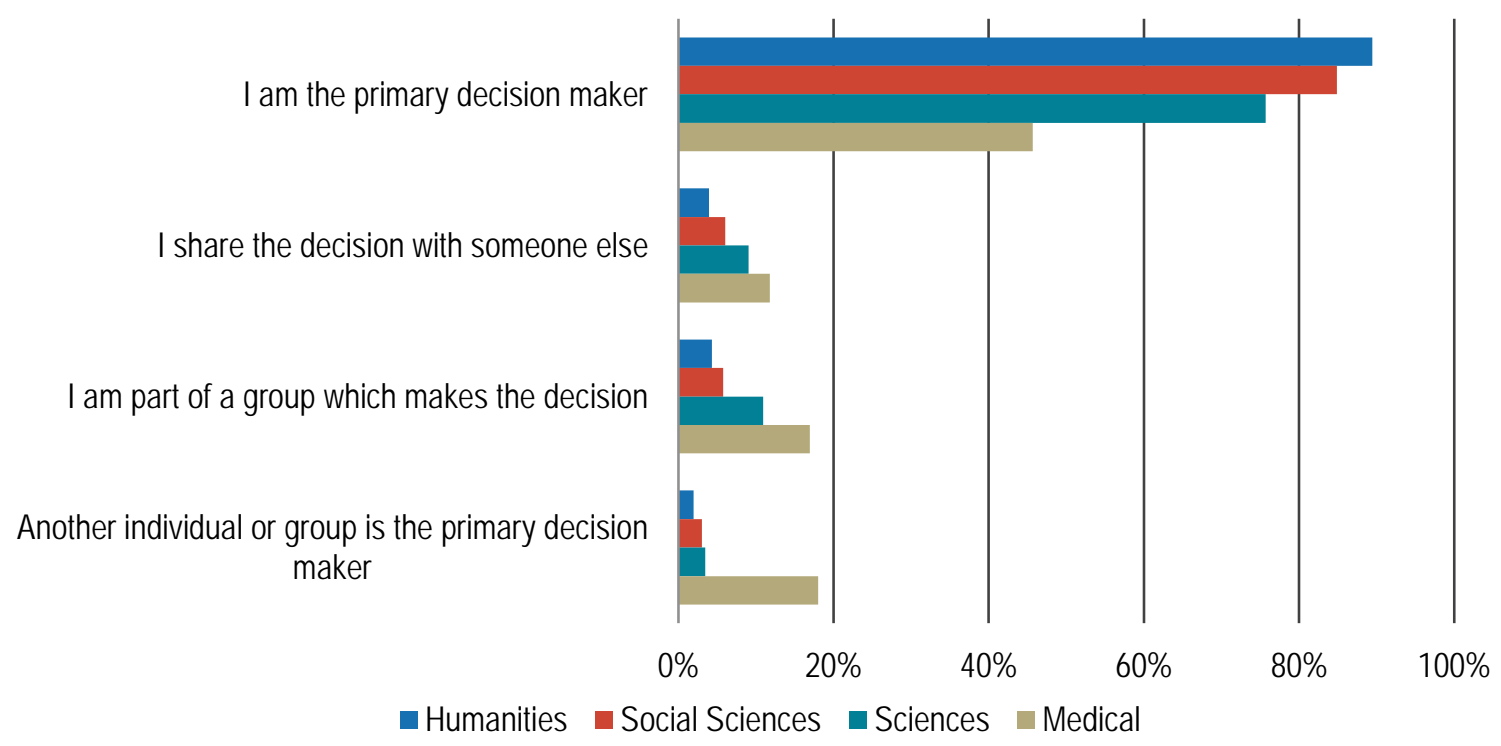

Faculty have noted great concern over the high costs of textbooks and course materials. Seven in ten respondents indicated that reducing the cost that students pay for textbooks and other course materials is highly important; this is broadly consistent across institution types and disciplines, though medical faculty members demonstrated relatively less concern. Approximately $87 \%$ of faculty often or occasionally give preference to assigning low- or no-cost textbooks, while $59 \%$ give preference to assigning course text or materials that are available through the library.

About $57 \%$ of respondents indicated interest in using OER, while $48 \%$ agreed or strongly agreed they would like to adopt new pedagogies or instructional approaches to take advantage of the opportunities offered by OER. Approximately a third of faculty agreed or strongly agreed they are interested in creating and publishing OER. However, medical faculty are much less interested in the adoption, use, and creation of OER than those in other disciplines (See Figure 38). 
Figure 38: Please read the following statements and indicate the degree to which you agree or disagree with each. Percent of respondents who strongly agreed/agreed with each statement.

\section{Reducing the cost that students pay for textbooks and other course materials is very important to me}

I am interested in using open educational resources in my teaching

I would like to adopt new pedagogies or instructional approaches that take advantage of the opportunities offered by open educational resources

I am interested in creating and publishing open educational resources

I find it difficult to locate open educational resources for my teaching

My institution offers excellent training and support for using open educational resources

My institution recognizes or rewards faculty for taking the time to integrate open educational resources into their teaching

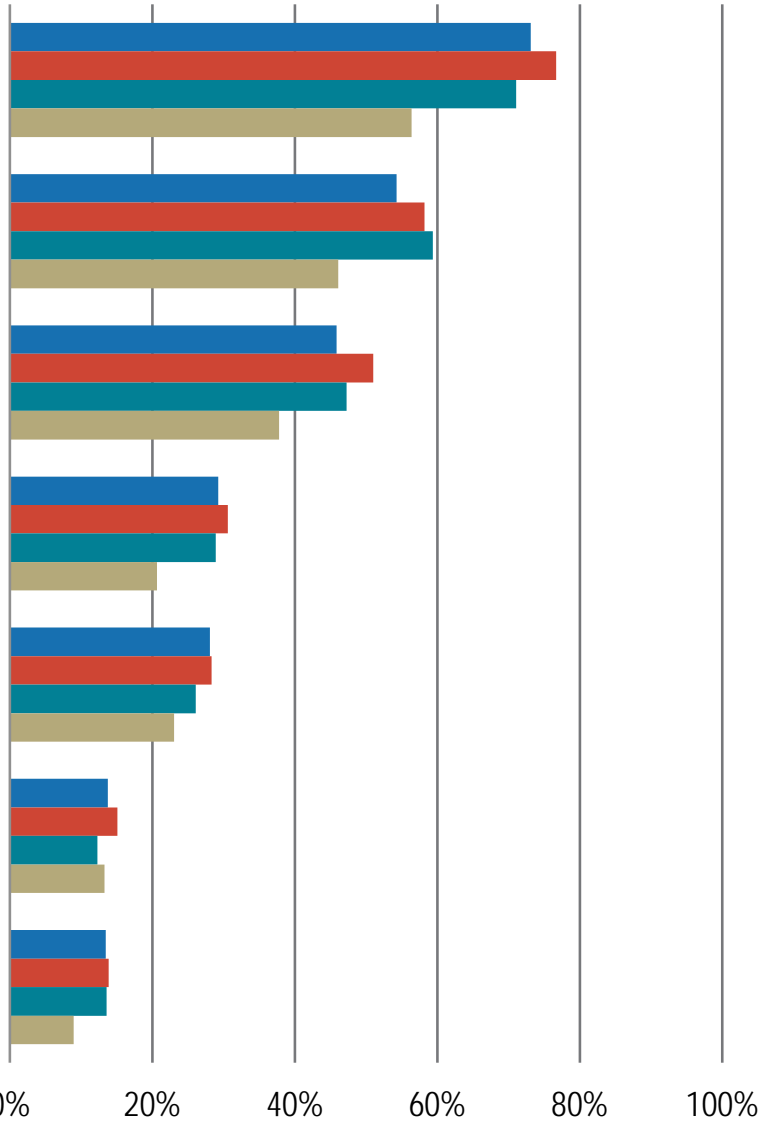

- Humanities $\square$ Social Sciences $\square$ Sciences Medical

Attitudes regarding the implementation of OER within one's instructional practices vary predominately by age cohort and title. Younger faculty display much more enthusiasm towards OER than older faculty, and are interested in both adopting them into their teaching pedagogies and creating them (See Figure 39). Further, faculty in professor and associate professor roles are relatively less likely to be interested in creation and use. 
Figure 39: Please read the following statements and indicate the degree to which you agree or disagree with each. Percent of respondents who strongly agreed/ agreed with each statement.

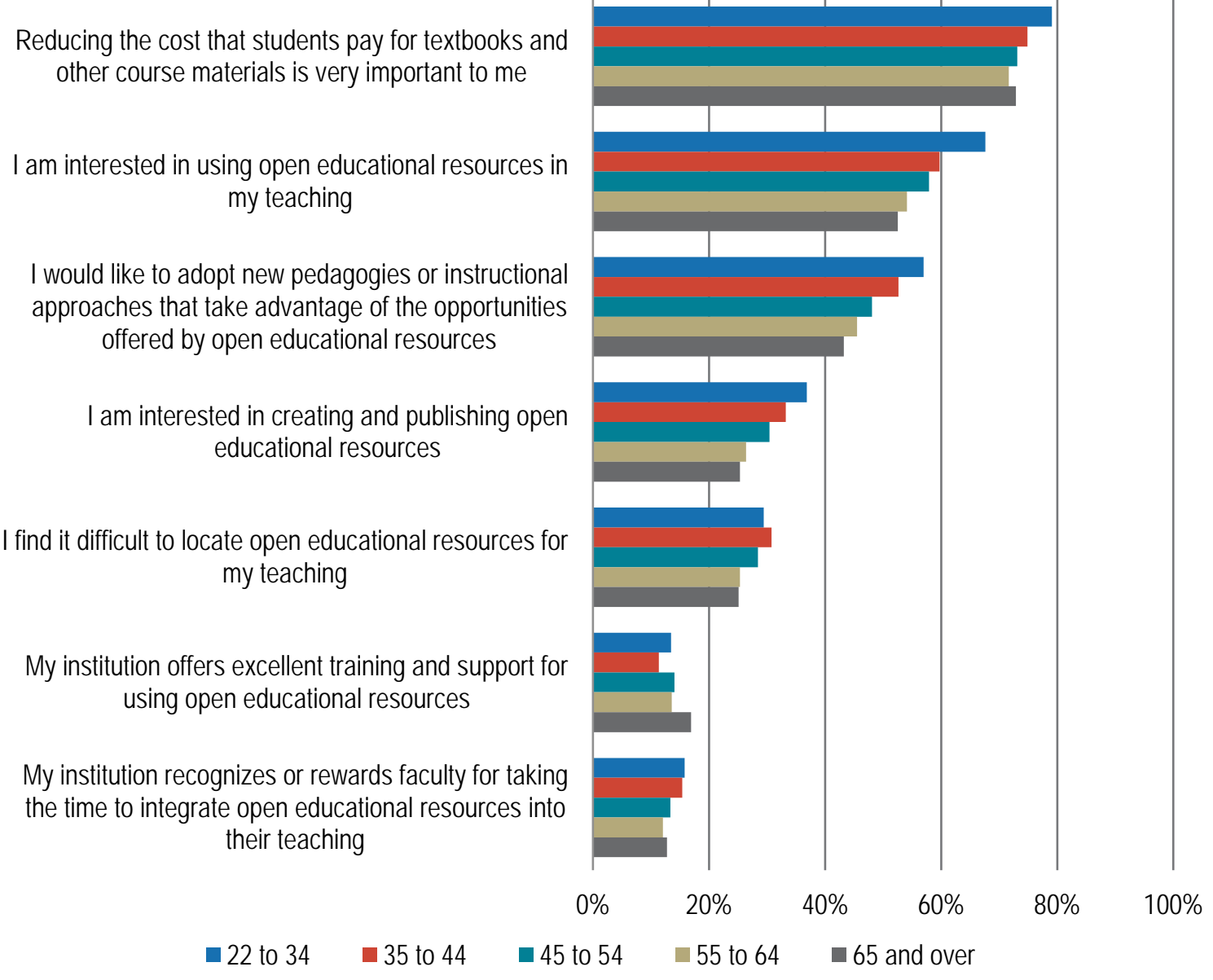

Providing excellent training and incentives for using OER are possible ways to increase their use and effectiveness in instructional practices. Only approximately $14 \%$ of respondents agreed or strongly agreed that their institution provides excellent training and support for using OER and that their institution recognizes or rewards faculty for taking time to integrate OER into their instructional practices.

When faculty members were asked if they have used or created open textbooks, open course modules, or open video lectures within their courses, approximately $32 \%$ have used open textbooks, $24 \%$ have used open course modules, and 32\% have used open video lectures. Fewer faculty have created any OER; $7 \%$ of faculty have created open 
textbooks, $14 \%$ have created open course modules, and $11 \%$ have created open video lectures. $^{5}$

There are some differences between age cohorts in the creation of open textbooks and course modules in particular, as older cohorts are more likely to have created both types of course materials (see Figure 40). While younger faculty indicated a relatively higher interest in creating OER than older faculty, more support or guidance may be needed to help them achieve the creation of these resources for their and others' instructional practices.

Figure 40: Which, if any, of the following open educational resources have you created and/ or used in your courses? Please check all that apply. Percent of respondents who indicated they have created and/ or used each of the following.

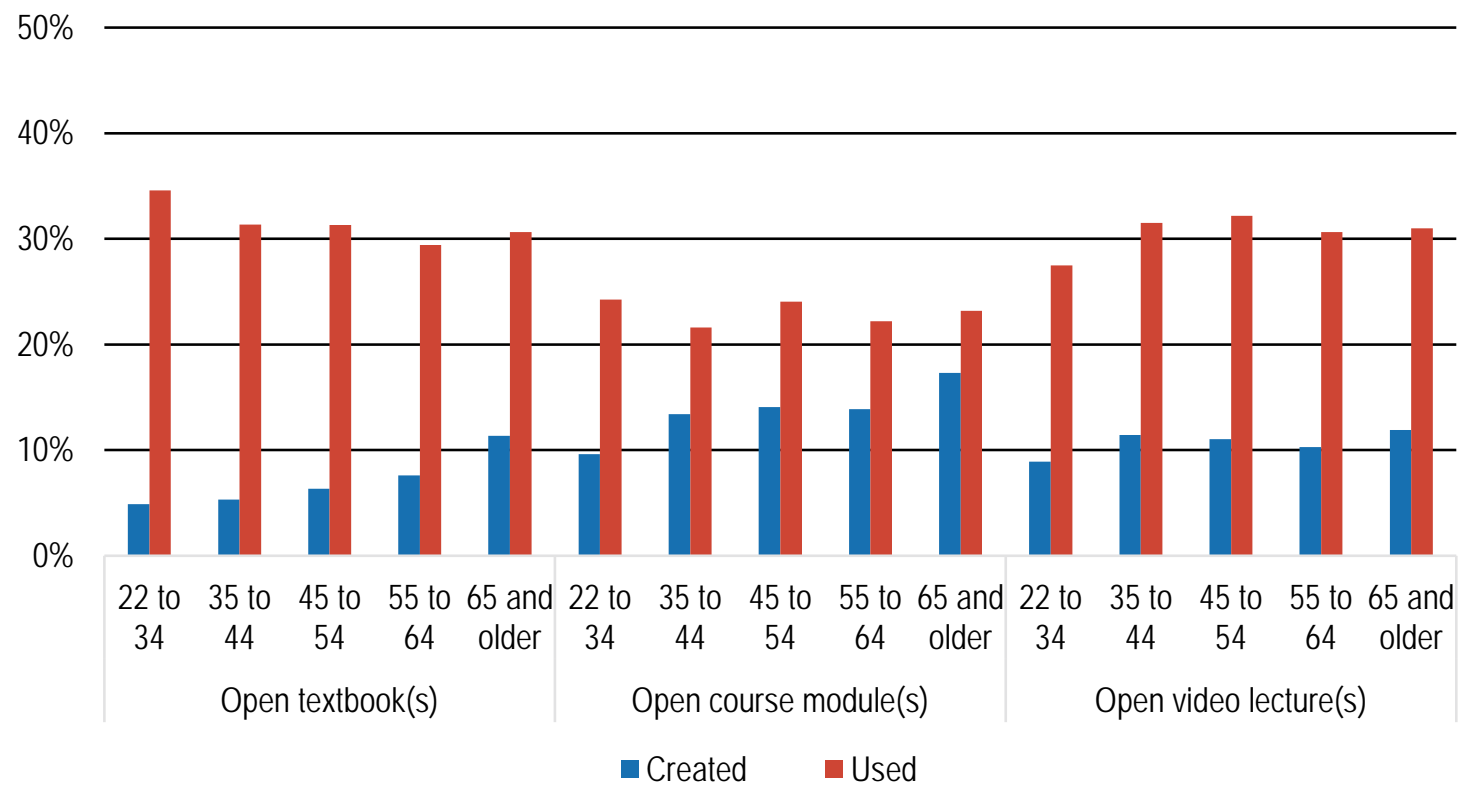

\section{Learning Analytics Tools}

Faculty were also queried on their perceptions surrounding the use of learning analytics tools within their instructional practices. Learning analytics tools were defined as those used to summarize and/ or analyze student activities, learning, or performance through a dashboard, early alert emails, or other method of delivery. When asked specifically if

\footnotetext{
${ }^{5}$ While we provided a definition of open educational resources to respondents, interpretations of open educational resources often vary greatly; this was evident in our testing of this survey instrument.
} 
they use learning analytics tools, 39\% indicated they have, 51\% that they have not, and $11 \%$ were unsure. ${ }^{6}$ Younger faculty are relatively more likely to have used these tools than older faculty, though they are also more likely to be unsure if they have used these tools (see Figure 41).

Figure 41: Do you use learning analytics tools through your course management system or other courseware system(s)? Percent of respondents who indicated they have, have not, or are unsure if they have used learning analytics tools.

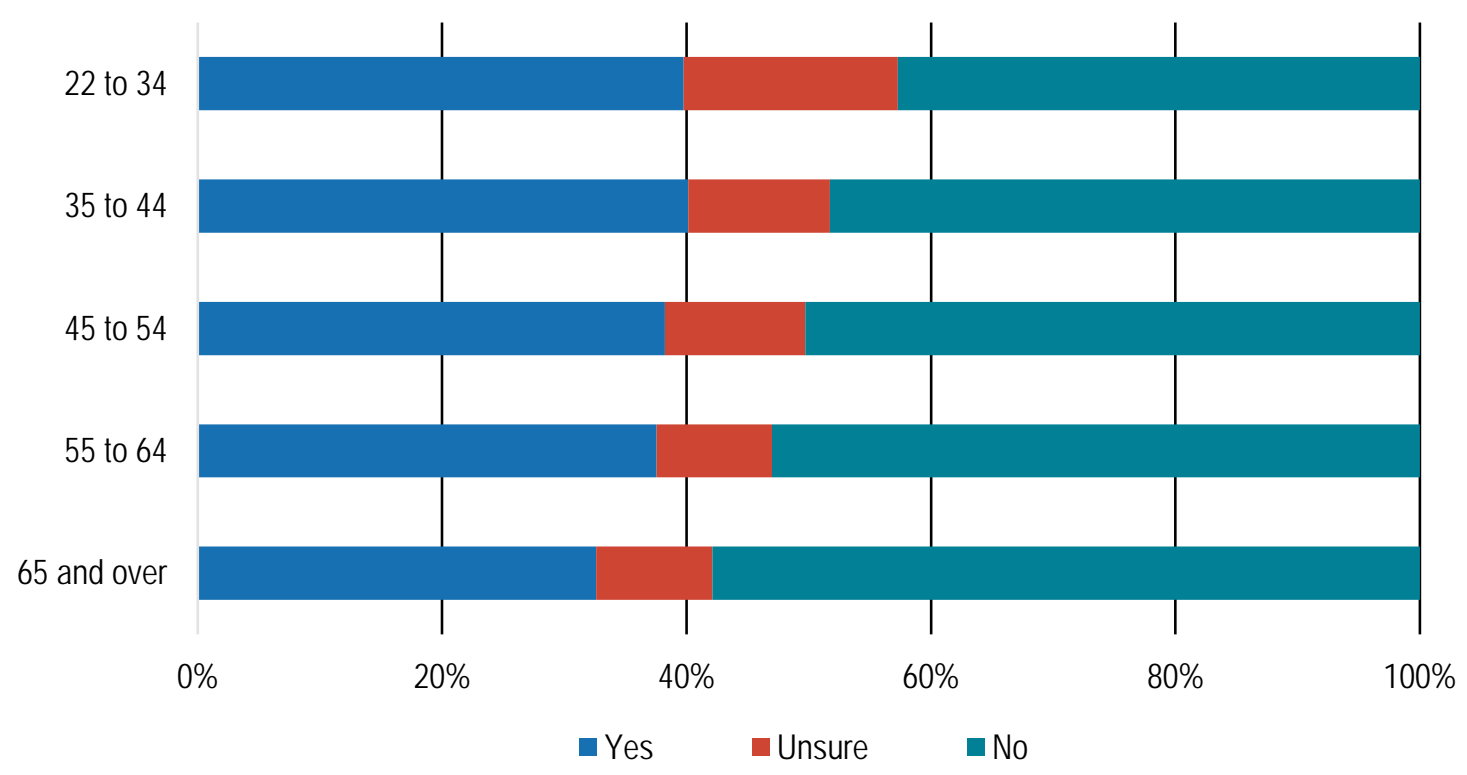

Faculty who reported they do not use or were unsure of using learning analytics tools were further queried regarding their interest in potentially using them. This group shows no widespread interest in doing more with these tools; approximately $17 \%$ agreed or strongly agreed they would be interested in using them, only $14 \%$ agreed or strongly agreed that using them would help to improve their teaching practices, and 17\% agreed or strongly agreed that these tools would help them to intervene with students who might be struggling.

This skepticism on the usefulness of learning analytics tools is predominately driven by humanists and older faculty. Humanists who have not used or are unsure if they have used learning analytics tools are much less likely than their colleagues in other disciplines to display interest in using them and are much less likely to agree or strongly agree that using such tools would improve their teaching practices or help them

${ }^{6}$ Percentages sum to more than $100 \%$ due to rounding. 
intervene with struggling students (see Figure 42). Additionally, younger faculty who have not used or are unsure if they have used learning analytics tools are more likely than their older colleagues to report interest in them and to agree or strongly agree that using such tools would improve their teaching practices (see Figure 43).

Figure 42: Please use the following statements and indicate the degree to which you agree or disagree with each. Of the respondents who do not use or are unsure of using learning analytics tools, the percent who strongly agreed/agreed with each statement.

Using learning analytics tools would help me to improve my teaching

I am interested in using learning analytics tools

Using learning analytics tools would help me to intervene with students who might be struggling

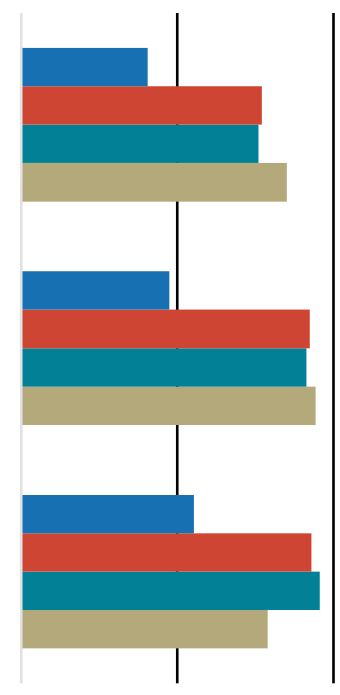

$0 \%$ $10 \%$

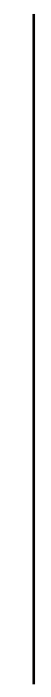

$30 \%$

- Humanities

- Social Sciences

- Sciences Medical

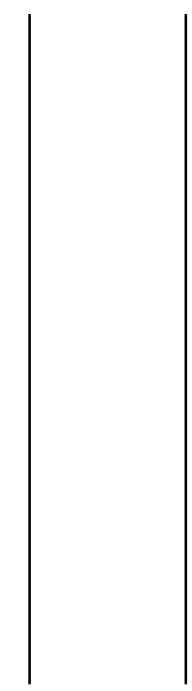

$40 \%$

$50 \%$ 
Figure 43: Please use the following statements and indicate the degree to which you agree or disagree with each. Of the respondents who do not use or are unsure of using learning analytics tools, the percent who strongly agreed/agreed with each statement.

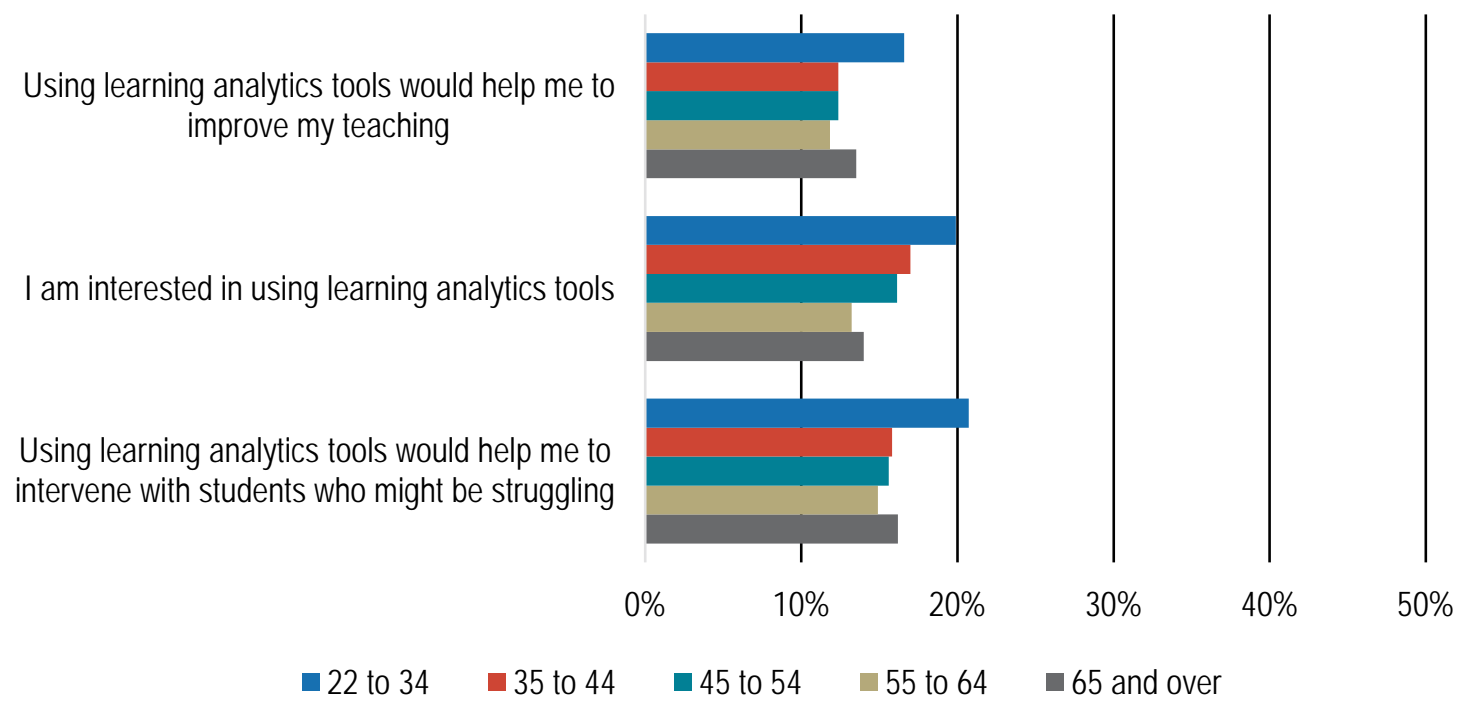

The attitudes and skepticism stemming from those who have not used or are unsure if they have used learning analytics tools substantially differs with the perceptions of those who have, though neither group holds especially positive views of these tools. Of the faculty who reported they do use learning analytics, 37\% agreed or strongly agreed that using learning analytics tools helps to improve their teaching and $44 \%$ agreed or strongly agreed that using these tools helps to intervene with students who might be struggling in their courses.

A substantial share of humanists who use learning analytics tools agree or strongly agree that using these tools helps to intervene with students who may be struggling, but are less likely than faculty in other disciplines to agree or strongly agree that using such tools helps to improve their teaching (see Figure 44). Additionally, of those who have used these tools, contingent faculty, particularly adjunct professors and instructors, are more likely than tenure-line faculty to agree or strongly agree that using these tools helps to improve their teaching and intervene with students who may be struggling (see Figure 45). 
Figure 44: Please use the following statements and indicate the degree to which you agree or disagree with each. Of the respondents who do use learning analytics tools, the percent who strongly agreed/agreed with each statement.

Using learning analytics tools helps me to improve my teaching

Using learning analytics tools helps me to intervene with students who might be struggling

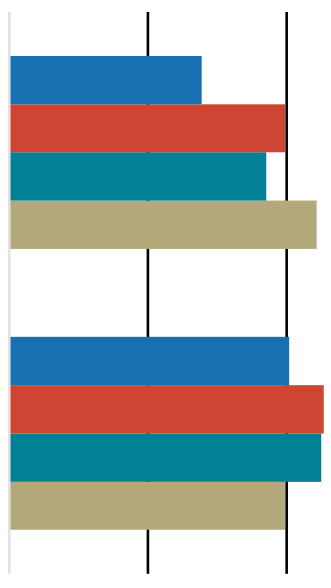

$0 \%$

$20 \%$

$40 \%$
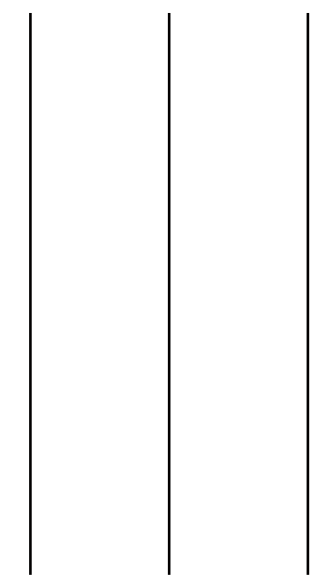

Humanities $\square$ Social Sciences $\square$ Sciences $\square$ Medical

Figure 45: Please use the following statements and indicate the degree to which you agree or disagree with each. Of the respondents who do use learning analytics tools, the percent who strongly agreed/agreed with each statement.

Using learning analytics tools helps me to improve my teaching

Using learning analytics tools helps me to intervene with students who might be struggling

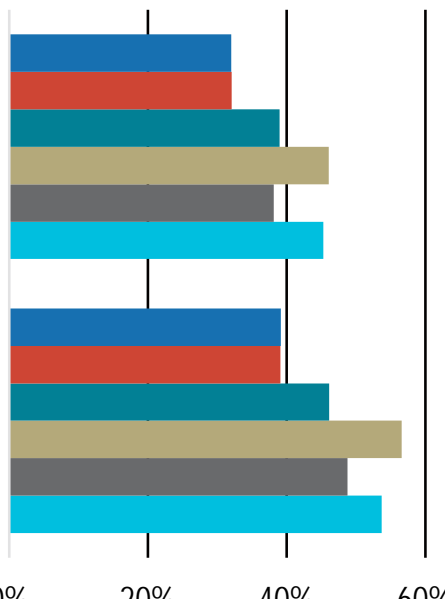

$0 \%$

$20 \%$

$40 \%$

$60 \%$

$80 \%$

$100 \%$

arofessor $\square$ Associate Professor $\quad$ Assistant Professor $\square$ Adjunct Professor $\quad$ Lecturer $\square$ Instructor 
All respondents, regardless of previous use of learning analytics tools, were queried regarding their perceptions of relevant institutional protocols. About $16 \%$ of respondents indicated that their institution's use of these tools might limit their autonomy and $20 \%$ indicated that they are concerned about the extent to which their institution might rely on algorithms in these tools. Approximately a quarter of faculty agreed or strongly agreed that their institution has sufficient systems in place to prevent a breach of student data.

Humanists are much more concerned than faculty in other disciplines regarding the extent to which their institution may rely on algorithms within learning analytics tools and that use of such tools may limit their autonomy in how they choose to teach (see Figure 46). They are also less likely to agree that their institution has sufficient protocols in place to prevent a breach of student data.

Figure 46: Please use the following statements and indicate the degree to which you agree or disagree with each. Percent of respondents who strongly agreed/ agreed with each statement.

My college or university's use of learning analytics may limit my autonomy in how I choose to teach

I am concerned about the extent to which my college or university may rely on algorithms within learning analytics tools

My college or university has sufficient systems and protocols in place to prevent a breach of student activity data

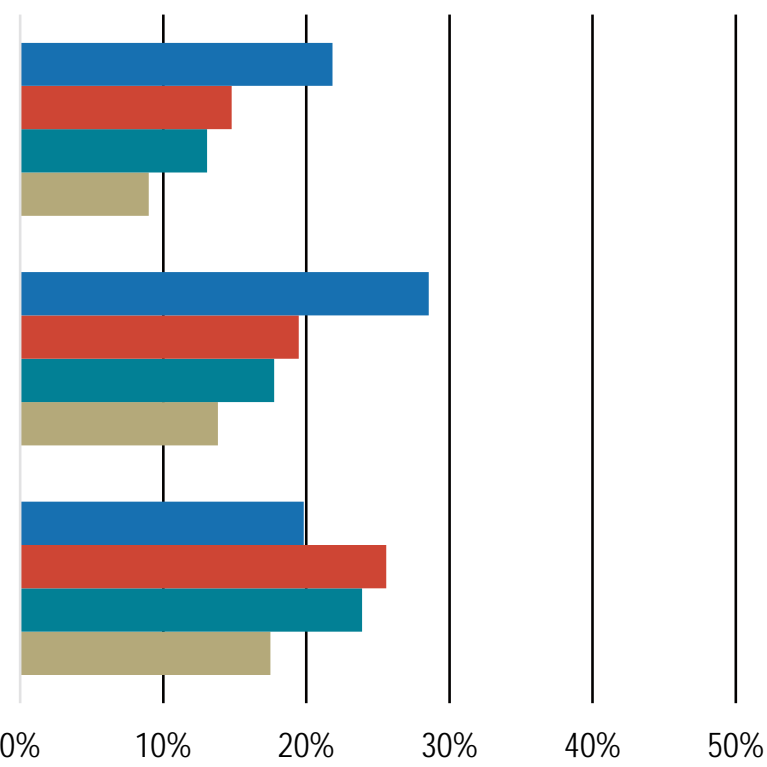

- Humanities $\square$ Social Sciences $\square$ Sciences $\square$ Medical 


\section{Role of the Library}

One of the longest standing areas of interest in the US Faculty Survey is in understanding how the role of the library has evolved and continues to evolve over time. Questions on this topic cover how the library is valued and perceived by faculty, how faculty are using the library, perceptions of the importance of collections and other service-related functions of the library, as well as the library's perceived support to students within one's institution.

A well-established question posed to respondents pertains to the continued relevance of librarians, the library, and its budget. Since 2012, there has been little to no change in perceptions regarding librarians and the library's budget (See Figure 47). Only approximately $22 \%$ of respondents believe that the librarians' role has diminished due to easier access of academic content electronically, and just $17 \%$ of faculty agree that because of this increased access, money should be redirected from the library to other university or college needs. Medical faculty members and scientists agreed slightly more with these perceptions than their social scientist or humanist colleagues, with humanists agreeing with these sentiments the least (see Figure 48).

Figure 47: Please use the 10 to 1 scales below to indicate how well each statement describes your point of view. Percent of respondents who strongly agreed with each statement.

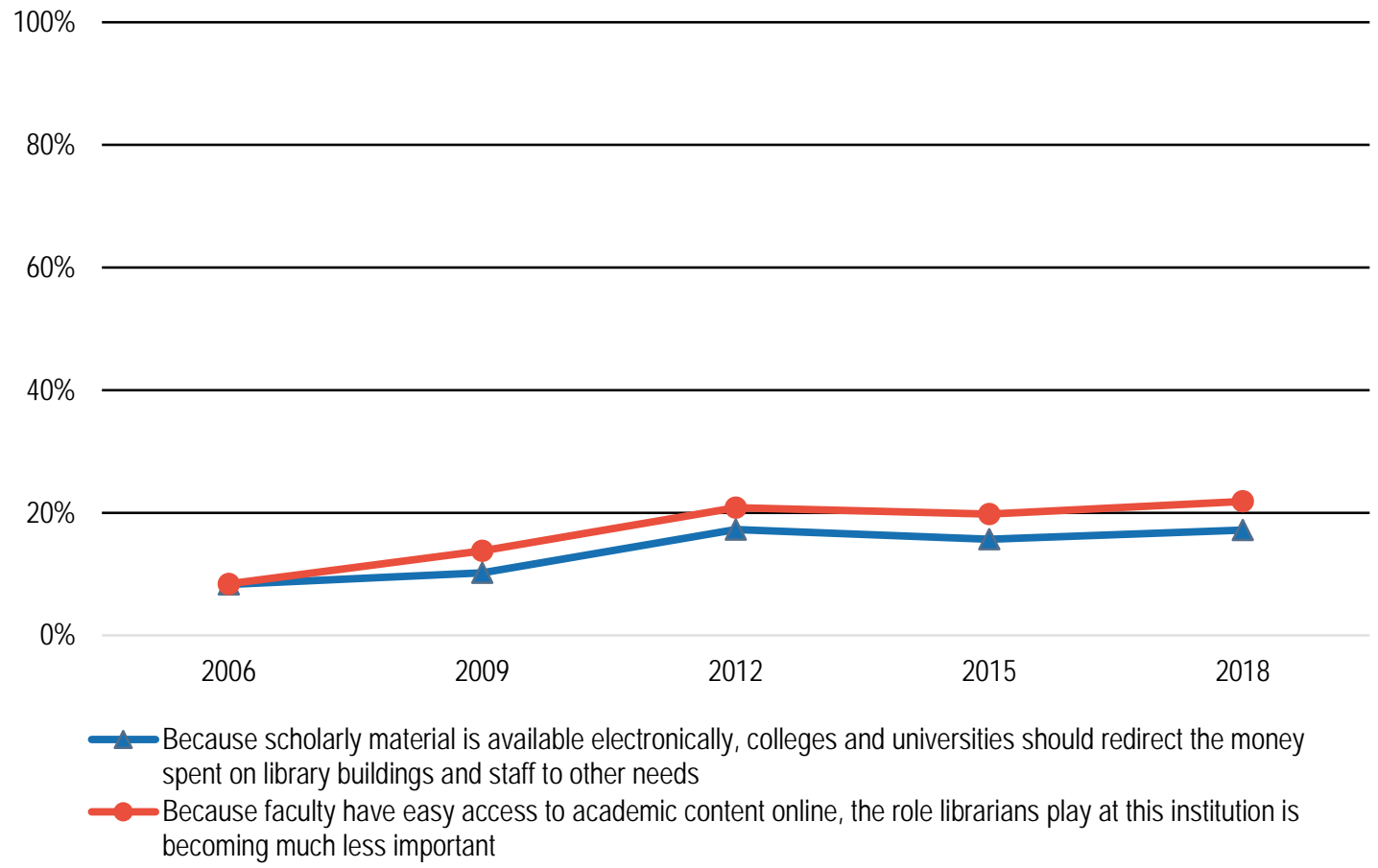


Figure 48: Please use the 10 to 1 scales below to indicate how well each statement describes your point of view. Percent of respondents who strongly agreed with each statement.

Because scholarly material is available electronically, colleges and universities should redirect the money spent on library buildings and staff to other needs

Because faculty have easy access to academic content online, the role librarians play at this institution is becoming much less important

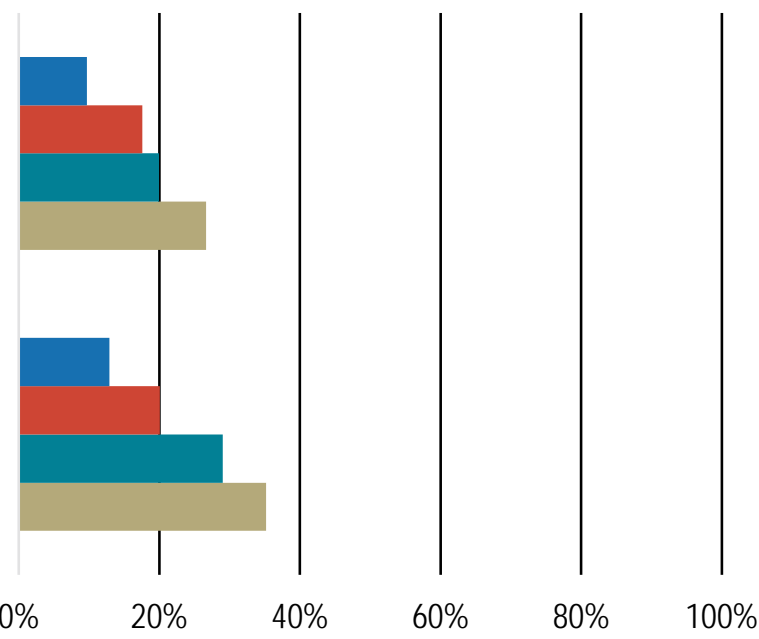

$\square$ Humanities $\square$ Social Sciences $\square$ Sciences Medical

Additionally, 83\% of faculty agreed that their library's budget should be supported when the prices of scholarly journals rise to ensure continued access to collections. As this is a newly added item the 2018 survey, opinions regarding the rising costs of scholarly journals cannot be tracked over time. Scientists agreed relatively less with this item, with $78 \%$ strongly agreeing, compared to $85 \%$ of social scientists and $86 \%$ of both humanists and medical faculty.

\section{Faculty Support}

Faculty were asked if they receive various support throughout the publication process from their library, scholarly society, university press, or another service provider. Approximately $40 \%$ of faculty indicated they receive assistance with managing a public webpage that lists links to recent scholarly outputs and provides other relevant professional and personal information. Less than $20 \%$ of respondents reported they receive help understanding and negotiating favorable contracts, determining where to publish to maximize impact, and assessing impact following publication. Faculty from Doctoral universities receive slightly more assistance with management of a public webpage than their colleagues at Baccalaureate colleges and Master's institutions. These findings have remained relatively stable across past survey cycles.

Faculty were then asked how valuable they do or would find these specific support services from their college or university library. Approximately four in ten faculty do or 
would find the library valuable in helping them manage a public webpage that links their research and scholarly output among other personal and professional information. About a quarter of respondents indicated they do or would find value in the library helping them to determine where to publish to maximize impact, to understand and negotiate favorable publication contracts, and to assess the impact of their work following publication.

Faculty within the first five years in their field find assistance with determining where to publish to maximize impact, as well as understanding or negotiating favorable publication contracts, much more valuable than those who have been in their field for six or more years (see Figure 49). However, faculty are finding these features slightly less valuable overall in 2018 than they did in the 2015 survey cycle (see Figure 50).

Figure 49: How valuable do you find support for your college or university library for each of the following aspects of the publication process, or how valuable would you find it if this support was offered to you? Percent of respondents by years in their field who indicated these items as highly valuable.

Managing a public webpage for me that lists links to my recent scholarly outputs, provides information on my areas of research and teaching, and provides contact information for me

Helping me to assess the impact of my work following its publication

Helping me determine where to publish a given work to maximize its impact

Helping me understand and negotiate favorable publication contracts
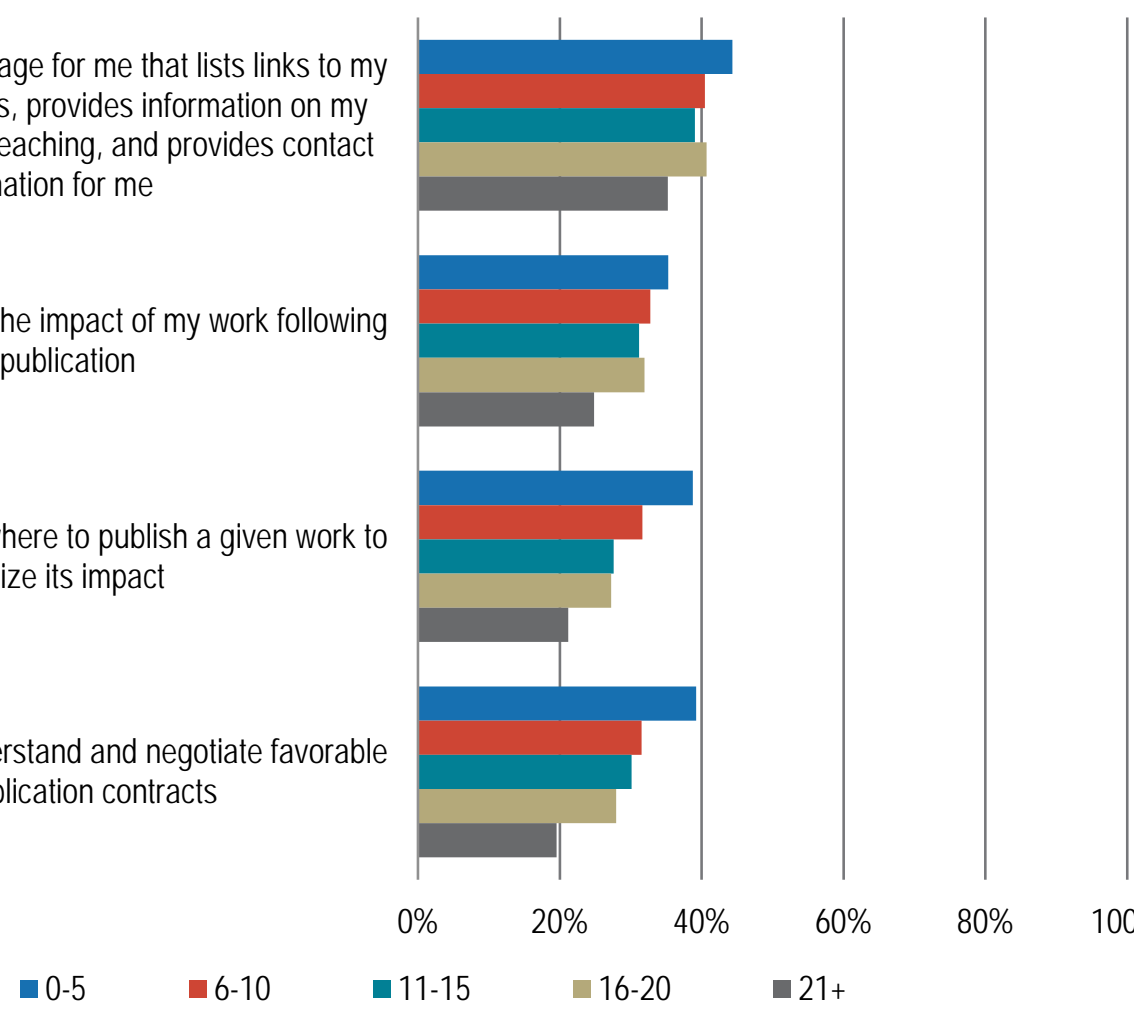

$80 \% \quad 100 \%$ 
Figure 50: How valuable do you find support for your college or university library for each of the following aspects of the publication process, or how valuable would you find it if this support was offered to you? Percent of respondents who indicated these items as highly valuable.

Helping me understand and negotiate favorable publication contracts

Helping me determine where to publish a given work to maximize its impact

Helping me to assess the impact of my work following its publication

Managing a public webpage for me that lists links to my recent scholarly outputs, provides information on my areas of research and teaching, and provides contact information for me
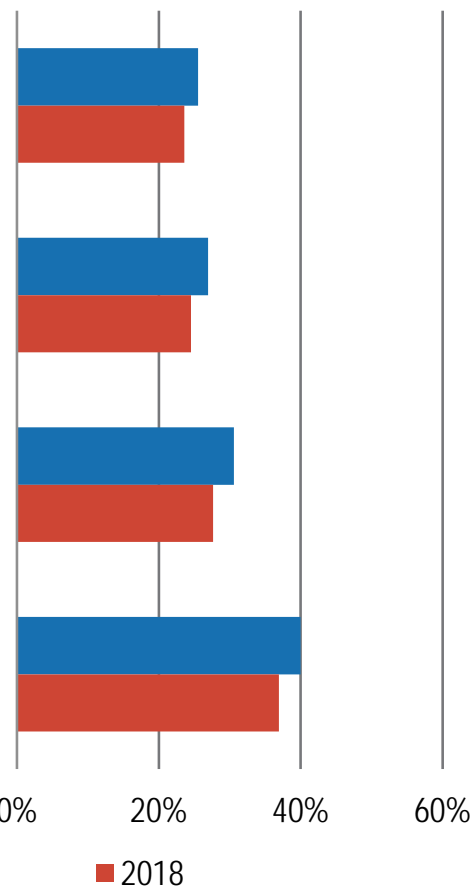

$60 \%$

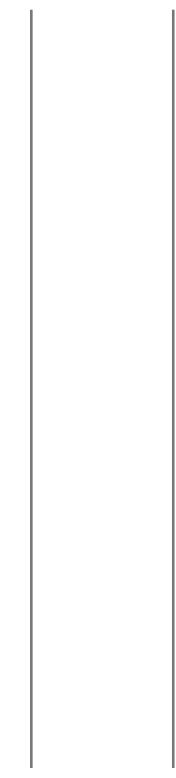

$80 \% \quad 100 \%$

$=2015 \quad \square 2018$

Faculty were also asked to rate the importance of various functions of their college or university library. This is a long standing question within the US Faculty Survey which allows us to track perceptions of the library over time. A new item was added to the 2018 survey cycle to include the role of the library in supporting graduate students for their research processes, data management, and publishing scholarship. The following are the seven items presented to respondents, including a shorthand name used in this document (but not presented to respondents in the survey) for reference:

- Gateway: "The library serves as a starting point or "gateway" for locating information for my research"

- Buyer: "The library pays for the resources I need, from academic journals to books to electronic databases"

- Archive: "The library serves as a repository of resources - in other words - it archives, preserves, and keeps track of resources"

- Teaching Support: "The library supports and facilitates my teaching activities" 


\section{ITHAKA S·R}

- Research Support: “The library provides active support that helps to increase the productivity of my research"

- Undergraduate Support: “The library helps undergraduates develop research, critical analysis, and information literacy skills"

- Graduate Support: "The library supports graduate students in conducting research, managing data, and publishing scholarship"

Similar to previous findings, the library's most important function according to faculty continues to be the library's ability to pay for the resources they need, such as academic journals, books, and electronic databases. This buyer role has consistently been reported as the most important function of the library since 2003 (see Figure 51).

Figure 51: How important is it to you that your college or university library provides each of the following functions below or serves in the capacity listed below? Percent of respondents who indicated each item as highly important.

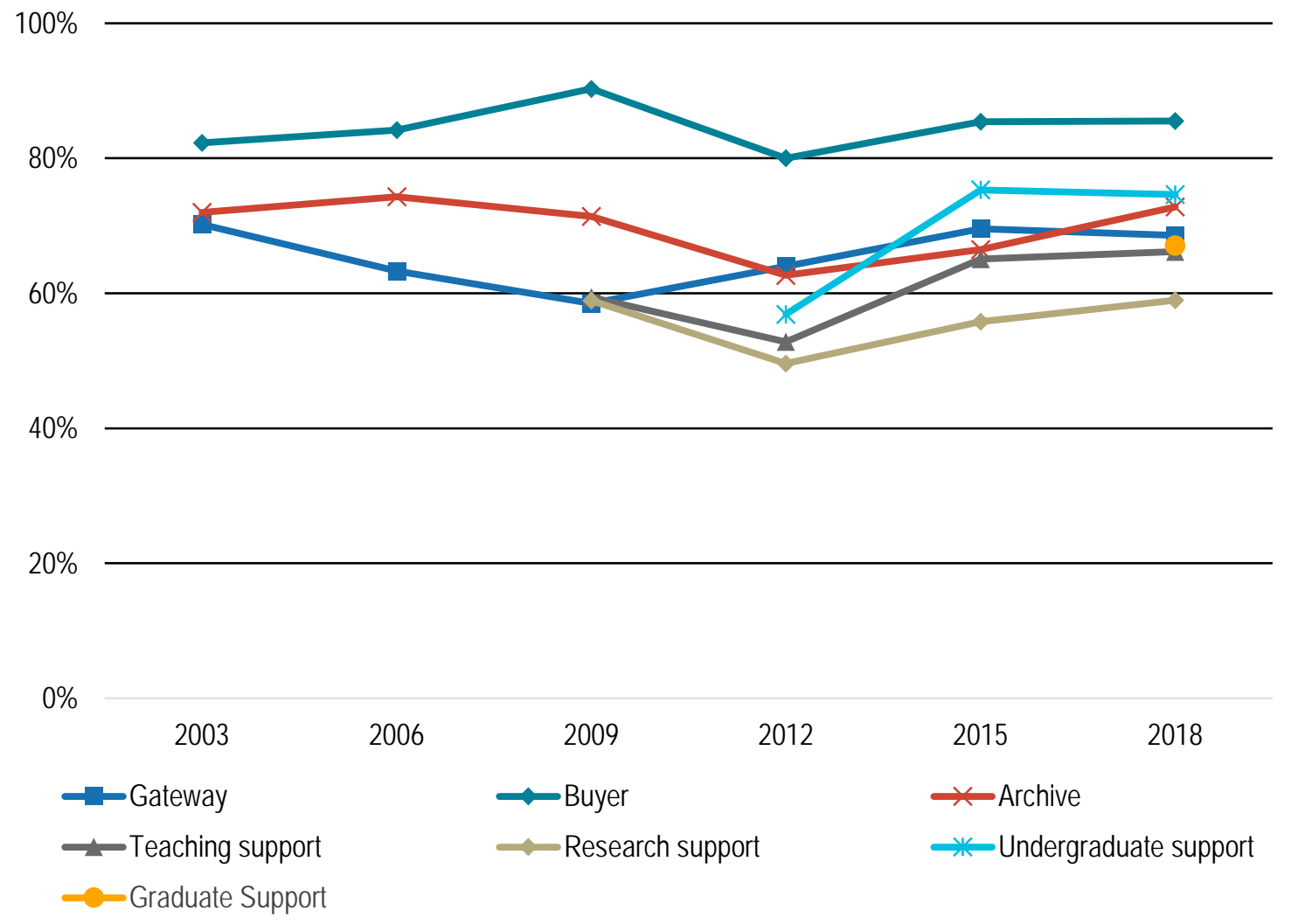


While responses to the 2018 survey cycle remain relatively similar to 2015, the most notable difference from last survey cycle is respondent endorsement of the archive role. Approximately $73 \%$ of faculty indicated the library's role as a repository of resources as highly important compared to 67\% of faculty in 2015.

Endorsement of the archive role has increased within each discipline since 2015 (see Figure 52). However, humanists are more likely than faculty in other disciplines to designate importance to this role.

Humanists also place more importance on most of the listed functions of the library compared to their colleagues in other disciplines, though humanists and social scientists indicate the same level of importance for the graduate support role, and faculty from all disciplines indicate the buyer role as highly important.

Figure 52: How important is it to you that your college or university library provides each of the following functions below or serves in the capacity listed below? Percent of respondents who indicated each item as highly important.

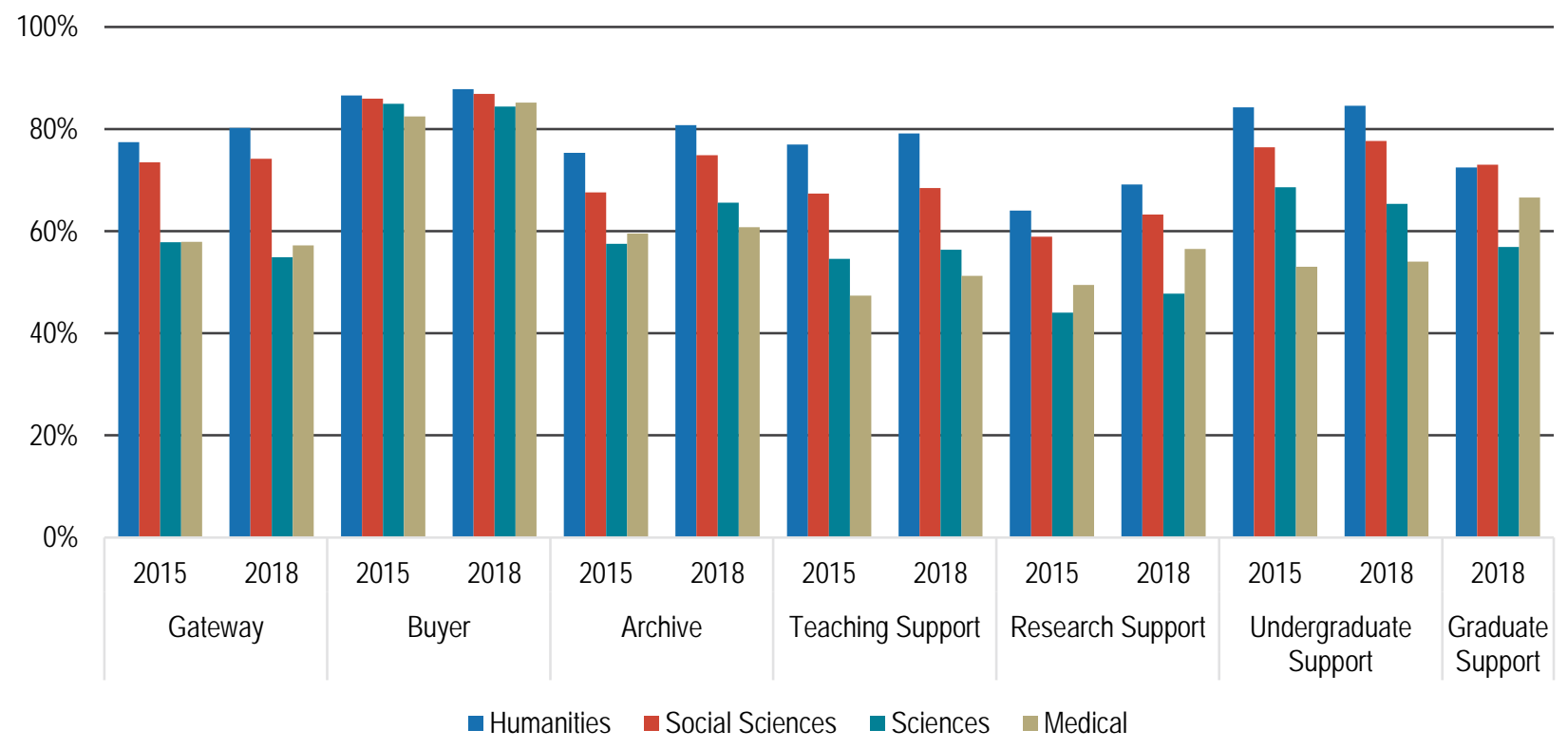

\section{Student Support}

When faculty are designing their undergraduate courses, 32\% inform a librarian when their course reading list or syllabus is issued to students, and approximately $20 \%$ liaise with a librarian before finalizing their selection of assigned course texts or materials. Humanists are more likely to inform and liaise with librarians when designing their 
undergraduate courses than faculty in other disciplines. These findings are consistent with the previous survey cycle.

While faculty broadly do not rely substantially on the library in designing their undergraduate courses, many faculty have indicated the importance of the library's value towards student success at their college or university. Half of faculty indicated librarians and library staff as highly important in contributing to student success. Overall, faculty members rate themselves as very important in contributing to student success, followed by students' peers (i.e. other students) and academic advisors (see Figure 53).

Approximately $61 \%$ of humanists consider librarians and library staff highly important, compared to $55 \%$ of social scientists, $37 \%$ of scientists, and $38 \%$ of medical faculty.

Figure 53: How important or unimportant are each of the following in contributing to student success at your college or university? Percent of respondents who indicated each of the following as highly important. ${ }^{7}$

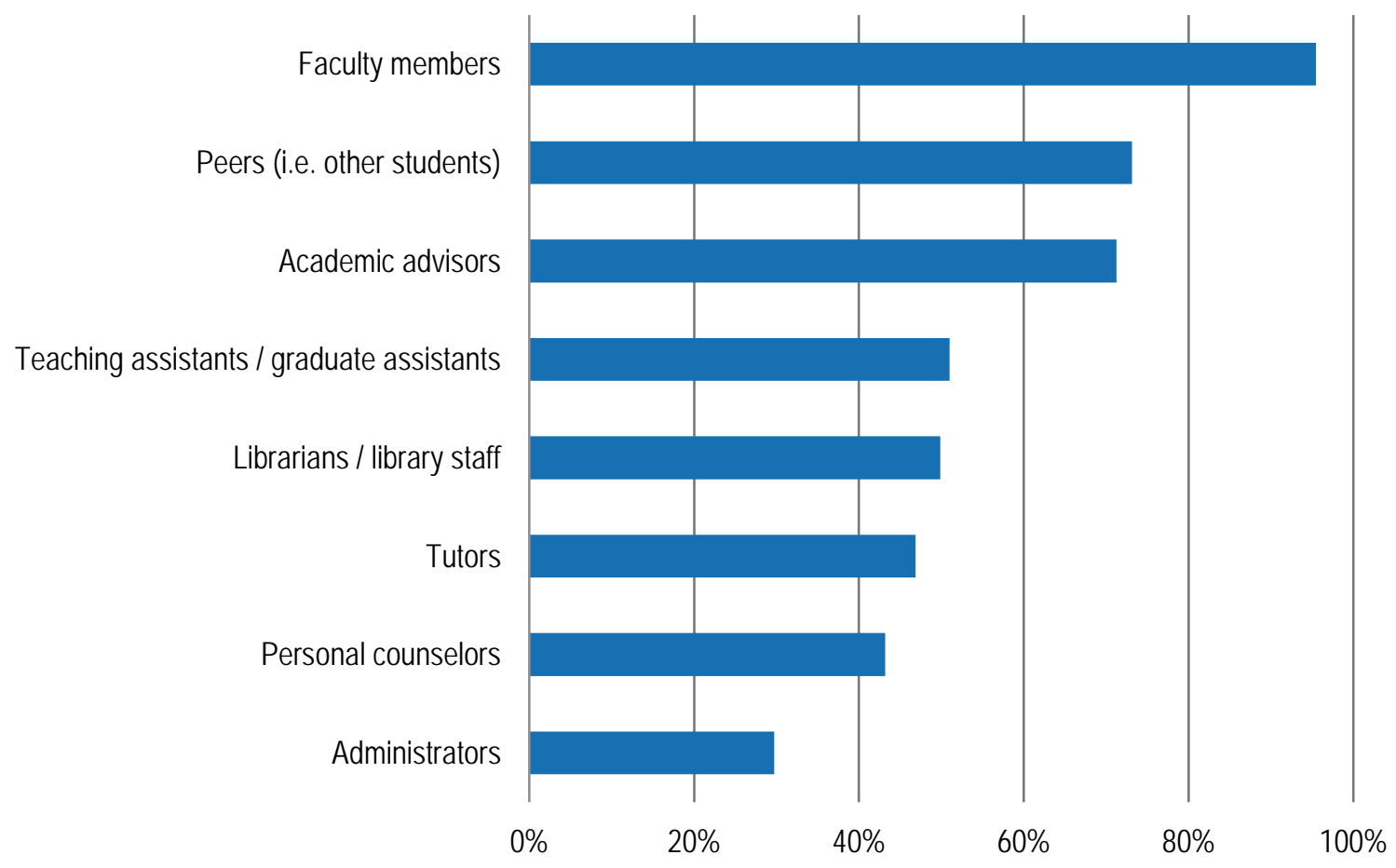

Additionally, about half of respondents continue to indicate strong agreement since 2015 that librarians at their college or university library contribute significantly to their students by helping them find, access, and use secondary and primary resources in their

${ }^{7}$ This list is not exhaustive of every individual who may contribute to student success. 
coursework, as well as by helping them to develop their research skills. A new item was included in this survey cycle to capture faculty's perception of the library's contribution towards developing skills in identifying media manipulation and disinformation. About four in ten respondents agreed that the library contributes significantly to helping students develop these skills.

Similar disciplinary differences were observed for these aspects of perceived librarian contribution to student success. Humanists and social scientists more strongly agree that librarians contribute significantly to students' learning and development of research skills within their college or university's students compared to their colleagues (see Figure 54). Faculty at Baccalaureate colleges are also more likely to agree that librarians contribute the development of research skills than faculty at Master's and Doctoral institutions (see Figure 55).

Figure 54: Please use the 10 to 1 scales below to indicate how well each statement below describes your point of view. Percent of respondents who strongly agreed with each statement.

Librarians at my college or university contribute significantly to helping students develop skills to identify media manipulation and disinformation

Librarians at my college or university library contribute significantly to my students' learning by helping them to develop their research skills

Librarians at my college or university library contribute significantly to my student's; learning by helping them to find, access, and make use of a range of secondary and primary sources in their coursework

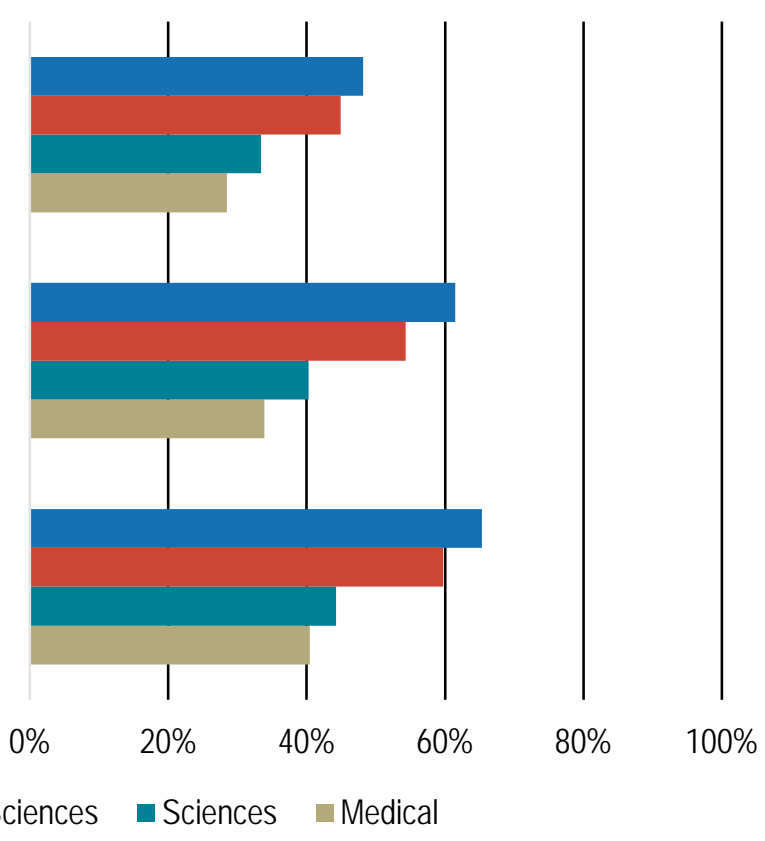

$\square$ Humanities $\square$ Social Sciences $\square$ Sciences $\square$ Medical 
Figure 55: Please use the 10 to 1 scales below to indicate how well each statement below describes your point of view. Percent of respondents who strongly agreed with each statement.

Librarians at my college or university contribute significantly to helping students develop skills to identify media manipulation and disinformation

Librarians at my college or university library contribute significantly to my students' learning by helping them to develop their research skills

Librarians at my college or university library contribute significantly to my student's; learning by helping them to find, access, and make use of a range of secondary and primary sources in their coursework

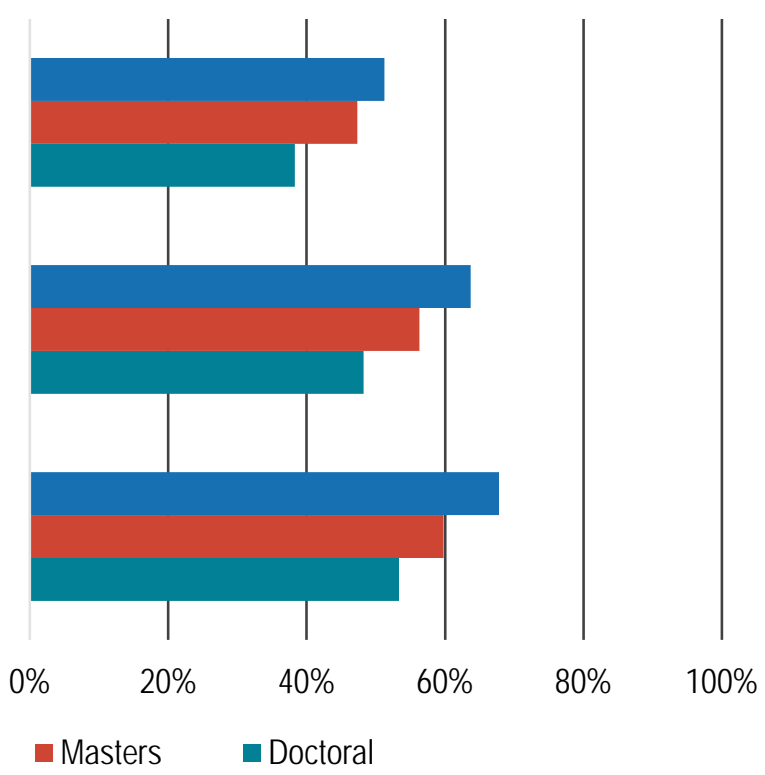

As access to scholarly information and materials online are increasing, we are observing distinct changes and shifts to the function of the library, faculty instructional practices, and publication decision-making. We have tracked a continual increase in the use of online tools, not only to discover new information, but to manage and preserve research data and materials. While libraries combat rising costs of journal subscriptions, the library's role continues to be most highly valued for its provision of resources but is increasingly viewed as important for its archiving of scholarly content. Faculty are more enthusiastic about open access scholarship, though their behavior continues to be influenced by traditional scholarly incentives. And, as students continue to be challenged by the high costs of course materials, faculty are looking to low- and no-cost solutions.

We look forward to hearing your thoughts, reflections, and questions on this latest cycle of findings. 


\section{Appendix: Methodology}

Consistent with previous cycles of the US Faculty Survey, our sample was drawn from a population of US faculty contact information collected and maintained by MDR, a marketing names list vendor.

Our sampling strategy for 2018 closely aligned with that from previous cycles of the survey. We selected a sample of faculty members at four-year colleges and universities from MDR's list affiliated with the following Carnegie Classifications: Baccalaureate Colleges - Arts \& Sciences; Baccalaureate Colleges - Diverse Fields; Master's Colleges \& Universities (smaller programs); Master's Colleges \& Universities (medium programs); Master's Colleges \& Universities (larger programs); Doctoral/ Professional Universities; Doctoral Universities (high research activity); Research Universities (very high research activity). ${ }^{8}$ Within these Carnegie Classifications, we sampled from the same range of fields and disciplines as the 2015 sample. As in 2015, we also included medical faculty members who were sampled from a separate population; these faculty were from all departments of medical schools and not from departments of nursing, dentistry, or other health professionals. In the 2018 survey cycle, we also added faculty members from the fields of foreign languages and agriculture. Respondents from these fields as well as those from medical fields have been excluded from aggregate results presented in this report to enable comparability with previous cycles. A total of 365,606 non-medical faculty members and 74,696 medical faculty members met these criteria for our population.

Consistent with the 2015 survey cycle, we slightly adapted the sampling procedure for faculty members at 13 colleges and universities out of the roughly 1,500 included in our sample. These institutions participated in fielding a local version of the US Faculty Survey concurrent with the administration of the national survey. Respondents at these institutions received the core national questionnaire and then following the national survey, faculty members at some of these locally participating institutions received a set of additional questions. In this way, responses to the national questionnaire were not influenced by the additional thematic items. Faculty members at these 13 institutions received email invitations from a member of their own campus community, and only those faculty members who were originally selected in the MDR sample were included in the national analysis of results. We enabled this by embedding metadata for any faculty members at the 13 local institutions who would have otherwise been selected as part of the national survey sample; faculty members who were identified within both the local and national survey sample only received one set of communications for the survey via

${ }^{8}$ Institutions were categorized based on their 2015 classification. 
their local institution, but their responses were merged into the dataset containing the responses to the national survey as garnered from the MDR sample.

In J une 2018, we conducted 12 in-depth cognitive interviews to ensure that the revised instrument for the 2018 cycle was understood clearly and consistently across respondents. Participants in this pre-testing phase were from a variety different fields, institution types, and roles.

The survey was distributed via email to a sample of 150,941 randomly selected faculty members according to the defined parameters detailed above. Invitations were deployed on October 3rd and three reminder messages were sent to those who had not yet completed the survey. As in previous cycles of the survey, we partnered with selected scholarly societies who served as signatories for communications to faculty members in corresponding disciplines. These societies included: the American Academy of Religion, the American Anthropological Association, the American Council on the Teaching of Foreign Languages, the American Educational Research Association, the American Historical Association, the American Musicological Society, the American Philosophical Association, the American Public Health Association, the Archaeological Institute of America, the College Art Association, the Geological Society of America, the Modern Language Association, the National Council of Teachers of English, the Society for Classical Studies, and the Society of Biblical Literature. For all other faculty members, invitation and reminder messages were sent from Catharine Bond Hill, Ithaka $S+R$ Managing Director, and Roger Schonfeld, Ithaka S+R Libraries, Scholarly Communication, and Museums Program Director.

The survey closed on December 21st. In total, we received 10,919 complete responses for an overall response rate of $7.2 \%$. Our analysis covers a number of key stratifications, including by discipline, institution type, job title/ role, and age. Response rates at the disciplinary level varied when compared against the MDR population due in large part to the effectiveness of outreach and communications via our scholarly society partners; the average response rate for respondents in disciplines who received invitations and reminders from these partners was $10.2 \%$ (ranging from $5.6 \%$ to $16.0 \%$ ), whereas the average under the Ithaka S+R signatory was $5.5 \%$

As in previous cycles, we continue to categorize respondents into disciplinary groupings of humanities, social sciences, sciences, and medical. In order to compare results of the 2018 survey to previous iterations, we formulated the categorizations in the same manner and report disciplinary findings at the level of these broad groupings. Based on disciplinary affiliations and our historic grouping rules, our sample of respondents broke down in the following manner: 
- Area studies: $140^{9}$

- Humanities: 3,460 10

- Social sciences: 3,697 11

- Sciences: 2,954 12

- Medical: 398

To adjust for uneven response rates by field, we have weighted the aggregate results from our sample proportionally to match population parameters. This approach is consistent with methodological adjustment techniques employed for previous cycles of the survey and affects results only to a very marginal degree. Consistent with previous survey cycles, we have excluded area studies from disciplinary analyses in this report due to the large difference in response levels between area studies faculty members and faculty members affiliated with the four other broad disciplinary categories. However, these faculty members are included in the aggregate response figures.

In this report, we also highlight stratified responses from respondents from different institution types, job titles/ roles, and age when clear and meaningful patterns present themselves. Our sample of respondents for these stratified responses broke down in the following manner:

\section{Carnegie Classification}

- Doctoral universities: 5,767

- Master's colleges and universities: 3,326

- Baccalaureate colleges: 1,438

Age

- 22 to $34: 746$

\footnotetext{
${ }^{9}$ Area studies includes: African-American studies, African studies, American studies, Asian studies, Indian studies, Latin American studies, Middle Eastern Studies, and Slavic studies (including Russia).

${ }^{10}$ Humanities includes: art history, classical studies, foreign languages, history (including the history of science), law, literature, music, philosophy, religion, and theater and drama.

11 Social sciences includes: anthropology (includes archeology), business \& finance, economics, education (includes higher education), geography, political science, psychology, public policy (including health policy), sociology, and women's studies.

12 Sciences includes: agricultural studies, biology (includes botany, ecology, zoology), chemistry, engineering, geology, mathematics (includes statistics), physics, physical sciences/astronomy, and public health.
} 
- 35 to $44: 2,210$

- 45 to $54: 2,661$

- 55 to $64: 2,920$

- 65 and over: 2,005

Title/Role

- Professor: 3,903

- Associate professor: 2,557

- Assistant professor: 1,823

- Adjunct professor: 738

- Lecturer: 661

- Instructor: 323

\section{Question types}

In this report, questions are presented as they were presented in the questionnaire itself. Many of our questions fell into three categories of response types: those that asked respondents to rate something between 1 and 10, those that asked them to rate the degree to which they agree or disagree with something, or those that asked them how often they do something from among the choices of "never," "rarely," "occasionally," and "often."

A common type of question posed a strongly worded statement, such as "Because faculty have easy access to academic content online, the role librarians play at this institution is becoming much less important," and asked scholars to rate from 1 to 10 how well each statement describes their point of view, where a 10 equals "extremely well" and a 1 equals "not at all well." In our reporting here, we have aggregated responses to simplify the presentation of findings; responses of 8, 9, and 10 are grouped together for analysis and characterized as "strongly agreeing" with the statement; responses of 1, 2, and 3 are grouped together for analysis and characterized as "strongly disagreeing" with the statement; and responses of 4, 5, 6, and 7 are grouped together and characterized as relatively neutral responses.

Another type of question posed a statement to which a respondent was asked to rate their actual degree of agreement or disagreement on seven-point scale. In our reporting, 


\section{ITHAKA S R}

we have combined levels of agreement and disagreement to further simplify findings: respondents who indicated either "strongly agree" or "agree" are grouped together; responses for "somewhat agree", "neither agree nor disagree", and "somewhat disagree" are grouped together; and responses of "disagree" and "strongly disagree" were grouped together.

We also often asked scholars other questions with 1-10 answer ranges, such as when we asked them to rate the importance of a given library role from "not at all important" to "extremely important." Again, we segmented responses as strong negative responses (13), neutral responses (4-7), and strong positive responses (8-10). We sometimes asked similar questions on a 1-6 scale, where this is required to track findings over time, and in those cases we segmented responses as strongly negative (1-2), neutral (3-4), and strongly positive (5-6).

In addition, several questions asked scholars how often they do something, with answer options of "never," "rarely," "occasionally," and "often." We typically group the responses of "often" and "occasionally" together, in order to characterize things that are done with some degree of regularity. 